IS ONLINE EDUCATION WORKING?

Duha Tore Altindag

Elif S. Filiz

Erdal Tekin

WORKING PAPER 29113 
NBER WORKING PAPER SERIES

IS ONLINE EDUCATION WORKING?

Duha Tore Altindag

Elif S. Filiz

Erdal Tekin

Working Paper 29113

http://www.nber.org/papers/w29113

\author{
NATIONAL BUREAU OF ECONOMIC RESEARCH \\ 1050 Massachusetts Avenue \\ Cambridge, MA 02138
}

July 2021, Revised March 2023

This paper uses confidential data from the student records of a higher education institution. To protect the confidentiality, the name of the higher education institution providing confidential student records in this paper is not disclosed. However, interested parties can obtain the data by submitting a request to the Office of Institutional Research at the institution. The authors are available to provide assistance with this process. IRB exempt status is received on 9/2/2020 from the university. The IRB number is IRB-20-389. The study uses existing data and records. The views expressed herein are those of the authors and do not necessarily reflect the views of the National Bureau of Economic Research.

NBER working papers are circulated for discussion and comment purposes. They have not been peer-reviewed or been subject to the review by the NBER Board of Directors that accompanies official NBER publications.

(C) 2021 by Duha Tore Altindag, Elif S. Filiz, and Erdal Tekin. All rights reserved. Short sections of text, not to exceed two paragraphs, may be quoted without explicit permission provided that full credit, including $\odot$ notice, is given to the source. 
Is Online Education Working?

Duha Tore Altindag, Elif S. Filiz, and Erdal Tekin

NBER Working Paper No. 29113

July 2021, Revised March 2023

JEL No. H75,I21,I23

\begin{abstract}
$\underline{\text { ABSTRACT }}$
This paper examines the effect of instruction modality on student learning outcomes, with a particular emphasis on the disparities observed before and after the pandemic. The analysis uses administrative data from a public university that spans seven pre-pandemic and five postpandemic semesters in a research design that controls for endogenous sorting into instruction modality at the student, instructor, and course levels using fixed effects. The findings show that face-to-face $(\mathrm{FtF})$ instruction leads to better student performance in the courses, i.e., higher grades, a greater likelihood of receiving a passing grade and achieving a grade of $\mathrm{A}$, and a lower tendency to withdraw from the course. Consistent with this finding, students who have had greater exposure to $\mathrm{FtF}$ instruction have a lower likelihood of course repetition, a higher probability of graduating on time, and achieving a higher graduation GPA. The findings further reveal that these differences have been decreasing over time, and the post-pandemic differences are much smaller. The results are largely consistent across students and instructors with different characteristics and subject areas, except for students in the Honors program and graduate students, where the FtF advantage is either smaller or statistically insignificant.

Duha Tore Altindag

Auburn University

Department of Economics

136 Miller Hall

Auburn AL, 36849

altindag@auburn.edu

Elif S. Filiz

University of Southern Mississippi

School of Social Science and Global Studies

Liberal Arts Building 407

Hattiesburg, MS 39406

Elif.Filiz@usm.edu

\section{Erdal Tekin}

School of Public Affairs

American University

4400 Massachusetts Avenue NW

Washington, DC 20016-8070

and IZA

and also NBER

tekin@american.edu
\end{abstract}




\section{Introduction}

The effectiveness of online course delivery methods on student learning has been a topic of debate since universities and colleges began offering these alternatives in the early 1990s. Recently, this debate has become more urgent with the outbreak of the COVID-19 pandemic, which brought the education system to a complete halt in March 2020, causing the most severe disruption of education in history. With most universities and colleges transitioning to virtual instruction in the early stages of the pandemic, the significance of online education tools and platforms has become even more prominent. The abrupt shift to remote learning has presented challenges to traditional educational methods and has required both educators and students to adapt to a new way of teaching and learning. As we navigate this new landscape of education, it becomes increasingly important to understand the impact of online education on academic performance.

This paper has two primary objectives. First, it attempts to shed new light on the understanding of the effect of online instruction on student learning outcomes in general. Second, it aims to assess the impact of online instruction on student performance in the context of the recent pandemic and to examine the degree to which this relationship has changed between pre- and postpandemic education landscapes.

With the threat of coronavirus having diminished and on-campus operations resumed, it is imperative to reflect on how the experience of online instruction during the pandemic will shape the future of education. At the center of this debate is the question of how the widespread adoption of online instruction will continue to be used moving forward. In a way, the shift to online instruction during the pandemic has presented universities with a unique opportunity to explore innovative instruction through the use of technology-enhanced methods across various subjects and education levels. Many experts believe that the integration of online instruction into university 
education will continue to gain prominence in the post-pandemic era and will eventually become an integral part of the whole university experience (Lieberman 2020; Schwartz et al. 2020; Xie et al. 2020). ${ }^{1}$ However, the extent to which online instruction can serve as a viable substitute for faceto-face (FtF) instruction, especially in the post-pandemic era, remains an important question. Given the significant changes in the educational landscape, it is also not clear whether the inferences drawn from studies conducted solely in the pre-pandemic can serve as a reliable guide for the relationship between online instruction and student performance in the current context. Therefore, it is important to study the causal relationship between instruction modality and academic performance in the post-pandemic period.

To accomplish its goals, this paper draws upon twelve semesters of transcript-level panel data between Fall 2016 and Spring 2022 from a medium-sized public R1 university, referred to as the University hereafter. In addition to traditional FtF instruction, the University also has a longstanding, well-established online education program, which offers a convenient and flexible learning platform for its students. Notably, many online classes are taught by instructors who deliver the FtF versions of the same courses. In a typical semester, a non-trivial proportion of classes (about one in four) is offered in an online modality at this institution. With the outbreak of the pandemic, the University, like most other higher education institutions, switched to online instruction in March 2020, discontinuing in-person education. ${ }^{2}$ With a comprehensive data set

\footnotetext{
${ }^{1}$ Note that the growth in online education has begun well before the pandemic. According to data from the National Center for Education Statistics, the proportion of undergraduate students who take online courses rose from $15 \%$ in 2003 to $34.5 \%$ in 2018 (De Brey et al. 2021). Proponents of online education argue that this type of modality leads to lower costs of instruction and improves access and affordability for students, especially those from underrepresented minority groups (e.g., Cowen and Tabarrok 2014; Deming et al. 2015; Bailey et al. 2018; Barrera-Osorio et al. 2020). In fact, low cost and convenience are the most important explanations behind the rapid growth in online education (McPherson and Bacow 2015).

${ }^{2}$ These online courses were not impacted (in terms of their method of delivery) when the University switched to remote instruction in March 2020. However, those that started in the FtF modality in Spring 2020 had to convert to online instruction with the onset of the COVID-19 outbreak.
} 
consisting of seven semesters of pre-pandemic data and five semesters of post-pandemic data, our analysis is poised to not only uncover the impact of online instruction on student learning outcomes more broadly but also offer valuable insights into how this relationship has changed over time with a clear distinction between pre- and post-pandemic periods.

It is important to note that the impact of online instruction on student academic performance is unclear a priori and, therefore, an empirical question. On the one hand, FtF instruction offers unique benefits that can be more conducive to motivation and engagement. For instance, in-person interactions with teachers and peers can foster a sense of community, which can motivate students to remain engaged with the course material. Additionally, FtF courses may provide more opportunities for hands-on, experiential learning, which can be more stimulating and engaging than remote coursework. Moreover, the accountability that comes from being present in a traditional classroom setting can incentivize students to be more attentive and active in the classroom, whereas online courses may be perceived as more passive and detached. On the other hand, online courses provide students with greater flexibility in terms of time and location, which can enable them to balance their studies with work or other obligations. This flexibility can also facilitate access to education for students who may not have been able to attend traditional FtF courses due to factors such as distance or disability. Additionally, the use of technology in online courses can offer a variety of multimedia resources, such as videos, interactive simulations, and other digital tools, that can enhance the learning experience. Furthermore, the use of online discussion forums and other collaborative tools can facilitate peer-to-peer learning and encourage students to engage in deeper, more critical discussions about course material.

The estimation of the causal effect of online instruction on student performance is complicated by endogenous selection into different modalities of education. For instance, students 
who enroll in online courses likely differ from those in FtF courses in ways that are correlated with their academic performance, such as prior academic achievement, motivation, or learning styles. It is also possible that instructors who teach online classes may have different characteristics, such as effectiveness in teaching or approaches to grading, that are correlated with student learning outcomes. Our approach to overcoming bias from endogenous selection is to incorporate a series of fixed effects at the student, instructor, and course levels into the empirical analysis. We also explore heterogeneity in the estimated relationship between online instruction and learning outcomes across a variety of student, course, and instructor attributes. Our primary measures of student learning outcomes include an indicator of withdrawing from a course, an indicator of receiving a passing grade, a dummy variable that takes on the value of one if the student obtains the grade A, and the final course grade. In addition to the contemporaneously measured outcomes captured at the term level, we also examine outcomes that occur later, such as graduation GPA and course repetition. Finally, this paper provides novel evidence on the extent to which the effectiveness of online instruction on student performance has changed in the post-pandemic era.

Our findings indicate that students in FtF classes outperform their online peers during most of the analysis period, especially in semesters prior to the pandemic. FtF advantage follows a declining trend as the performance of students that take online instruction catches up to that of their FtF counterparts. That is, the post-pandemic differences in student performance between $\mathrm{FtF}$ and online instruction are smaller. Our results are consistent across students and instructors with different characteristics and subject areas, except for the more motivated and skilled students, such as those in the Honors program and graduate students, where the FtF advantage is smaller or statistically insignificant both before and after the pandemic. 


\section{Literature}

The literature on the impact of instruction modality (FtF vs. online) on student learning outcomes can be grouped into two broad categories: experimental studies and quasi-experimental studies using administrative student records. Experimental studies provide causal evidence but are typically small-scale experiments conducted in a single-course setting, in which students are randomly assigned to purely $\mathrm{FtF}$, purely online, or blended versions of the same course. Despite some conflicting results or statistically insignificant differences, the evidence from these studies suggests that online education usually leads to less favorable academic outcomes. ${ }^{3}$ However, it is important to note that these experiments are typically limited to samples of $300-700$ students enrolled in introductory microeconomics courses. Therefore, the findings from these studies may not be representative of broader educational contexts.

There are two noteworthy examples of experimental studies conducted recently. Kofoed et al. (2021) performed an evaluation of academic performance among West Point students randomized across an FtF or an online version of a course in Fall 2020. The authors find that students performed worse in both assignments and exams in the sessions offered online than those in the FtF sessions, with the most significant difference concentrated among the academically atrisk students. By virtue of the randomized control design used in the study, the concern about selection bias is eliminated, and thus, the results represent causal evidence of the impact of online education on student outcomes. However, the study was conducted in Fall 2020, at the height of

\footnotetext{
${ }^{3}$ For example, Figlio et al. (2013) show that FtF instruction yields moderately higher scores, especially among Hispanic, male, and low-achieving students. Joyce et al. (2015) study the performance of students who are randomized between a traditional twice-per-week lecture format and a compressed version that meets once-per-week, with both groups having access to online material. While the students in the traditional format scored slightly better, albeit statistically insignificant, scores compared to those in the compressed format, there were no differences in attendance, withdrawal rates, or hours spent online doing assignments. Similarly, Alpert et al. (2016) find that students in the purely online section of a course received significantly lower grades than those in the FtF sections or the compressed sections with no significant differences between the latter two versions.
} 
the COVID-19 crisis. Therefore, it is uncertain how informative these results are in the current context, now that the pandemic has subsided, and life has largely returned to normal. Cacault et al. (2021) examine the impact of distance learning technology on student performance using a randomized field experiment where first-year students at a Swiss university could attend livestreamed lectures for their compulsory economics and management courses. The results reveal that live-streamed lectures had different effects on low- and high-ability students, lowering performance for the former and increasing it for the latter. Unlike previous studies, which relied on volunteer participants, this study focused on "required" courses, reducing the risk of selfselection bias. However, the study is limited in scope, focusing only on management and economics courses, making it unclear if the results can be applied to other subject areas.

The second approach to estimating the effect of instruction modality on student performance is to use quasi-experimental methods using administrative student records. As an example, Bird et al. (2022) evaluate the impact of the pandemic-triggered shift to online education in Spring 2020 on the academic performance of students attending Virginia's community colleges. Using a difference-in-differences strategy and exploiting the within-course variation on whether students started their Spring 2020 courses in person or online, the authors find that the shift to the online modality led to a decrease in course completion driven primarily by withdrawals and, more narrowly, by course failures.

Another recent example is Rodríguez-Planas (2022a), who uses administrative academic records between Spring 2017 to Spring 2020 from Queens College of the City University of New York system to study the impact of COVID-19 on academic performance in a difference-indifferences framework. She documents the COVID-19 pandemic had a differential effect on students' GPAs based on income. Specifically, lower-income students in the bottom quartile of 
the GPA distribution prior to the pandemic outperformed their wealthier peers in Spring 2020. Moreover, this differential is fully explained by students' use of flexible grading. In a related paper using data from the same context, Rodríguez-Planas (2022b) studies the effect of the COVID-19 pandemic on the immediate and short-term educational, financial, and personal burdens faced by urban public university students in the U.S. The author shows that low-income college students were more likely than general students at Queens College to experience challenges while attending online classes during Spring 2020, mostly due to higher childcare responsibilities, greater lack of internet, or greater probability of being sick or stressed. They were also more likely to consider dropping a course because of concerns that their grade would jeopardize their financial assistance.

Aside from these pandemic-era studies, one notable example is Hart et al. (2018), who examine the difference in student performance in online and $\mathrm{FtF}$ course modalities in the California Community College system. The research design relies on a variety of fixed effects at the student, instructor, and course levels as the primary approach to accounting for the endogeneity of enrollment into a particular format of instruction. The results show that, on average, students perform worse in online courses, as indicated by a lower likelihood of course completion, passing with a grade, and receiving an A or B. Moreover, the study suggests that taking online courses has downstream effects, including a higher likelihood of repeating the course but a lower likelihood of taking new courses in the same subject after taking an online course. This is a careful study with numerous robustness analyses across different types of students and courses, as well as careful attention paid to the extent to which the results are explained by sorting into online versus inperson classes by students and instructors.

The majority of the studies in the literature use fixed effects to control for endogeneity when examining the impact of the decision to take a course in an online or in-person section. Three 
notable exceptions are Bettinger et al. (2017), Xu and Jaggars (2011), and Xu and Jaggars (2013). Bettinger et al. (2017) use an instrumental variable strategy to overcome the selection bias. Specifically, the authors use the interaction of changes in in-person course offerings from term to term and the distance each student must travel to attend an in-person course to document that enrolment in on-line courses reduces success and progress among students in a large for-profit college. Xu and Jaggars (2013) use the travel distance between a student's home and college campus as an instrumental variable along with course-by-college fixed effects to examine the impact of online versus FtF course delivery on student performance among students enrolled in Washington State's 34 community or technical colleges. They found that the online format had a significant negative effect on both course persistence and grade. Finally, Xu and Jaggars (2011) use multilevel propensity score matching to estimate the impact of taking math or English courses in the online format on retention and performance among students enrolled in 23 community colleges in Virginia. The findings of this paper indicate a robust negative effect of online coursetaking for both subjects.

Our study stands out from the existing literature on the impact of online instruction on student performance in several ways. Unlike most studies in the literature, which use data from the pre-pandemic period, our study has transcript-level administrative data covering 12 semesters, with approximately half of the data coming from the post-covid period. This allows us to make inferences about the impact of online instruction in the post-pandemic landscape and to make comparisons between the pre- and post-covid relationship between online course taking and student learning outcomes.

Additionally, while many of the quasi-experimental studies in the literature rely on data from community or technical colleges, our study uses data from a sizeable public university. Our 
study also thoroughly examines the heterogeneity in the causal relationship between online instruction and student learning outcomes such that it goes beyond the scope of most previous research. Unlike most previous studies, besides only examining student and teacher demographics, we also investigate how the estimated effect differs for honors versus non-honors students, as well as various student majors. In addition, ours is the first study that investigates the impact of course modality on graduate student outcomes. Moreover, we look at both contemporaneous course performance outcomes as well as long-term outcomes such as repeating a course, graduation GPA, and timely graduation. Finally, another unique aspect of our paper is that we possess data on the utilization of anti-plagiarism proctoring software among some instructors. With this information, we investigate how the use of such software impacts the relationship between academic performance and instruction modality.

\section{Data}

Our analysis is based on administrative student records from a public research university granting bachelor's, master's, and doctoral degrees between Fall 2016 and Spring 2022. With close to 15,000 students enrolled annually from all U.S. states and many countries, the University attracts a diverse student population. The full cost of attendance at the University is around $\$ 25,000$ per year for in-state students, which matches almost perfectly with the average cost of attendance for a student living on campus at a public 4-year in-state institution in the United States (Hanson, 2022). The 4-year graduation rate for the University is approximately 33 percent compared to 39 
percent among other universities in the same region and 46 percent in the rest of the country (IPEDS, 2021).

In addition to the standard $\mathrm{FtF}$ instruction, the University also has a long-established online education program, which offers a flexible learning platform for its students. In response to the pandemic and following the state Governor's declaration of a state of emergency around midMarch 2020, the University shifted all instruction to online modalities and remained online throughout the Spring 2020 semester. Like most colleges and universities around the country, the University enacted a change to its grade policy by allowing the students to opt into a grade of $\mathrm{Z}$ (for A, B, and C), P for grade D, and NP for grade F as an alternative to standard grades. These options did not count towards the students' GPA, but grade Z satisfied the degree requirements. However, we are able to observe the actual grades of the students in our data, and we use them in our analysis instead of these options.

We use four metrics of student learning outcomes in our analysis, including (i) a binary variable indicating whether the student withdrew from the course and received a W; (ii) a binary variable indicating whether the student earned an A; (iii) a binary variable indicating whether the student received a passing grade by achieving an A, B, C, or D; and (iv) the final course grade $(\mathrm{A}=4, \mathrm{~B}=3, \mathrm{C}=2, \mathrm{D}=1$, and $\mathrm{F}=0)$.

In addition to these outcome variables, we also have information on various student, instructor, and course characteristics. At the student level, we have information on students' age, gender, ethnic background, major, honors program status, zip code of their residence, whether the student is international, and whether the student lives in a dorm. At the instructor level, we know the age, gender, and race/ethnicity. Finally, at the course level, we possess data on the course name, 
delivery format, course level, and whether the student took the course to satisfy the University's capstone course or writing intensive course requirements.

Figure 1 shows the share of students in FtF classes in each of the twelve semesters. The proportion of students in $\mathrm{FtF}$ classes remained between 70 and 80 percent up until the beginning of the pandemic. In Spring 2020, around 73 percent of students began the semester in FtF classes, but due to the outbreak of the pandemic in March 2020, virtually all of these students had to switch to online courses. In the subsequent two semesters, Fall 2020 and Spring 2021, most of the classes offered by the University were online due to the pandemic restrictions. However, at the start of the 2021-2022 academic year, the percentage of FtF classes increased sharply as the University fully reopened.

Figure 2 illustrates the grade distributions for online and in-person classes in each of the twelve semesters. The figure suggests that student performance has improved gradually over time in both $\mathrm{FtF}$ and online courses across all four outcome measures. However, students in $\mathrm{FtF}$ classes outperform their peers in online classes in each of the four learning outcome measures, at least until the start of the pandemic in Spring 2020. In the post-pandemic period, there does not seem to be any noticeable disparities in the proportion of students who withdrew from or passed their classes between those who took them in-person or online. In terms of the final course grade and the percentage of students earning an $\mathrm{A}$, there was a noticeable spike among students in FtF instruction during the early stages of the pandemic, followed by a subsequent decline after Spring 2021.

Table 1 displays the summary statistics for all the outcome variables as well as student and course characteristics for the full sample as well as separately for treatment (students in FtF classes) and control (online classes) groups. With respect to learning outcomes, students enrolled 
in online classes have higher rates of course withdrawals, lower probabilities of receiving a passing grade of A, B, C, or D, lower probabilities of earning an A grade, and lower final grades compared to those in FtF classes. While these differences are statistically significant, they are small in magnitude. In terms of student characteristics, there are noticeable differences between the treatment and control groups. For instance, students taking online classes are relatively older, more likely to be female and black, but less likely to be international, reside in dormitories, or be enrolled in the Honors program. The Honors program is intended to enhance the academic experience of exceptionally motivated and high-achieving students who have demonstrated excellence in specific subjects. As such, enrollment in the Honors program can serve as a representation of a student's high-achievement status. ${ }^{4}$

Finally, in terms of instructor and course characteristics, online classes are more likely to be delivered by women and black professors. Online courses are also more likely to be classified as Capstone/Writing classes compared to FtF classes. Freshman and senior level courses are more likely to be offered in FtF format, whereas sophomore and junior level courses are more likely to be offered online.

In Table 2, we provide summary statistics separately for the pre- and post-pandemic periods. ${ }^{5}$ The table reveals that the differences between students enrolled in $\mathrm{FtF}$ and online classes decreased during the pandemic. Additionally, we observe a slight rise in the percentage of Black students enrolled in online classes compared to FtF classes after the pandemic. Both the share of students residing in dormitories and enrolled in the honors program increased after the pandemic,

\footnotetext{
${ }^{4}$ To be a part of this program, students must meet a GPA requirement in their majors and complete several specialized honors courses. Typically, students who are in this program take courses such as "Honors Colloquium," "Honors Seminar," and "Honors Thesis." We identified a student as an Honors student if she/he took one of these classes at any point during our sample period.

${ }^{5}$ The semesters ranging from Fall 2016 to Spring 2020 are categorized as pre-pandemic, whereas the semesters from Fall 2020 to Spring 2022 are classified as post-pandemic. Reclassifying Spring 2020 as part of the post-pandemic period does not change the patterns observed in Table 2.
} 
with greater increases noted among students taking online classes. Concerning instructor characteristics, the percentage of female instructors in online classes dropped from 63 percent to 53 percent after Spring 2020.

It is noteworthy that our main approach to obtaining the causal effect of instruction modality on student performance is by incorporating fixed effects at the student, instruction, and course levels into our empirical model. In order for this approach to succees, it is essential to have a good mixture of students enrolled in both $\mathrm{FtF}$ and online courses, as well as instructors teaching both FtF and online courses in a particular semester. Appendix Table 1 shows that the University's undergraduate enrollment figures remained relatively constant over time, totaling 128,213 across all twelve semesters. According to the second column of Appendix Table 1, almost half of the students enroll in both $\mathrm{FtF}$ and online courses within a given semester. Additionally, the majority of students take courses from various academic departments, with the average number of courses taken fluctuating between 5.5 and 6 . The bottom panel of the table displays the same statistics for instructors. The analysis sample includes 10,682 instructors, approximately 19 percent of which teach a mix of online and $\mathrm{FtF}$ courses in an average semester. On average, an instructor teaches 2.3 courses per semester, with 11 percent of instructors teaching courses in different departments/subjects. ${ }^{6}$ Additionally, the table also displays the percentage of students who take these courses in an FtF format.

Our dataset includes a total of 2,872 distinct courses offered by the University. Many of these courses have multiple offerings in a semester and, therefore, are taught in multiple classes (sections of a course). In addition, there is considerable variation in the modalities in which the same courses are delivered. For example, in our sample period, while 117 out of approximately

\footnotetext{
${ }^{6}$ For example, a music professor teaches classes in music subjects and also in the music education subjects.
} 
150 sections of a particular statistics for social sciences course are offered in an FtF modality, only 52 out of 110 course sections of a lower-level sociology are delivered with FtF instruction.

\section{Empirical Strategy}

To determine the causal impact of FtF versus online instruction on student learning outcomes, we use a fully interacted model that includes fixed effects at multiple levels, which is specified as follows:

$$
Y_{s c j i t}=\beta_{1} F 2 F_{c j t}+\sum_{t} \alpha_{t} \operatorname{Term}_{t}+\sum_{t} \gamma_{t} \operatorname{Term}_{t} \times F 2 F_{c j t}+X_{s c j i t} \mu+\phi_{s}+\phi_{c}+\phi_{i}+\varepsilon_{s c j i t^{\prime}}
$$

where $Y_{\text {scjit }}$ represents one of the learning outcome variables for student $s$ in section $j$ of course $c$ taught by instructor $i$ in semester $t$. In the analysis below, we define a class as a section of a course taught in a semester. For example, the MWF 9-10 am section of a particular course in Spring 2021 is a separate class from the TTh 9-10:30 am section of the same course in the same semester. Thus, the unit of observation in equation (1) is a student $\times$ class. $F 2 F_{c j t}$ is a binary indicator for whether the student took the class in-person; Term $_{t}$ is a vector of twelve binary variables indicating academic semesters ranging from Fall 2016 to Spring 2022, with Fall 2019 chosen as the reference category; the $X_{s c j i t}$ is a vector of time-varying student, instructor, and course characteristics, including indicators for the age group of the student and the instructor, a dummy for whether the student lives in a dorm, and another indicator for whether the student takes the course to satisfy the capstone course or writing-intensive course requirement of the University.

Equation (1) specifies the impact of $\mathrm{FtF}$ instruction compared to online instruction in a flexible manner, enabling the effect to vary across each semester. To clarify, the $\beta_{1}$ represents the difference in the outcomes between FtF versus online classes in Fall 2019 (the reference category). 
Similarly, the coefficients on term fixed effects, $\alpha_{t}$, capture the difference in student performance outcomes between online courses taken in semester $t$ relative to Fall 2019, and the $\gamma_{t}$ coefficients reveal the differences in outcomes between $\mathrm{FtF}$ and online course sections in each semester relative to this contrast observed in Fall 2019. Our main goal is to track the causal difference in student performance associated with enrolling in an $\mathrm{FtF}$ versus an online class over time on a semesterby-semester basis. While the coefficient of FtF represents the difference in outcomes between enrolling in an FtF course section versus an online course section in Fall 2019, the impact on other semesters can be obtained by the sum of $\beta_{1}$ and the $\gamma_{t}$ coefficients. For example, $\beta_{1}+\gamma_{\text {Spring }} 2022$ would reveal the difference in student performance between enrolling in an FtF class versus an online class in Spring 2022.

The causal interpretation of the estimates in equation (1) hinges upon the assumption that the selection into an $\mathrm{FtF}$ versus an online class is as good as random conditional on the vector $X_{s c j i t}$ and the fixed effects. Students who opt into FtF classes may systematically differ from their peers in online sections in ways that are correlated with their academic performance. For example, they may be more motivated to take advantage of the unique benefits of FtF instruction, such as in-person interactions with teachers and peers as well as hands-on and experiential learning that can promote academic performance. Conversely, some students who select FtF classes may be drawn to other aspects of in-person education that can be detrimental to learning, such as socializing and partying. To guard against bias arising from student sorting into instruction modality, we include student fixed effects, $\phi_{s}$, in equation (1). Therefore, the model identifies off of the variation within 34,601 unique students who take $\mathrm{FtF}$ or online classes.

Similarly, it is plausible that FtF enrollment may be concentrated in classes that are either more or less demanding than the average online course. If this is the case, our estimates may be 
subject to bias due to sorting in the way FtF classes are structured within the institution (Hart et al. 2018). It is also conceivable that students may select their course modality based on their anticipation regarding the level of difficulty or degree of rigor of a course. To account for these possibilities, we control for course fixed effects, $\phi_{c}$, in equation (1), which amounts to including 2,872 distinct dummy variables for courses offered online or in-person.

Finally, there is also the possibility that $\mathrm{FtF}$ and online course sections may be taught differently as a result of varying expectations, grading standards, and teaching intensity among instructors. For instance, instructors who are less proficient in teaching or have a more stringent approach to grading may be more likely to teach online courses. Conversely, instructors who are more proficient in integrating technological tools for pedagogy into their classes and motivated to incorporate the latest technological advancements into their teaching may sort into online instruction. To account for the possibility of selection by instructors, we also include instructor fixed effects, $\phi_{i}$, in our regression model. Therefore, the identification comes from the withinvariation in 2,101 unique instructors who teach in both online or FtF courses. The empirical model specified in equation (1) offers a significant advantage by allowing us to examine the relationship between instruction modality and student performance on a semester-by-semester basis, including the periods before and after the pandemic. As a result, we can provide new and unique insights into how the causal relationship between the two may differ between the pre- and post-pandemic periods. The standard errors are clustered at the class level. ${ }^{7}$

In addition to incorporating student, course, and instruction fixed effects to mitigate potential bias arising from the endogenous selection at various levels, we further delve into the

\footnotetext{
${ }^{7}$ The total number of clusters is 31,011. We also estimated our models clustering standard errors at the student level. The significance of our estimates remained robust to this exercise. These results are available from the authors upon request.
} 
issue of selection through several robustness analyses. Specifically, we explore the extent to which several factors may contribute to the observed differences in student performance between FtF and online instruction. These factors include student, instructor, and course characteristics, as well as the role of teacher leniency and the use of anti-plagiarism software. We investigate the role of these factors both generally and also analyze how they may vary over time, with particular attention paid to differences between the pre- and post-pandemic periods.

\section{Results}

We begin by presenting results from the estimation of equation (1). The full set of estimates is shown in Table 3. The coefficient on FtF in the first row reveals the impact of FtF instruction on student learning outcomes in the omitted semester, Fall 2019, relative to online instruction. As indicated by the results, students in the FtF format perform better than those in the online format for all four outcomes. The estimates on the individual semester dummies represent the difference in the student learning outcomes in the online courses between each of these semesters and Fall 2019. Consistent with the raw trends shown in Figure 2, student performance measured by these four outcomes appears to follow an upward trend over time. If we consider the pre-Fall 2019 and post-Fall 2019 periods separately, an interesting picture emerges about the evolvement of student performance in online courses between the pre- and post-pandemic periods. Specifically, the estimates are much more precise in the post-pandemic semesters. Furthermore, the effect sizes appear to get stronger over time, at least in Spring 2020, Fall 2020, and Spring 2021. This pattern 
suggests the upward trend in student learning outcomes in online courses became more pronounced in the post-COVID-19 era, or at least during the height of the pandemic.

Next, we direct our attention to semester-by-semester differences in learning outcomes among students between $\mathrm{FtF}$ and online classes. Note that this is calculated as the sum of parameter estimates on $F 2 F_{c j t}$ and the interaction term between $\gamma_{t}$ Term $x F 2 F_{c j t}$, i.e., $\beta_{1}+\gamma_{t}$. To enhance clarity and assist with the interpretation of this discussion, we present these estimates in the form of a figure, along with their corresponding 95 percent confidence intervals. Most of our discussion going forward will focus on the estimates reflecting the semester-by-semester differences in student learning outcomes between FtF and online instruction.

As shown in Figure 3, there is an advantage to taking a class in FtF format across all four outcome measures in the pre-pandemic period. This pattern is evident across all outcome measures, including the probability of withdrawing from a course, receiving a passing grade, and the final course grade, and, to a lesser extent, the likelihood of receiving an A. In terms of effect sizes, students enrolled in $\mathrm{FtF}$ courses are approximately 2.5 percentage points less likely to withdraw from a course and receive an incomplete relative to their online counterparts. The share of students who withdraw from an online course averages 5.1 percentage points in the pre-pandemic period semesters between Fall 2016 and spring 2020. Therefore, a back-of-the-envelope calculation indicates that switching to $\mathrm{FtF}$ instruction is responsible for the decrease in the propensity to withdraw from a course by about 50 percent. Similarly, the probability of receiving a passing grade is 4 to 7 percentage points higher in $\mathrm{FtF}$ courses compared to online courses. However, the results are less clear for the likelihood of receiving an A, with a 2 to 5-percentage point advantage for students in FtF courses in the pre-pandemic period, except for Fall 2017 and Spring 2018, during 
which the effect was either reversed or statistically insignificant. ${ }^{8}$ Interestingly, the gap in the student learning outcomes between $\mathrm{FtF}$ and online instruction presents a different pattern in the post-pandemic period. Specifically, the significant advantage in learning outcomes experienced by students in FtF courses seems to have dissipated in the post-pandemic period. Overall, the differences between the two instruction formats are either statistically insignificant or minor. ${ }^{9}$

Taken together, the picture emerging from Table 3 and Figure 3 suggests that FtF instruction consistently yielded better student performance outcomes before the pandemic, despite the gap narrowing over time. In the post-pandemic period, the differences between the two modalities of instruction are no longer distinguishable from each other for the outcomes of withdrawing from a class or receiving a passing grade. Regarding the outcomes of receiving an A and the final grade in the class, there is a reversal of the previous trend during Fall 2020 and Spring 2021, where students enrolled in online courses appeared to outperform their FtF counterparts. Nevertheless, this pattern vanished as the outcomes of the two modalities started to converge with the lifting of pandemic restrictions and a complete resumption of regular operations, starting in Fall 2021. Recall that, as illustrated in Figure 1, the University offered very few FtF courses during the Fall 2020 and Spring 2021 semesters. Since the number of students enrolled in the University did not change dramatically during this period, it can be inferred that most students who would have taken a course in $\mathrm{FtF}$ format decided to enroll in an online version instead, either by choice

\footnotetext{
${ }^{8}$ We spoke to the administrators who are responsible for issues of instructional operations at the University to find out if there was any policy change or reorganization at the university level that may explain this pattern. To our understanding, the only major policy change in Fall 2017 was the adoption of a new learning management system. It is possible instructors who taught online classes may have had an advantage in adapting to the new system due to their familiarity and experience with remote instruction tools. In contrast, instructors who primarily taught in-person classes may have experienced more difficulties during the transition.

${ }^{9}$ Our results are remarkably robust to even higher levels of fixed effects. In fact, we subject our results to further scrutiny by replacing semester and student fixed effects by student-by-semester fixed effects, which identifies off of the within-variation among students within the same semester. These results are largely consistent with our main findings and available from the authors upon request.
} 
or due to an absence of an FtF option. To the extent that these students would have performed better than online students who would have taken the course remotely, irrespective of the pandemic, this could account for the advantage that favored online students in these two semesters. As described in the empirical strategy section, our approach to accounting for endogeneity bias stemming from various types of selection is to control for fixed effects for each type. For example, by controlling for student fixed effects, our identification is achieved by comparing the learning outcomes of students in FtF classes with their own performance in online classes. This approach enables us to eliminate any confounding caused by time-invariant student tastes toward a particular instruction format. It could also be courses that are offered online differ from those offered in person in ways correlated with student performance. We account for this possibility through course fixed effects, which amounts to comparing student performance between the same courses offered through different delivery modalities. Finally, instructor fixed effects account for the possibility of sorting into online versus FtF course sections by instructors, which may generate differences in teaching performance or leniency in grading by the two types of instructors that can be correlated with student learning outcomes. Instructor fixed effects eliminate this bias as it allows us to compare the outcomes of students in $\mathrm{FtF}$ and online classes taught by the same instructors. ${ }^{10}$

\footnotetext{
${ }^{10}$ While our most comprehensive specification accounts for all these different types of sorting, we also estimate a sequence of models that starts with a model including only semester and student effects, followed by subsequent models that add course and instructor fixed effects. As shown in Appendix Figure 1, the specification with only semester and student fixed effects yields rather noisy results. Concerning the outcomes of receiving a grade of A and Final Grade, the estimates are highly volatile with no discernable relationship. If anything, the picture suggests that students in online instruction outperform their $\mathrm{FtF}$ counterparts in terms of achieving an $\mathrm{A}$ as a course grade, which is contrary to our main findings. The estimates for the likelihood of withdrawing from the course or receiving a passing grade are also weaker in size and less precise during the pre-pandemic period compared to our main results. Moreover, the estimates for these outcomes appear to reverse direction in the post-pandemic period when compared to our main results. Upon adding course fixed effects to the model in Appendix Figure 2, the outcomes become almost identical to our primary results, with both the magnitude and statistical significance of the coefficients closely resembling our main findings. In addition, we also explore a specification that replaces course fixed effects with instructor fixed effects, as demonstrated in Appendix Figure 3. These results are generally consistent with our main findings, particularly during the pre-pandemic period. However, the pattern becomes somewhat more unstable in the postpandemic era. Overall, the results shown in Appendix Figures 1-3 highlight the importance of controlling for student level selection through student fixed effects. Furthermore, accounting for differences among courses and instructors
} 
Next, we explore the factors that may be responsible for the shift in the causal relationship between instruction modality and student performance outcomes observed after the pandemic. It is important to note that the convergence in academic performance between FtF and online instruction commenced before the pandemic, as the disparity between the two had been narrowing in the pre-pandemic period. Furthermore, the trends depicted in Figure 2 suggest that the primary factor responsible for the convergence is the improvement in learning outcomes among students in online instruction rather than a decline in the performance of students in FtF instruction. One possible explanation for this development could be the changes in the composition of students and instructors observed in these two modalities. In Table 2, we offered a glimpse of some of these differences between the pre- and post-pandemic periods. We now dig deeper into this issue by exploring how various student and instructor characteristics evolved over time between the two modalities. In Appendix Table 2, we present average student characteristics in FtF and online instruction over time along several dimensions, including age, gender, race, nationality, living in a dormitory, and being an honors student. There are slight changes in the proportion of students with a particular attribute over time. For example, the share of students who are in the Honors program appeases to increase over time for both online and FtF students. However, there are no significant or abrupt movements in one direction or the other. A similar table presenting the changes in average instructor characteristics over time is shown in Appendix Table 3. Again, there is no apparent shift in the share of instructors with a particular age, gender, or race favoring one type of modality over the other over time.

between online and FtF instruction seems to be important. However, it is also revealed that controlling for course differences between the two instruction delivery modes is sufficient and captures most of the heterogeneity associated with instructor differences, as adding instructor fixed effects makes little difference once course fixed effects are controlled for. 
To gain a more nuanced understanding of the role of compositional changes, we explore the semester-by-semester partial correlations between student characteristics and the likelihood of enrolling in an online course after controlling for semester, course, and instructor fixed effects. ${ }^{11}$ Appendix Figure 4 presents the results of this analysis, which reveals some changes in certain student characteristics once other factors are controlled for. Prior to the pandemic, black students had a higher tendency to be enrolled in FtF classes, while white students had a lower propensity. However, gender differences in race representation seem to have disappeared in the post-pandemic period. In terms of nationality, FtF courses were more likely to be enrolled by international students than domestic students before the pandemic. This trend seems to have completely vanished following the pandemic, likely due to challenges in obtaining visas. Notably, FtF instruction is strongly and positively correlated with living in a dormitory, which remains consistent throughout our analysis period, except for the first two semesters after the pandemic when the university canceled most FtF classes. Finally, an interesting trend emerges in the likelihood of being an Honors program student. We observe that the representation of students in the Honors program has consistently increased over time, with the Honors program expanding for both FtF and online students (as shown in Appendix Table 2). However, the pattern suggests that the rise occurred more dramatically among students in FtF instruction compared to their online counterparts.

We repeated the above exercise for instructor and course characteristics. As shown in Appendix Figure 5, we observe some indications that instructors in FtF course sections are becoming younger and less likely to be female and black over time, although these differences are

\footnotetext{
${ }^{11}$ These models are similar to the specification in equation (1), except that some fixed effects and controls are not included in the right-hand side depending on the outcome. For example, when the outcomes are student characteristics (such as student's age, race, and so on), we do not control for student fixed effects or time varying student characteristics.
} 
not statistically significant in several semesters. Finally, with regard to course types, there is a tendency for freshman-level courses to be offered online rather than FtF over time, as demonstrated in Appendix Figure 6. However, we did not find any noticeable changes over time in other courselevel variables we examined. ${ }^{12}$

\section{Falsification Analysis}

Although controlling for fixed effects at the student, course, and instructor levels is a robust approach to eliminate bias resulting from endogenous sorting into $\mathrm{FtF}$ versus online classes, we further examine the selection issue by subjecting our analysis to additional testing. We do this by performing two falsification tests. First, we consider student performance in all FtF classes in the Fall semesters and estimate regression models with an indicator for whether a student is observed in an online course in the subsequent two semesters. ${ }^{13}$ If our specification does a good job in controlling for selection, then the indicator on online instruction should not be associated with performance in the Fall semesters. As shown in Appendix Table 4, there is no evidence of future online course taking explaining the performance in the FtF class in past semesters.

Second, we examine whether lagged measures of student performance are related to student choices about whether a course is offered in FtF or online modality. We do this by regressing average measures of performance in $\mathrm{FtF}$ course sections over the past four semesters on the current decision of course modality. Following Hart et al. (2018), we use the average measures in the past FtF classes to avoid the possibility that differences in grading practices and general student achievement in FtF versus online modality contaminate our measures. As illustrated in Appendix

\footnotetext{
${ }^{12}$ In the Appendix, we discuss the heterogeneity of the impact of FtF instruction with respect to the student and instructor characteristics. In our analyses, we found that the patterns depicted in Figure 3 applies to almost all subsamples. The results are given in Appendix Tables 6A-6D and 7A-7D. In the Appendix, we additionally include an examination of heterogeneity with respect to students' majors and access to high-speed internet. Again, we found no significant differences of the impact of FtF modality by these groups. These results are presented in Appendix Figures $7 \mathrm{~A}-7 \mathrm{E}$ and $8 \mathrm{~A}-8 \mathrm{~B}$.

${ }^{13}$ This exercise is similar to the falsification test performed in Hart et al. (2018).
} 
Table 5, we again see no evidence to suggest that our results might be biased due to selection, as the average past student performances in the FtF courses in which they enroll are not correlated with their current decisions on course modality.

\section{Role of Plagiarism and Cheating in FtF versus Online Classes}

An interesting question in this context is how opportunities for students to engage in academic misconduct, such as plagiarism or cheating, can influence the relationship between academic performance and instruction modality. Academic misconduct can potentially affect student outcomes in both FtF and online classes. However, it may be more challenging for instructors to monitor student activities in online classes and therefore detect plagiarism. Students may also feel more intrigued to engage in plagiarism in these classes since they know that they are less likely to be detected. They may also have access to a wide range of online resources that make it easier to copy and paste information without properly citing the source. In contrast, resources available to students may be more limited in $\mathrm{FtF}$ sections, making it more difficult to plagiarize. More importantly, the physical presence of the instructor can make it easier to detect instances of plagiarism, cheating, or other academic misconduct. However, this does not necessarily mean that students in FtF classes are less likely to plagiarize, as there may still be many ways to cheat.

We can gain insights into how opportunities for academic misconduct may affect student performance and instruction by using the information on a remote proctoring service used by the University instructors to ensure academic integrity. ${ }^{14}$ This service allows instructors to proctor an exam by authenticating students as well as recording and monitoring personal computer activity during an exam. Instructors teaching online or FtF classes in the University have the option to administer their exams with online proctoring, and we have information on whether an instructor

\footnotetext{
${ }^{14}$ To preserve anonymity of the University, we refrain from naming the company name for the remote proctoring service. We call it "Online Proctoring."
} 
has requested the online proctoring service and has an account in our data. We have information on the use of proctoring software for five semesters, including Fall 2019, Spring 2020, Spring 2021, Fall 2021, and Spring 2022. Each semester, instructors who plan to use this service in their class send a request to the University for an account. ${ }^{15}$ Then, their course gets linked to these services. The number of instructors who requested the service is 95 in our data. Furthermore, 33 of these instructors teach an FtF course. There are 802 courses in our sample (for which we have information about proctoring software use) that have both an online and FtF section.

To explore this issue empirically, we regress our student performance measures on indicators of FtF instruction and the use of Online Proctoring. These regressions also control for all the variables in our most comprehensive specification, including semester, student, course, and instructor fixed effects. The results from this analysis are presented in Table $4 .{ }^{16}$ The FtF coefficients shown in the table refer to the impact of $\mathrm{FtF}$ instruction in classes where no proctoring software is used. Consistent with our main findings, these results indicate that students in FtF instruction outperform their online counterparts in courses with no proctoring software used. The estimates on Proctoring indicator reveal the differences in student learning outcomes between online classes with and without the use of the proctoring software. These estimates indicate that, in addition to students in online instruction performing worse than their FtF counterparts, there is an additional decline in academic performance if online students were monitored through the use

\footnotetext{
${ }^{15}$ Note that an instructor teaching a FtF course may request the proctoring service and administer the tests online for some or all students, although the lectures are FtF. An instructor has to include this information in the course syllabus, along with the cost of the online proctoring service to the students. A closer look at our data reveals that some FtF courses linked to online proctoring have a laboratory component. This may be due to greater challenges to monitoring individual student actions in laboratory sessions. It could also be that an instructor who is teaching both an online and a FtF version of the same course could offer tests online in order to save effort and time to prepare different tests for different modalities. Although we do not have information on whether instructors with an account for the online proctoring service do in fact use this tool in administering their exams, it is reasonable to assume that they do. To the extent that some instructors do not, the estimates from this analysis would represent a lower bound.

${ }^{16}$ We repeat this analysis excluding observations from Spring 2020. These results are similar to those reported in Table 4.
} 
of the proctoring software. However, the gap in the likelihood of withdrawing from a course and receiving a passing grade between students in online and $\mathrm{FtF}$ classes becomes larger if the instructors in online courses administer exams using proctoring software, as shown by the interaction coefficients between $\mathrm{FtF}$ instruction and online proctoring indicators. Finally, the use of proctoring software is associated with a decline in student performance in FtF classes as well. This is revealed by the last row, which displays the estimates on the sum of proctoring software and the interaction term. According to the point estimates, students in FtF classes are less likely to receive a passing grade, a grade of $\mathrm{A}$, and earn a lower final grade when instructors use the proctoring software. Interestingly, the decline in final grade or the likelihood of receiving a grade of A associated with the use of proctoring software appears to be larger among students in FtF classes compared to their online counterparts. Taken together, these findings suggest that incorporating technological tools like authentication software could be a crucial factor in minimizing academic integrity violations in both online and $\mathrm{FtF}$ classes.

\section{Students in the Honors Program and Graduate Students}

To investigate whether the instruction modality makes a difference in terms of performance between students in the Honors program and the regular students, we next estimate our models separately for these two groups. This question is valuable in its own right, but the findings can also provide further insights into the role of student sorting by skill in each type of instruction in explaining performance differences between $\mathrm{FtF}$ and online classes. To identify high-achieving students, we focus on the University's Honors Program, which provides additional academic opportunities for motivated and talented students who have excelled in specific subjects. ${ }^{17}$ The

\footnotetext{
17 Typically, students who are in this program take courses such as "Honors Colloquium," "Honors Seminar," and "Honors Thesis." We identified a student as an Honors Program student if she/he took one of these classes at any point during our sample period. In the Colloquium courses, students are required to take several honors courses designed to improve and teach students' writing, analytical reading, collaboration, engaging in academic discussions, ethics of
} 
Honors Program offers more personalized, intensive coursework taught by experienced faculty members, as well as other resources such as mentorship and advising. Admission to the program is selective and requires a certain GPA and successful completion of additional coursework.

To answer this question, we estimate our models separately for students in the Honors Program and the rest of the student body. There are 1,088 unique students enrolled in the Honors Program, resulting in 42,172 student-by-class observations, while the rest of the sample is comprised of 33,513 students resulting in 691,167 observations. As shown in Figure 4, the performance of non-Honors students follows a pattern similar to the one observed in the full sample. Students in FtF instruction tended to outperform online students before the pandemic, and this relationship seems to have been reversed early on in the post-pandemic period, only to be reversed back to the pre-pandemic pattern in the last two semesters. However, the differences between the two modalities are smaller and much less precisely estimated in the post-pandemic period. The results of the students in the Honors Program shown in Figure 5 reveal a different picture. The coefficients are much less precisely estimated, and most of the differences are no longer statistically different between the two groups of students. While the wider confidence intervals are likely due to the smaller sample size of Honors students, the effect sizes also appear to be smaller than those observed for the non-Honors students. Taken together, these findings indicate that for more talented and better-motivated students, the course modality is much less important for academic performance.

While the analysis in this paper focuses on the population of undergraduate students, we also possess information on graduate students. Specifically, we have data on 72,974 master's students, 28,324 doctorate students, and 11,730 post-baccalaureate students. The results for the

research and how to conduct research. In Seminar courses, students take 300 level honors courses on a variety of topics. As part of their curriculum, honors students write a thesis under the supervision of a faculty. 
performance differences between online vs. FtF classes in graduate classes are displayed in Figure 6. As shown in the figure, the picture is similar to the one obtained from the analysis of Honors students. Specifically, the differences in performance between the two types of instruction are much smaller and less precisely estimated. This is consistent with the notion that the course modality matters less for more motivated students.

\section{Downstream Outcomes: Subsequent Course Taking and Graduation}

As a final investigation, we explore whether instruction modality affects success down the road by considering the likelihood of repeating a class and graduation performance. For the latter, we consider observations from semesters in which the student repeated at least one course in the future semesters and examine how FtF course taking is related to the likelihood of repeating the same course in the future. ${ }^{18}$ As shown in Table 5, FtF instruction appears to be positively associated with course repetition in the specification with only student and semester fixed effects. However, this relationship is reversed once either course or instruction fixed effects are included in the regressions, highlighting the importance of controlling for selection at the course and instruction levels. The results from our most comprehensive specification indicate that FtF course-taking reduced the propensity to repeat a course in the future by 5.4 percentage points, which is equivalent to an effect size of 20 percent (based on the mean of the outcome, 0.270).

For graduation analysis, we explore three measures: (1) timely graduation, defined as an indicator variable if the student graduated in eight or fewer semesters; (ii) number of semesters it took a student to graduate; and (iii) graduation GPA. ${ }^{19}$ We then regress these measures on the

\footnotetext{
${ }^{18}$ That is, the outcome in these regressions in an indicator that is equal to one if the student will repeat the course in the future semesters.

${ }^{19}$ We first-time observe some students not as a freshman but as higher classes, such as sophomore, junior, or senior. This is because of transfers into the school and because our sample starts from Fall 2016. The timely graduation variable is defined based on student's first-time observed class. For example, if we observe a student as a freshman in Fall 2016, and if that student graduated by the end of Spring 2020 semester ( 8 semesters after Fall 2016), then the
} 
percentage of courses taken in FtF modality during the student's studies at the University along with student characteristics, binary indicators for the student's first semester at the university, dummy variables for seniority in their first semester (freshman, sophomore, etc.), and student's major fixed effects. In addition to the percentage of courses taken in the FtF modality, we estimate these regressions using a non-parametric specification splitting the FtF distribution into quartiles. As shown in Table 6A, a higher percentage of $\mathrm{FtF}$ courses is associated with a better likelihood of timely graduation, fewer semesters to graduation, and a higher graduation GPA. Additionally, the relationship appears to be nonlinear as graduation success monotonically increases with the percentage of courses taken in the FtF modality (Table 6B).

\section{Conclusion}

As on-campus operations resume and the threat of COVID-19 diminishes, the debate about the future of online instruction in education continues. Although online instruction has gained prominence in the post-pandemic landscape, skepticism about its quality persists, and a wide range of audiences and stakeholders in higher education, including instructors, academic leaders, and the public, remain skeptical about the merits of online education, which they perceive as inferior to traditional FtF instruction (Baum, 2020). However, the extent to which online instruction can be a viable substitute for FtF instruction, especially in the post-pandemic period, remains an unanswered question. Due to significant changes in the educational landscape, it is crucial to study

timely graduation variable equals to one. But if we first time observe a student as a junior in Fall 2016, then the timely graduation outcome equals to one if that student graduated by Spring 2018 (4 semesters after Fall 2016). 
the causal relationship between instruction modality and academic performance in the postpandemic period.

In this paper, we try to help inform this debate by providing insights on the impact of online instruction on student learning outcomes both in general and with a focus on the pre- and postpandemic differences. To do this, we analyze twelve semesters of administrative data at the student, instruction, and course levels from a large public university. Our research design controls for various levels of sorting into course modalities using fixed effects. It appears important to account for differences in student preferences for instruction modality through student fixed effects as well as accounting for differences at the instructor and course levels. However, our analysis reveals that controlling for course differences between the two instruction delivery modes is sufficient and captures most of the heterogeneity associated with instructor differences, as adding instructor fixed effects makes little difference once course fixed effects are controlled for.

Another finding emerging from our analysis is that the FtF advantage in student performance, while consistently present, follows a declining trend in the semesters prior to the pandemic as the performance of students in online instruction catches up to that of their FtF counterparts. At the onset of the pandemic, the differences in student learning outcomes between the two categories appear to have vanished, only to begin reemerging after Fall 2021 with the resumption of campus operations. However, the post-pandemic differences in student performance between FtF and online instruction are much smaller in the post-pandemic period. Our results are largely consistent across students and instructors with different characteristics and across different subject areas as well as majors. One important exception is the groups of students who are likely to be more motivated and possibly better skilled than others, including students in the Honors 
program and graduate students. Among these students, the FtF advantage in academic performance is either much smaller or statistically insignificant.

While the disparities in student performance between $\mathrm{FtF}$ and online instruction have narrowed in the post-pandemic era, it is too early to determine if this shift is permanent or temporary. However, there are reasons to anticipate that the differences will remain smaller than those in the pre-pandemic era. This is due to the fact that the student experience in both online and FtF instruction has evolved significantly since the pandemic. Prior to the pandemic, remote learning technologies were primarily used in online instruction, but now they have become commonplace in $\mathrm{FtF}$ instruction as well. For example, learning management systems like Blackboard and Canvas, videoconferencing tools such as Zoom and Microsoft Teams, and discussion forums like Piazza are now standard tools used in FtF courses. Consequently, the differences in student experience between purely online classes and FtF classes have become less distinct in the post-pandemic period. It is possible that the integration of information technology in education could further diminish the differences in student experience between online and FtF instruction, leading to comparable academic outcomes. However, data with a longer duration from the post-pandemic period is crucial to make a definitive determination on this question, highlighting the need for future research on the subject. Lastly, we recognize that the results obtained from a single university setting may not necessarily generalize to students attending other public universities or students in other types of institutions (e.g., community colleges, for-profit universities, etc.). 


\section{References}

Alpert, W. T., K. A. Couch and O. R. Harmon. (2016). "A Randomized Assessment of Online Learning." American Economic Review 106 (5), pp. 378-82.

Bailey, A., N. Vaduganathan, T. Henry, R. Laverdiere, and L. Pugliese. (2018). "Making digital learning work: success strategies from six leading universities and community colleges." Boston Consulting Group, Boston.

Barrera-Osorio, F., K. Gonzalez, F. Lagos, D. J. Deming. (2021). "Providing Performance Information in Education: An Experimental Evaluation in Colombia." Journal of Public Economics 186, 104185.

Baum, S. (2020). "Does Online Education Live up to its Promise? A Look at the Evidence." Urban Institute. Accessed from

<https://www.urban.org/sites/default/files/publication/101762/Does\%2520Online\%2520Educati on $\% 2520$ Live $\% 2520$ Up $\% 2520$ To $\% 2520$ Its $\% 2520$ Promise $\% 2520 \mathrm{a} \% 2520$ Look $\% 2520 \mathrm{at} \% 2520 \mathrm{~T}$ he\%2520Evidence 0.pdf> on July 24, 2021.

Bettinger, E., L. Fox, S. Loeb, and E. Taylor. (2017). "Virtual classrooms: How online college courses affect student success." American Economic Review 107(9), pp. 2855-2875.

Bird, K. A., B. L. Castleman, and G. Lohner. (2022). "Negative impacts from the shift to online learning during the COVID-19 crisis: evidence from a statewide community college system." Aera Open, 8, 23328584221081220.

Cacault, M. P., C. Hildebrand, J. Laurent-Lucchetti, and M. Pellizzari. (2021). "Distance learning in higher education: evidence from a randomized experiment." Journal of the European Economic Association 19 (4), pp. 2322-2372.

Cowen, T., and A. Tabarrok. (2014). "The Industrial Organization of Online Education.” American Economic Review 104 (5), pp. 519-22.

De Brey, C., T. D. Snyder, A. Zhang, and S. A. Dillow. (2021). "Digest of Education Statistics 2019” (NCES 2021-009). National Center for Education Statistics, Institute of Education Sciences, U.S. Department of Education. Washington, DC.

Deming, D. J., C. Goldin, L. F. Katz, and N. Yuchtman. (2015). “Can Online Learning Bend the Higher Education Cost Curve?” American Economic Review 105 (5), pp. 496-501.

Figlio, D., M. Rush, and L. Yin. (2013). "Is It Live or Is It Internet? Experimental Estimates of the Effects of Online Instruction on Student Learning." Journal of Labor Economics 31(4), pp. 763784. 
Hart, C. M., E. A. Friedmann, M. Hill. (2018). "Online course-taking and student outcomes in California Community Colleges." Education Finance and Policy 13(1), pp. 42-71.

Joyce, T., S. Crockett, D. A. Jaeger, O. Altindag, and S. D. O'Connell. (2015). "Does classroom time matter?" Economics of Education Review 46(1), pp. 64-77.

Hanson, M. (2022). "Average Cost of College and Tuition." Accessed from $<$ https://educationdata.org/average-cost-of-college $>$ on October 24, 2022.

Integrated Postsecondary Education Data System (IPEDS), 2021. U.S. Department of Education, National Center for Education Statistics. Accessed from < https://nces.ed.gov/ipeds/datacenter/InstitutionByName.aspx?goToReportId=1> on February 9, 2023.

Kofoed, M. S., L. Gebhart, D. Gilmore, and M. Moschitto. (2021). "Zooming to Class?: Experimental Evidence on College Students' Online Learning during COVID-19." IZA Discussion Papers 14356, Institute of Labor Economics (IZA).

Lieberman, M. (2020). "Like it or not, K-12 schools are doing a digital leapfrog during COVID19." Education Week, 39(34), p. 13.

McPherson, M. S., and L. S. Bacow. (2015). "Online Higher Education: Beyond the Hype Cycle." Journal of Economic Perspectives 29 (4), pp. 135-54.

Rodríguez-Planas, N. (2022a). "COVID-19, College Academic Performance, and the Flexible Grading Policy: A Longitudinal Analysis.” Journal of Public Economics, 104606.

Rodríguez-Planas, N. (2022b). "Hitting Where It Hurts Most: COVID-19 and Low-Income Urban College Students.” Economics of Education Review, 102233.

Schwartz, H. L., D. M. Grant, M. Diliberti, G. P. Hunter, and C. M. Setodji. (2020). "Remote learning is here to stay: Results from the first American School District Panel survey." RAND Corporation. Accessed from < https://www.rand.org/pubs/research_reports/RRA956-1.html $>$ on March 9, 2023.

Xie, X., K. Siau, Knd F. F. H. Nah. (2020). "COVID-19 pandemic-online education in the new normal and the next normal." Journal of Information Technology Case and Application Research 22(3), pp. 175-187.

Xu, D., and S. S. Jaggars. (2013). "The impact of online learning on students outcomes: Evidence from a large community and technical college system." Economics of Education Review 37, pp. 46-57.

Xu, D., and S. S. Jaggars. (2014). "Performance gaps between online and face-to-face courses: Differences across types of students and academic subject areas." The Journal of Higher Education 85(5), pp. 633-659. 
Figure 1

Share of Students in FtF Classes Over Time

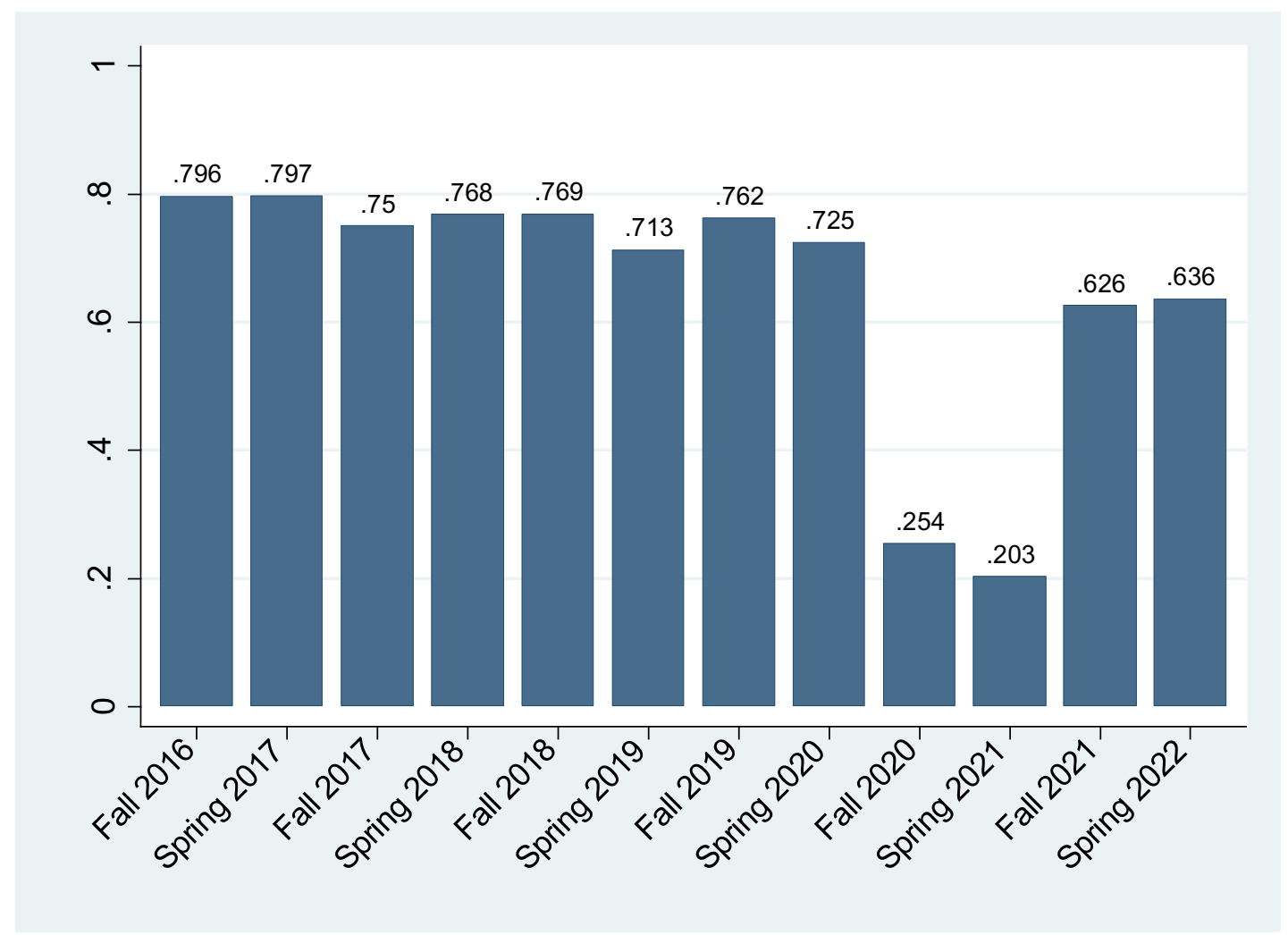

Note:The figure shows the shares of student $\times$ class observations. 
Figure 2

\section{Means of Student Learning Outcomes Over Time}

\section{Withdraw}

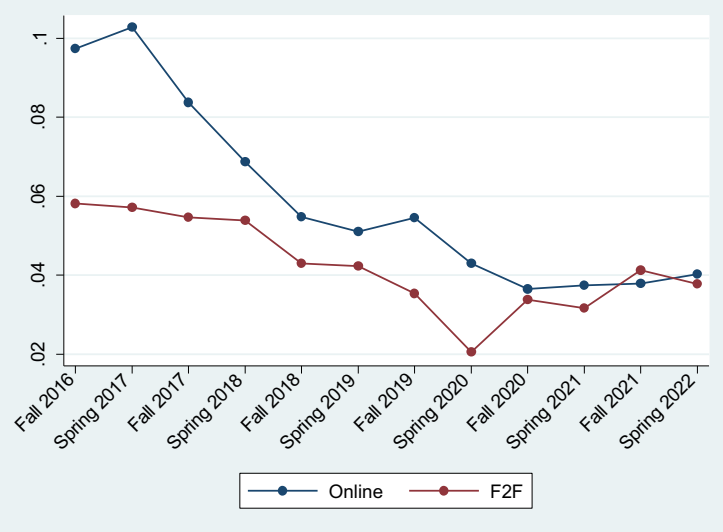

Passing Grade

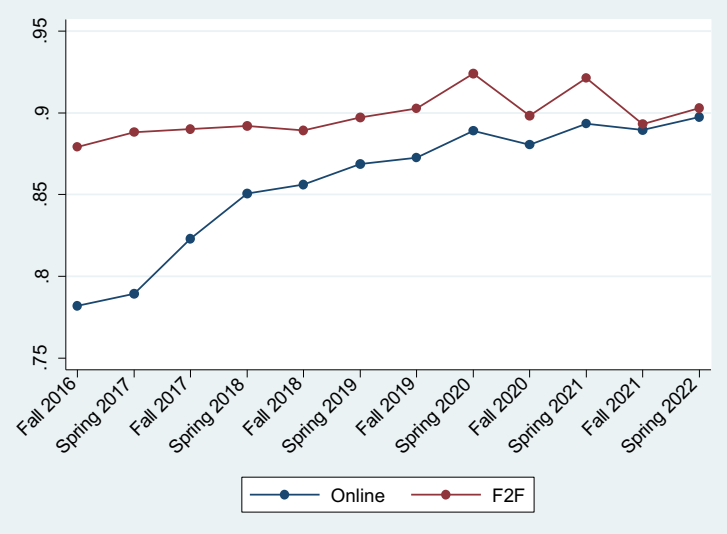

Grade A

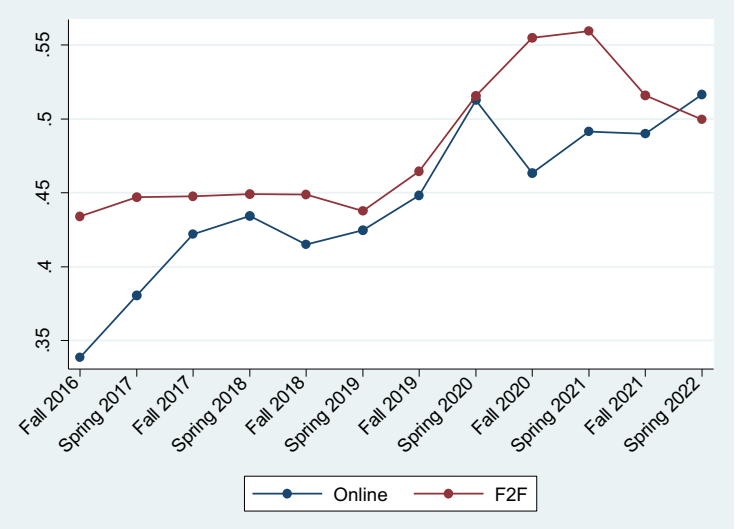

Final Grade

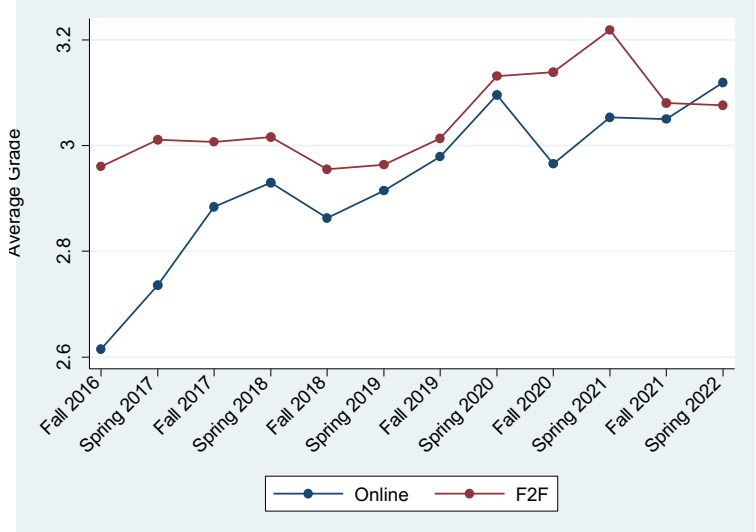

Note: The figure shows the averages of the student $\times$ class observations. 
Figure 3

\section{The Difference in Student Learning Outcomes Between FtF vs. Online Classes Over Time}

Withdraw

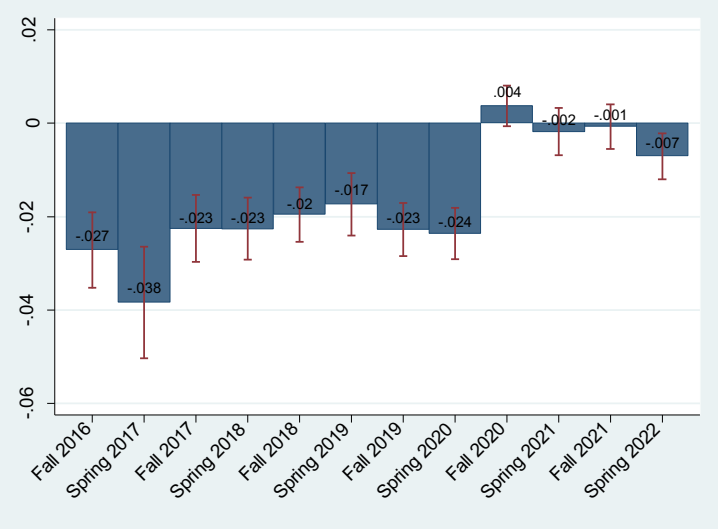

Passing Grade

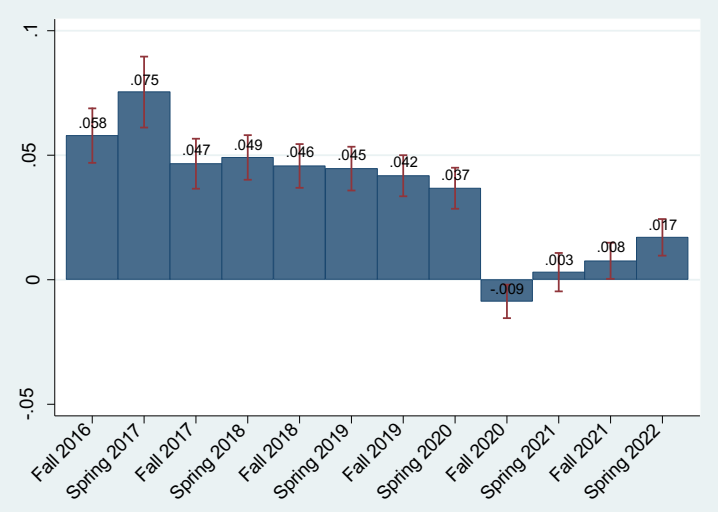

Grade A

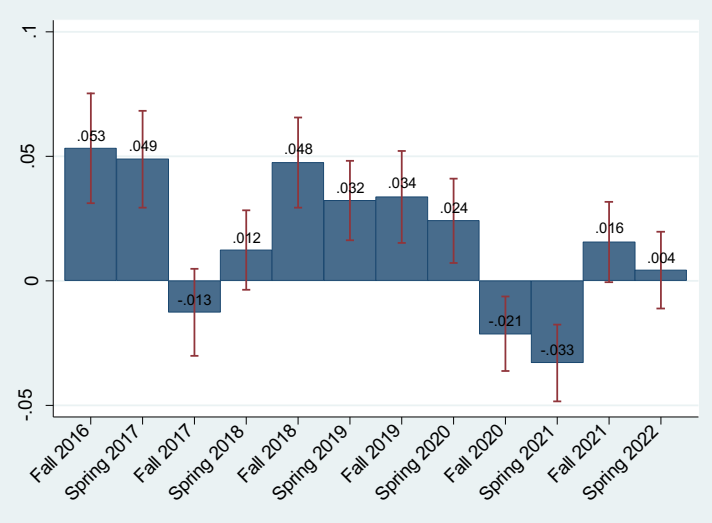

Final Grade

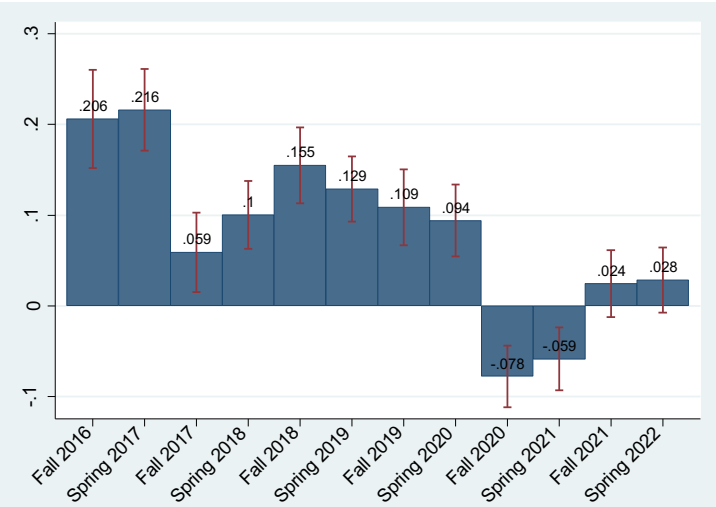

Notes: Bars represent the sum of the coefficients of the FtF dummy and the corresponding semester dummy obtained from estimating equation (1) (see Table 3 for the complete set of coefficients). Capped lines are twostandard deviation confidence intervals. Numbers over the bars are the values of the point estimates. 
Figure 4

The Difference in Student Learning Outcomes Between FtF vs. Online Classes Over Time For Non-Honors Students

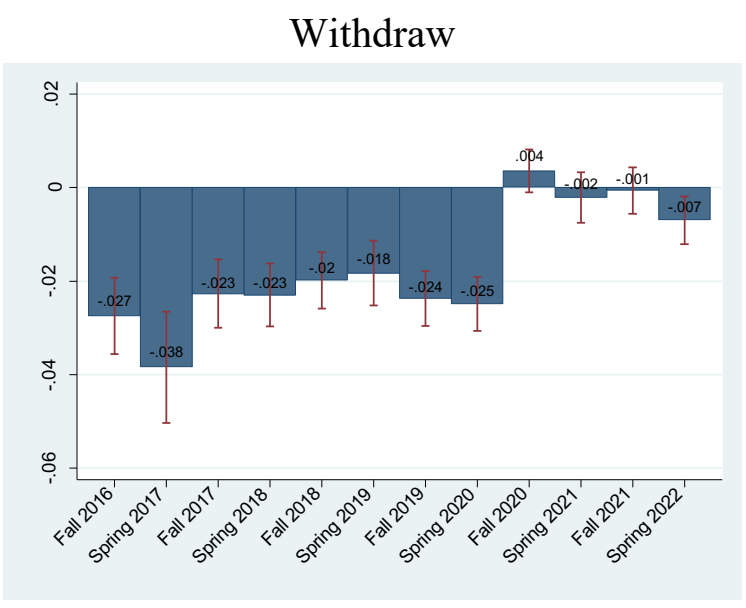

Pass

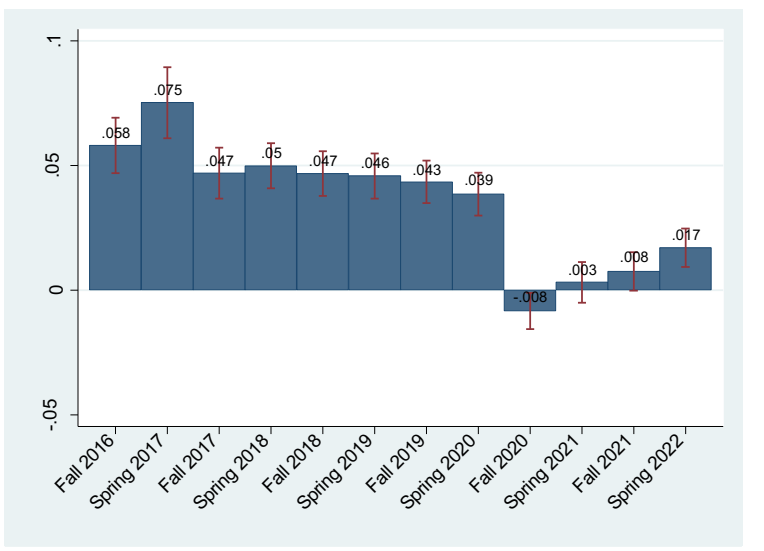

Obtained Grade A

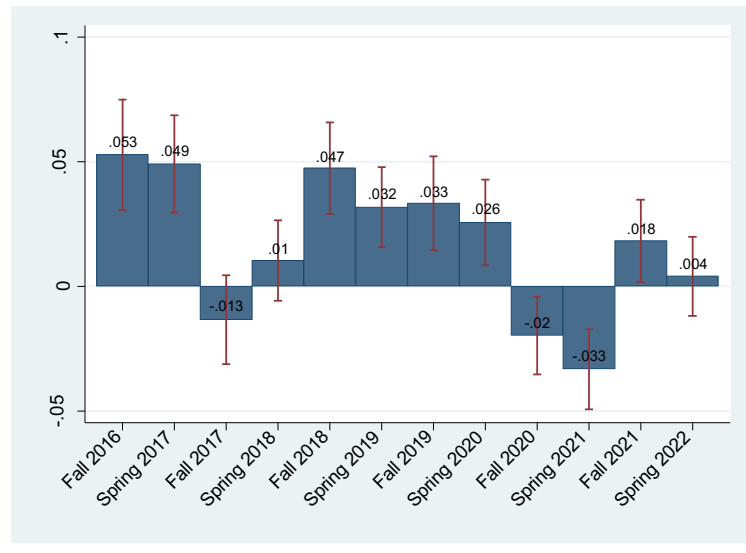

Final Grade

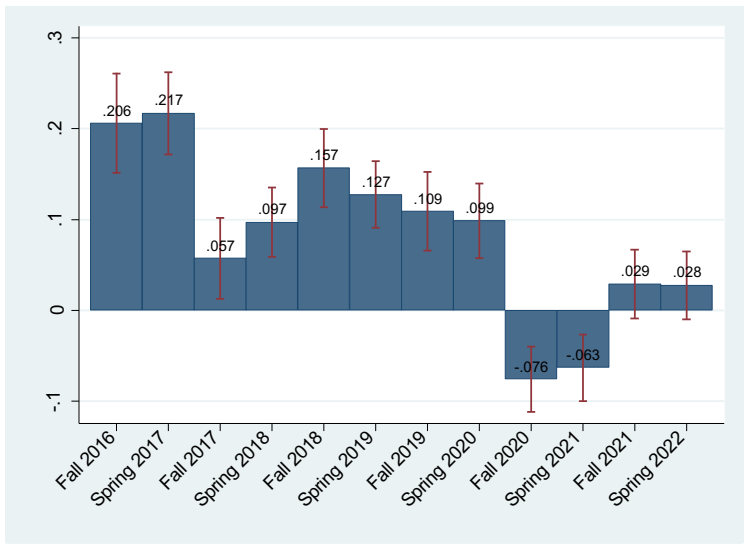

Notes: See notes in Figure 3. Only non-honors students enter into the regressions. The number of observations is 691,167 . 
Figure 5

The Difference in Student Learning Outcomes Between FtF vs. Online Classes Over Time For Honors Students

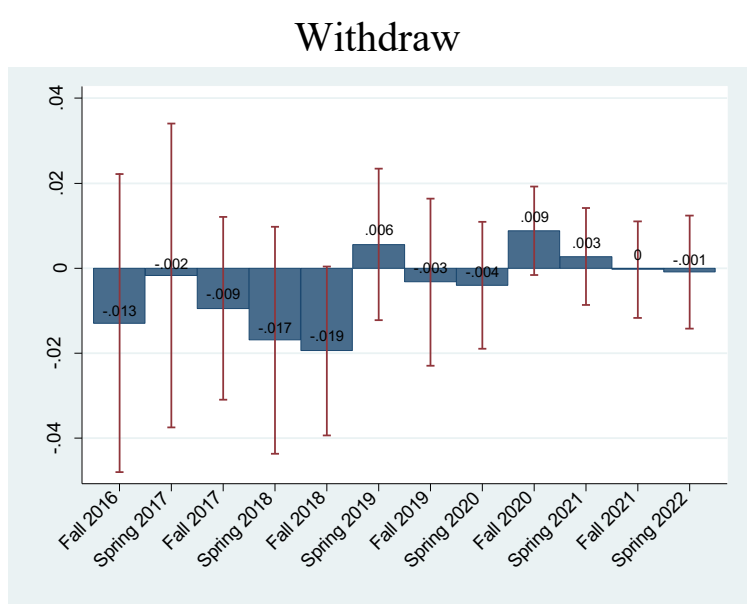

Pass

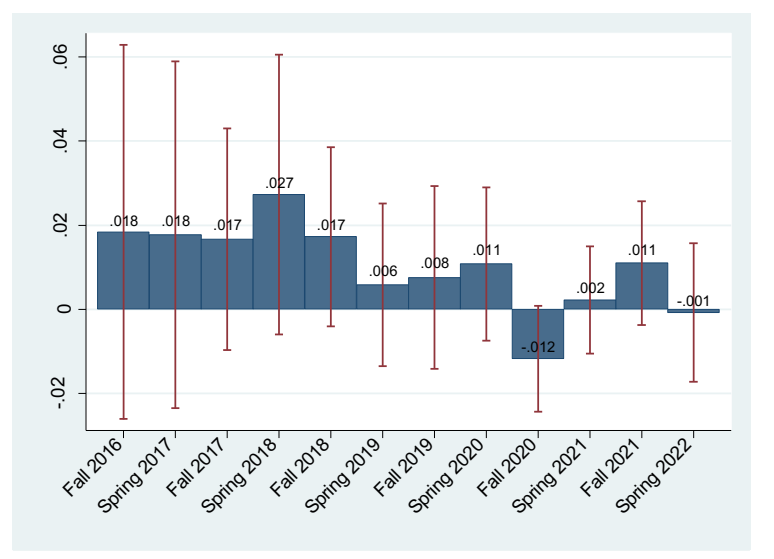

Obtained Grade A

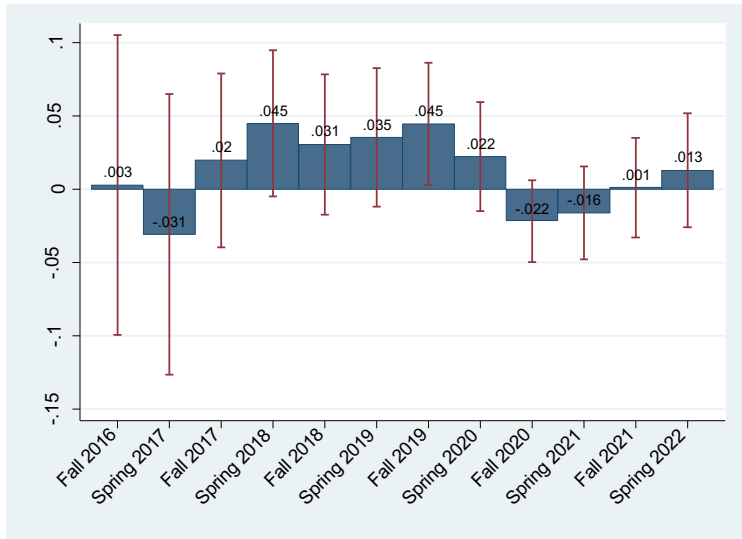

Final Grade

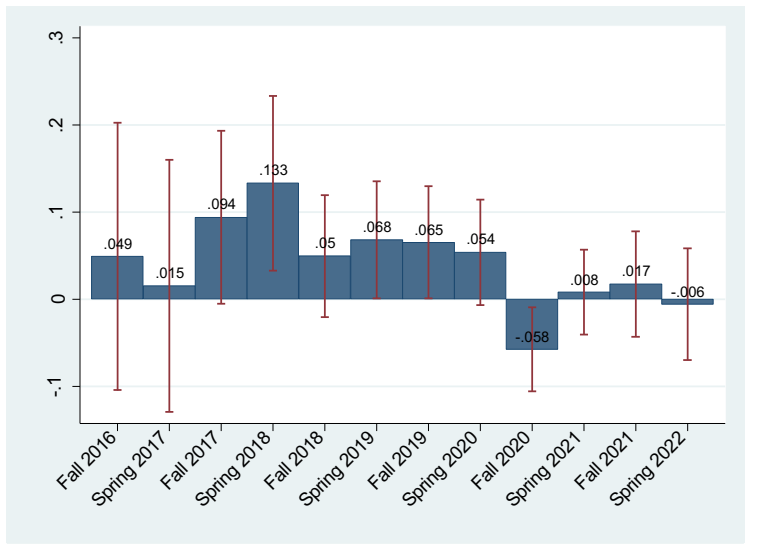

Notes: See notes in Figure 3. Only honors students enter into the regressions. The number of observations is 42,172. 


\section{Figure 6}

Graduate Students

\section{The Difference in Student Learning Outcomes Between FtF vs. Online Classes Over Time For Graduate Students}

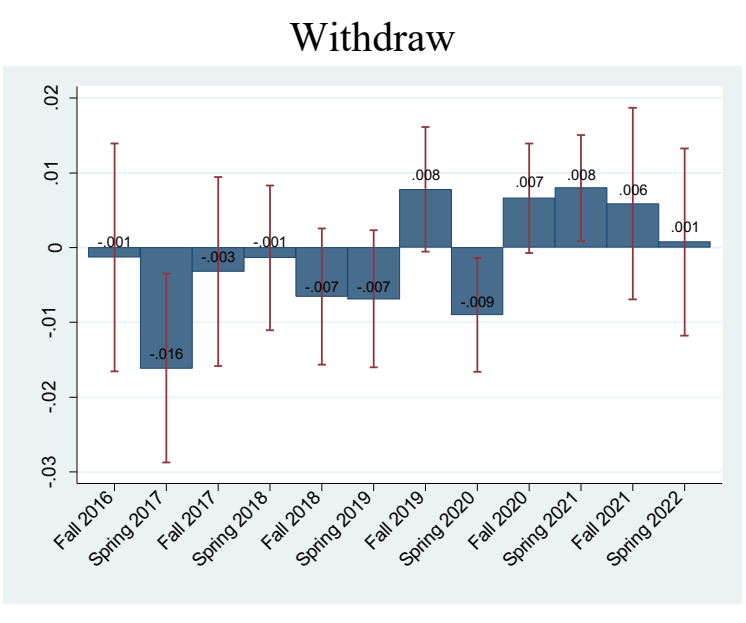

Pass

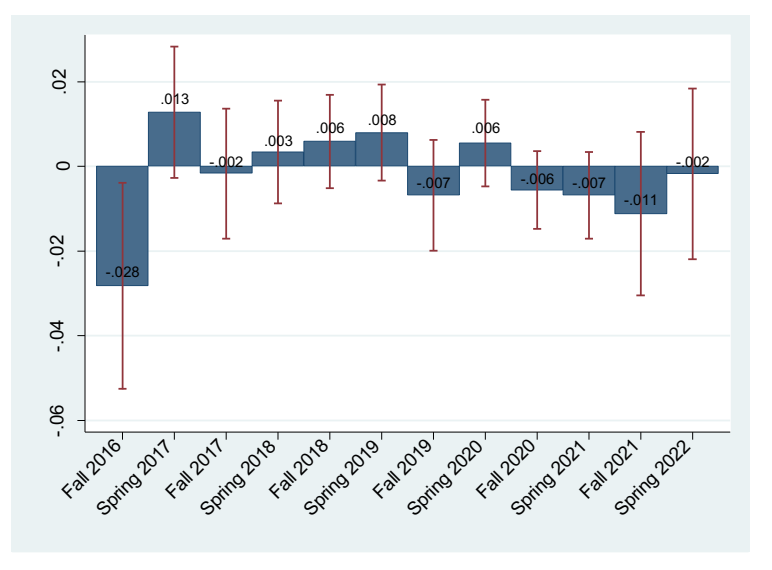

Obtained Grade A

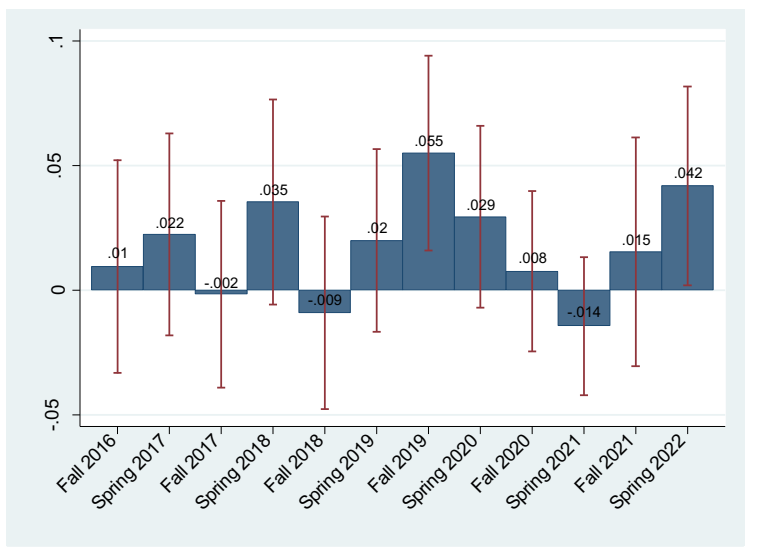

Final Grade

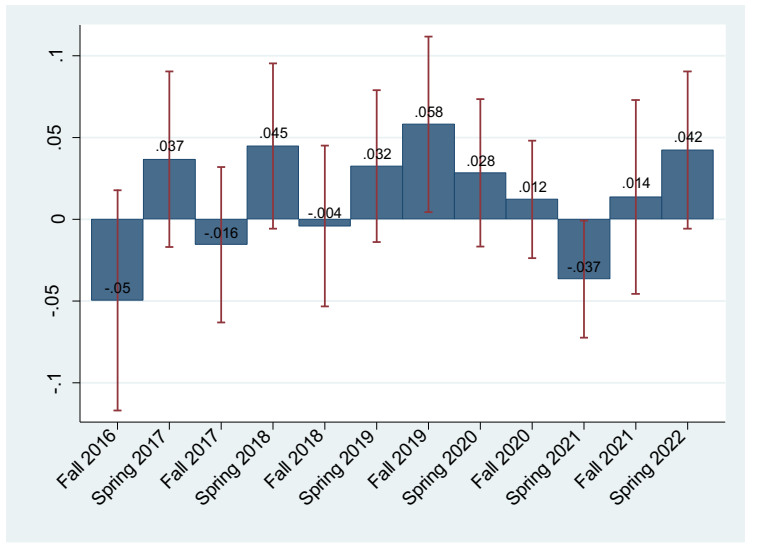

Notes: See notes in Figure 3. Unlike our other analyses that use observations from undergraduate students, only graduate students enter into these regressions. The number of observations is 113,028 . Included in the sample are the observations of Master students $(72,974)$, Doctoral students $(28,324)$, and Post-Baccalaureate students $(11,730)$. 
Table 1

Summary Statistics by Instruction Modality

\begin{tabular}{|c|c|c|c|c|}
\hline & (1) & (2) & (3) & (4) \\
\hline & $\begin{array}{l}\text { Full Sample } \\
(\mathrm{N}=733,339)\end{array}$ & $\begin{array}{c}\mathrm{FtF} \\
(\mathrm{N}=479,696)\end{array}$ & $\begin{array}{c}\text { Online } \\
(\mathrm{N}=253,463)\end{array}$ & $\begin{array}{l}\text { Difference } \\
\text { (2)-(3) }\end{array}$ \\
\hline \multicolumn{5}{|l|}{ Course Outcomes } \\
\hline Withdraw & 0.05 & 0.04 & 0.05 & $-0.01 * * *$ \\
\hline Passed & 0.89 & 0.90 & 0.87 & $0.03 * * *$ \\
\hline Earned Grade A & 0.46 & 0.47 & 0.46 & $-0.01 *$ \\
\hline Final Grade (0-4) & 3.00 & 3.03 & 2.96 & $0.06^{* * *}$ \\
\hline \multicolumn{5}{|l|}{ Student Characteristics } \\
\hline Age & 21.93 & 21.04 & 23.61 & $-2.57 * * *$ \\
\hline Female & 0.64 & 0.63 & 0.65 & $-0.02 * * *$ \\
\hline White & 0.61 & 0.61 & 0.60 & 0.00 \\
\hline Black & 0.29 & 0.28 & 0.30 & $-0.01 * * *$ \\
\hline Other Race & 0.11 & 0.11 & 0.10 & $0.01 * * *$ \\
\hline International Student & 0.02 & 0.03 & 0.01 & $0.01 * * *$ \\
\hline Lives in Dorm & 0.31 & 0.36 & 0.21 & $0.14 * * *$ \\
\hline Honors Student & 0.06 & 0.07 & 0.04 & $0.03 * * *$ \\
\hline Fast Internet at home ZIP & 0.57 & 0.57 & 0.58 & $-0.01 * * *$ \\
\hline \multicolumn{5}{|l|}{$\begin{array}{l}\text { Instructor } \\
\text { Characteristics }\end{array}$} \\
\hline Age & 44.83 & 44.78 & 44.91 & -0.13 \\
\hline Female & 0.53 & 0.50 & 0.58 & $-0.08 * * *$ \\
\hline White & 0.85 & 0.85 & 0.84 & $0.01^{*}$ \\
\hline Black & 0.05 & 0.04 & 0.06 & $-0.02 * * *$ \\
\hline Other Race & 0.11 & 0.11 & 0.10 & 0.00 \\
\hline \multicolumn{5}{|l|}{ Course Characteristics } \\
\hline Capstone/Writing Class & 0.05 & 0.05 & 0.06 & $-0.01 * *$ \\
\hline 100-Level & 0.35 & 0.36 & 0.33 & $0.03 * *$ \\
\hline 200-Level & 0.16 & 0.15 & 0.17 & $-0.02 * *$ \\
\hline 300-Level & 0.26 & 0.24 & 0.29 & $-0.06^{* * *}$ \\
\hline 400- or Higher Level & 0.24 & 0.26 & 0.21 & $0.05^{* * *}$ \\
\hline
\end{tabular}

Notes: The unit of observation is a student $\times$ class. Column 4 shows the difference between columns 2 and 3 .

Standard errors of the estimates are obtained from regressions of the variables on a $\mathrm{FtF}$ dummy. ***, **, and * indicate statistical significance at the $1 \%, 5 \%$, and $10 \%$ levels, respectively. 
Table 2

Summary Statistics by Instruction Modality Before and After Pandemic

Fall 2016-Spring 2020

\begin{tabular}{|c|c|c|c|c|c|c|c|}
\hline & $(1)$ & (2) & (3) & (4) & (5) & (6) & (7) \\
\hline & $\begin{array}{c}\mathrm{FtF} \\
\mathrm{N}=381,409\end{array}$ & $\begin{array}{c}\text { Online } \\
\mathrm{N}=119,986\end{array}$ & $\begin{array}{c}\text { Difference } \\
(1)-(2)\end{array}$ & $\begin{array}{c}\mathrm{FtF} \\
\mathrm{N}=98,287\end{array}$ & $\begin{array}{c}\text { Online } \\
\mathrm{N}=133,657\end{array}$ & $\begin{array}{c}\text { Difference } \\
(4)-(5)\end{array}$ & $(6)-(3)$ \\
\hline \multicolumn{8}{|l|}{ Course Outcomes } \\
\hline Withdraw & 0.05 & 0.07 & $-0.02 * * *$ & 0.04 & 0.04 & 0.00 & $0.02 * * *$ \\
\hline Passed & 0.89 & 0.84 & $0.05 * * *$ & 0.90 & 0.89 & $0.01 * * *$ & $-0.04 * * *$ \\
\hline Earned Grade A & 0.45 & 0.43 & $0.03 * * *$ & 0.52 & 0.48 & $0.04 * * *$ & 0.01 \\
\hline Final Grade (0-4) & 3.00 & 2.89 & $0.12 * * *$ & 3.10 & 3.03 & $0.07 * * *$ & -0.04 \\
\hline \multicolumn{8}{|c|}{ Student Characteristics } \\
\hline Age & 21.12 & 24.63 & $-3.50 * * *$ & 20.70 & 22.69 & $-1.99 * * *$ & $1.52 * * *$ \\
\hline Female & 0.63 & 0.65 & $-0.03 * * *$ & 0.64 & 0.65 & $-0.01 * *$ & 0.01 \\
\hline White & 0.61 & 0.61 & $-0.01 *$ & 0.61 & 0.60 & $0.02 * * *$ & $0.02 * * *$ \\
\hline Black & 0.29 & 0.29 & $-0.01 * *$ & 0.27 & 0.30 & $-0.03 * * *$ & $-0.02 * * *$ \\
\hline Other Race & 0.11 & 0.09 & $0.02 * * *$ & 0.11 & 0.10 & $0.01 * * *$ & 0.00 \\
\hline International & & & & & & & \\
\hline Student & 0.03 & 0.01 & $0.01 * * *$ & 0.02 & 0.01 & $0.01 * * *$ & $-0.01 * * *$ \\
\hline Lives in Dorm & 0.35 & 0.19 & $0.17 * * *$ & 0.37 & 0.24 & $0.13 * * *$ & $-0.03 * * *$ \\
\hline Honors Student & 0.06 & 0.02 & $0.04 * * *$ & 0.09 & 0.06 & $0.04 * * *$ & 0.00 \\
\hline $\begin{array}{l}\text { Fast Internet at } \\
\text { home ZIP }\end{array}$ & 0.57 & 0.58 & $-0.01 * * *$ & 0.57 & 0.58 & -0.00 & 0.00 \\
\hline \multicolumn{8}{|c|}{ Teacher Characteristics } \\
\hline Age & 44.96 & 44.18 & $0.78 * *$ & 44.08 & 45.57 & $-1.49 * * *$ & $-2.27 * * *$ \\
\hline Female & 0.50 & 0.63 & $-0.13 * * *$ & 0.51 & 0.53 & -0.02 & $0.11 * * *$ \\
\hline White & 0.85 & 0.86 & 0.00 & 0.83 & 0.82 & 0.01 & 0.01 \\
\hline Black & 0.04 & 0.05 & $-0.01 * *$ & 0.04 & 0.06 & $-0.02 * * *$ & -0.01 \\
\hline Other Race & 0.10 & 0.09 & $0.01 *$ & 0.13 & 0.12 & 0.01 & 0.00 \\
\hline \multicolumn{8}{|c|}{$\begin{array}{l}\text { Course Characteristics } \\
\text { Capstone/Writing }\end{array}$} \\
\hline Class & 0.05 & 0.06 & $-0.01 * *$ & 0.06 & 0.06 & 0.00 & 0.01 \\
\hline 100-Level & 0.37 & 0.32 & $0.05 * * *$ & 0.32 & 0.34 & -0.02 & $-0.07 * * *$ \\
\hline 200-Level & 0.15 & 0.17 & $-0.02 * *$ & 0.15 & 0.16 & -0.01 & 0.01 \\
\hline 300-Level & 0.24 & 0.31 & $-0.08 * * *$ & 0.24 & 0.28 & $-0.04 * * *$ & $0.04 * *$ \\
\hline $400+$ Level & 0.25 & 0.19 & $0.05 * * *$ & 0.29 & 0.22 & $0.07 * * *$ & 0.02 \\
\hline
\end{tabular}

Notes: Column 3 (6) shows the difference between columns 1 and 2 (4 and 5). Column 7 presents the difference between columns 3 and 6 . See notes to Table 1 for other details. 
Table 3

Complete Set of Coefficients from Equation (1)

\begin{tabular}{|c|c|c|c|c|}
\hline & (1) & (2) & (3) & (4) \\
\hline & Withdraw & Pass & Grade A & Final Grade \\
\hline \multirow[t]{2}{*}{$\mathrm{FtF}$} & $-0.023 * * *$ & $0.042 * * *$ & $0.034 * * *$ & $0.109 * * *$ \\
\hline & $(0.003)$ & $(0.004)$ & $(0.009)$ & $(0.021)$ \\
\hline \multicolumn{5}{|l|}{$\mathrm{FtF} \times \ldots$} \\
\hline \multirow[t]{2}{*}{... Fall 2016} & -0.004 & $0.016 * *$ & 0.020 & $0.097 * * *$ \\
\hline & $(0.005)$ & $(0.006)$ & $(0.014)$ & $(0.033)$ \\
\hline \multirow[t]{2}{*}{... Spring 2017} & $-0.016 * *$ & $0.034 * * *$ & 0.015 & $0.107 * * *$ \\
\hline & $(0.006)$ & $(0.008)$ & $(0.013)$ & $(0.029)$ \\
\hline \multirow[t]{2}{*}{... Fall 2017} & 0.000 & 0.005 & $-0.046 * * *$ & $-0.050^{*}$ \\
\hline & $(0.004)$ & $(0.006)$ & $(0.012)$ & $(0.029)$ \\
\hline \multirow{2}{*}{... Spring 2018} & 0.000 & 0.007 & $-0.021 *$ & -0.009 \\
\hline & $(0.004)$ & $(0.006)$ & $(0.011)$ & $(0.026)$ \\
\hline \multirow[t]{2}{*}{... Fall 2018} & 0.003 & 0.004 & 0.014 & $0.046^{*}$ \\
\hline & $(0.004)$ & $(0.005)$ & $(0.012)$ & $(0.027)$ \\
\hline \multirow[t]{2}{*}{... Spring 2019} & 0.005 & 0.003 & -0.001 & 0.020 \\
\hline & $(0.004)$ & $(0.006)$ & $(0.011)$ & $(0.025)$ \\
\hline \multirow[t]{2}{*}{... Spring 2020} & -0.001 & -0.005 & -0.010 & -0.015 \\
\hline & $(0.004)$ & $(0.005)$ & $(0.012)$ & $(0.027)$ \\
\hline \multirow[t]{2}{*}{... Fall 2020} & $0.026 * * *$ & $-0.050 * * *$ & $-0.055 * * *$ & $-0.187 * * *$ \\
\hline & $(0.003)$ & $(0.005)$ & $(0.011)$ & $(0.026)$ \\
\hline \multirow[t]{2}{*}{... Spring 2021} & $0.021 * * *$ & $-0.039 * * *$ & $-0.067 * * *$ & $-0.167 * * *$ \\
\hline & $(0.004)$ & $(0.005)$ & $(0.012)$ & $(0.027)$ \\
\hline \multirow[t]{2}{*}{... Fall 2021} & $0.022 * * *$ & $-0.034 * * *$ & -0.018 & $-0.084 * * *$ \\
\hline & $(0.004)$ & $(0.005)$ & $(0.011)$ & $(0.026)$ \\
\hline \multirow[t]{2}{*}{... Spring 2022} & $0.016 * * *$ & $-0.025 * * *$ & $-0.029 * *$ & $-0.080 * * *$ \\
\hline & $(0.004)$ & $(0.005)$ & $(0.011)$ & $(0.026)$ \\
\hline \multicolumn{5}{|c|}{ Semester Dummies } \\
\hline \multirow[t]{2}{*}{ Fall 2016} & 0.006 & -0.006 & $-0.073 * * *$ & $-0.163 * * *$ \\
\hline & $(0.005)$ & $(0.007)$ & $(0.013)$ & $(0.032)$ \\
\hline \multirow[t]{2}{*}{ Spring 2017} & $0.029 * * *$ & $-0.041 * * *$ & $-0.054 * * *$ & $-0.165 * * *$ \\
\hline & $(0.006)$ & $(0.008)$ & $(0.012)$ & $(0.028)$ \\
\hline \multirow[t]{2}{*}{ Fall 2017} & $0.010 * *$ & -0.006 & 0.008 & 0.007 \\
\hline & $(0.004)$ & $(0.006)$ & $(0.011)$ & $(0.026)$ \\
\hline \multirow[t]{2}{*}{ Spring 2018} & $0.013 * * *$ & $-0.018 * * *$ & -0.005 & -0.035 \\
\hline & $(0.004)$ & $(0.005)$ & $(0.010)$ & $(0.024)$ \\
\hline \multirow[t]{2}{*}{ Fall 2018} & -0.001 & -0.005 & $-0.030 * * *$ & $-0.085 * * *$ \\
\hline & $(0.003)$ & $(0.005)$ & $(0.011)$ & $(0.025)$ \\
\hline \multirow[t]{2}{*}{ Spring 2019} & 0.001 & $-0.012 * *$ & -0.016 & $-0.072 * * *$ \\
\hline & $(0.004)$ & $(0.005)$ & $(0.010)$ & $(0.022)$ \\
\hline
\end{tabular}




\begin{tabular}{|c|c|c|c|c|}
\hline \multicolumn{5}{|c|}{ Table 3 Continued } \\
\hline & $(1)$ & $(2)$ & (3) & (4) \\
\hline & Withdraw & Pass & Grade A & Final Grade \\
\hline Spring 2020 & $\begin{array}{c}-0.011 * * * \\
(0.003)\end{array}$ & $\begin{array}{c}0.010 * * \\
(0.005)\end{array}$ & $\begin{array}{c}0.071 * * * \\
(0.010)\end{array}$ & $\begin{array}{c}0.120 * * * \\
(0.023)\end{array}$ \\
\hline Fall 2020 & $\begin{array}{c}-0.023 * * * \\
(0.003)\end{array}$ & $\begin{array}{c}0.028 * * * \\
(0.004)\end{array}$ & $\begin{array}{c}0.071 * * * \\
(0.010)\end{array}$ & $\begin{array}{c}0.150 * * * \\
(0.021)\end{array}$ \\
\hline Spring 2021 & $\begin{array}{c}-0.019 * * * \\
(0.003)\end{array}$ & $\begin{array}{c}0.020 * * * \\
(0.004)\end{array}$ & $\begin{array}{c}0.083 * * * \\
(0.010)\end{array}$ & $\begin{array}{c}0.152 * * * \\
(0.022)\end{array}$ \\
\hline Fall 2021 & $\begin{array}{c}-0.017 * * * \\
(0.003)\end{array}$ & $\begin{array}{l}0.010 * * \\
(0.005)\end{array}$ & $\begin{array}{c}0.055 * * * \\
(0.010)\end{array}$ & $\begin{array}{c}0.093 * * * \\
(0.023)\end{array}$ \\
\hline Spring 2022 & $\begin{array}{c}-0.009 * * \\
(0.004)\end{array}$ & $\begin{array}{l}-0.006 \\
(0.005)\end{array}$ & $\begin{array}{c}0.060 * * * \\
(0.010)\end{array}$ & $\begin{array}{c}0.065 * * * \\
(0.023)\end{array}$ \\
\hline Control Variables & & & & \\
\hline Student Age 19 & $\begin{array}{c}0.009 * * * \\
(0.001)\end{array}$ & $\begin{array}{c}-0.018 * * * \\
(0.002)\end{array}$ & $\begin{array}{c}-0.007 * * * \\
(0.003)\end{array}$ & $\begin{array}{c}-0.045^{* * *} \\
(0.006)\end{array}$ \\
\hline Student Age 20 & $\begin{array}{c}0.015 * * * \\
(0.002)\end{array}$ & $\begin{array}{c}-0.023 * * * \\
(0.003)\end{array}$ & $\begin{array}{c}-0.009 * * \\
(0.004)\end{array}$ & $\begin{array}{c}-0.053 * * * \\
(0.009)\end{array}$ \\
\hline Student Age 21 & $\begin{array}{c}0.016 * * * \\
(0.002)\end{array}$ & $\begin{array}{c}-0.022 * * * \\
(0.003)\end{array}$ & $\begin{array}{l}-0.005 \\
(0.005)\end{array}$ & $\begin{array}{c}-0.048 * * * \\
(0.011)\end{array}$ \\
\hline Student Age 22-23 & $\begin{array}{c}0.009 * * * \\
(0.003)\end{array}$ & $\begin{array}{l}-0.007 * \\
(0.004)\end{array}$ & $\begin{array}{c}0.007 \\
(0.006)\end{array}$ & $\begin{array}{c}0.009 \\
(0.014)\end{array}$ \\
\hline Student Age 24+ & $\begin{array}{c}0.006 \\
(0.004)\end{array}$ & $\begin{array}{c}0.009 \\
(0.006)\end{array}$ & $\begin{array}{c}0.020 * * \\
(0.009)\end{array}$ & $\begin{array}{c}0.091 * * * \\
(0.020)\end{array}$ \\
\hline Lives in Dorm & $\begin{array}{c}-0.006^{* * *} \\
(0.001)\end{array}$ & $\begin{array}{c}0.019 * * * \\
(0.001)\end{array}$ & $\begin{array}{c}0.014 * * * \\
(0.002)\end{array}$ & $\begin{array}{c}0.057 * * * \\
(0.005)\end{array}$ \\
\hline Instructor Age 30-39 & $\begin{array}{l}-0.002 \\
(0.003)\end{array}$ & $\begin{array}{c}0.013 * * * \\
(0.004)\end{array}$ & $\begin{array}{c}0.028 * * * \\
(0.009)\end{array}$ & $\begin{array}{c}0.082 * * * \\
(0.024)\end{array}$ \\
\hline Instructor Age 40-49 & $\begin{array}{l}-0.006 \\
(0.004)\end{array}$ & $\begin{array}{c}0.019 * * * \\
(0.006)\end{array}$ & $\begin{array}{c}0.049 * * * \\
(0.012)\end{array}$ & $\begin{array}{c}0.123 * * * \\
(0.029)\end{array}$ \\
\hline Instructor Age 50-59 & $\begin{array}{l}-0.006 \\
(0.005)\end{array}$ & $\begin{array}{c}0.021 * * * \\
(0.007)\end{array}$ & $\begin{array}{c}0.042 * * * \\
(0.014)\end{array}$ & $\begin{array}{c}0.115 * * * \\
(0.035)\end{array}$ \\
\hline Instructor Age $60+$ & $\begin{array}{c}-0.008 \\
(0.006)\end{array}$ & $\begin{array}{l}0.016 * \\
(0.009)\end{array}$ & $\begin{array}{c}0.011 \\
(0.017)\end{array}$ & $\begin{array}{c}0.044 \\
(0.040)\end{array}$ \\
\hline Capstone/Writing Int. Course & $\begin{array}{c}0.010 \\
(0.008)\end{array}$ & $\begin{array}{c}0.002 \\
(0.010)\end{array}$ & $\begin{array}{l}-0.015 \\
(0.018)\end{array}$ & $\begin{array}{c}0.019 \\
(0.038)\end{array}$ \\
\hline Constant & $\begin{array}{c}0.058 * * * \\
(0.005) \\
\end{array}$ & $\begin{array}{c}0.851 * * * \\
(0.007)\end{array}$ & $\begin{array}{c}0.402 * * * \\
(0.014)\end{array}$ & $\begin{array}{c}2.836 * * * \\
(0.033) \\
\end{array}$ \\
\hline $\mathrm{N}$ & 732074 & 732074 & 697466 & 697032 \\
\hline Student FEs & Yes & Yes & Yes & Yes \\
\hline Instructor FEs & Yes & Yes & Yes & Yes \\
\hline Course FEs & Yes & Yes & Yes & Yes \\
\hline
\end{tabular}

Note: Estimates are obtained from equation (1). 
Table 4

The Impact of Proctoring Software on Student Learning Outcomes

\begin{tabular}{lcccc}
\hline & $(1)$ & $(2)$ & $(3)$ & $(4)$ \\
\hline $\mathrm{FtF}$ & Withdraw & Pass & Earned A & Final Grade \\
& $-0.008^{* * *}$ & $0.016^{* * *}$ & $0.009^{*}$ & $0.033^{* * *}$ \\
Proctoring & $(0.002)$ & $(0.002)$ & $(0.005)$ & $(0.012)$ \\
& $0.019 * * *$ & $-0.030^{* * *}$ & $-0.066 * * *$ & $-0.148 * * *$ \\
Proctoring $\times \mathrm{FtF}$ & $(0.004)$ & $(0.006)$ & $(0.011)$ & $(0.026)$ \\
& $-0.012^{* *}$ & 0.013 & -0.025 & -0.055 \\
$\mathrm{~N}$ & $(0.005)$ & $(0.008)$ & $(0.030)$ & $(0.063)$ \\
\hline $\mathrm{FtF}+$ Interaction & 289521 & 289521 & 278884 & 278805 \\
& $-0.020 * * *$ & $0.029 * * *$ & -0.016 & -0.022 \\
Proctoring + Interaction & $(0.005)$ & $(0.008)$ & $(0.030)$ & $(0.061)$ \\
& 0.007 & $-0.017 * *$ & $-0.091 * * *$ & $-0.203 * * *$ \\
& $(0.005)$ & $(0.007)$ & $(0.032)$ & $(0.065)$ \\
\hline
\end{tabular}

Notes: The unit of observation is a student $\times$ class. Regressions include time-varying controls, student, instructor, course, and semester fixed effects. Observations from only Fall 2019, Spring 2020, Spring 2021, Fall 2021, and Spring 2022 semesters enter into the regressions.

Table 5

Repeating a Class

\begin{tabular}{lcccc}
\hline & $(1)$ & $(2)$ & $(3)$ & $(4)$ \\
\hline & Repeat & Repeat & Repeat & Repeat \\
\hline FtF & $0.020 * * *$ & $-0.029 * * *$ & $-0.062^{* * *}$ & $-0.054 * * *$ \\
& $(0.004)$ & $(0.005)$ & $(0.005)$ & $(0.006)$ \\
\hline Student FE & Yes & Yes & Yes & Yes \\
Semester FEs & Yes & Yes & Yes & Yes \\
Instructor FEs & & Yes & & Yes \\
Course FEs & & & Yes & Yes \\
\hline $\mathrm{N}$ & 131082 & 130919 & 130860 & 130708 \\
\hline
\end{tabular}

Notes: The unit of observation is a student $\times$ class. The outcome is equal to one if the student repeats the course in a future semester. We include only the observations from the semesters in which the student repeated at least one course in the future semesters. Regressions also include the control variables as in equation (1). 
Table 6A

The Impact of FtF Course-Taking on Graduation

\begin{tabular}{lcccc}
\hline & $(1)$ & $(2)$ & $(3)$ & $(4)$ \\
\hline & $\begin{array}{c}\text { Graduated } \\
\text { on time }\end{array}$ & $\begin{array}{c}\text { Graduated } \\
\text { on time }\end{array}$ & $\begin{array}{c}\text { Sumber of } \\
\text { to Graduate }\end{array}$ & $\begin{array}{c}\text { GPA at } \\
\text { Graduation }\end{array}$ \\
\hline \%FtF Courses & $0.089^{* * *}$ & $0.195^{* * *}$ & $-1.054^{* * *}$ & $0.118^{* * *}$ \\
& $(0.012)$ & $(0.023)$ & $(0.090)$ & $(0.029)$ \\
Age & $-0.005^{* * *}$ & $-0.008^{* * *}$ & $0.043^{* * *}$ & $0.005^{* * *}$ \\
& $(0.000)$ & $(0.001)$ & $(0.003)$ & $(0.001)$ \\
Female & $0.047^{* * *}$ & $0.044^{* * *}$ & $-0.161^{* * *}$ & $0.128^{* * *}$ \\
& $(0.006)$ & $(0.009)$ & $(0.032)$ & $(0.011)$ \\
Black & $-0.096^{* * *}$ & $-0.104^{* * *}$ & $0.315^{* * *}$ & $-0.331^{* * *}$ \\
& $(0.006)$ & $(0.010)$ & $(0.034)$ & $(0.011)$ \\
Other race & $-0.051^{* * *}$ & $-0.052^{* * *}$ & $0.094^{* *}$ & $-0.039^{* *}$ \\
& $(0.010)$ & $(0.014)$ & $(0.047)$ & $(0.016)$ \\
International & $0.071^{* * *}$ & $0.152^{* * *}$ & $-0.409^{* * *}$ & $0.279^{* * *}$ \\
& $(0.026)$ & $(0.031)$ & $(0.095)$ & $(0.036)$ \\
Lives in dorm & $-0.060^{* * *}$ & $0.112^{* * *}$ & $-0.225^{* * *}$ & $0.192^{* * *}$ \\
& $(0.009)$ & $(0.013)$ & $(0.038)$ & $(0.015)$ \\
Honors Student & $0.283^{* * *}$ & $0.032^{*}$ & $0.201^{* * *}$ & $0.391^{* * *}$ \\
& $(0.019)$ & $(0.017)$ & $(0.041)$ & $(0.018)$ \\
\hline $\mathrm{N}$ & 26006 & 13962 & 13962 & 13962 \\
\hline
\end{tabular}

Notes: The unit of observation is a student. Column 1 includes all students who were expected to graduate in four years as of Spring 2022. Columns 2-4 include students who actually graduated by Spring 2022. Regressions also include dummies for students' first semester at the University, dummies for seniority in their first semester at the University (freshman, sophomore, etc.), and students' major fixed effects. \% FtF is the share of classes the student took in the FtF modality. 
Table 6B

The Impact of FtF Course-Taking on Graduation

\begin{tabular}{|c|c|c|c|c|}
\hline & (1) & (2) & (3) & (4) \\
\hline & $\begin{array}{c}\text { Graduated } \\
\text { on time }\end{array}$ & $\begin{array}{c}\text { Graduated } \\
\text { on time }\end{array}$ & $\begin{array}{c}\text { Number of } \\
\text { Semesters Taken } \\
\text { to Graduate }\end{array}$ & $\begin{array}{c}\text { GPA at } \\
\text { Graduation }\end{array}$ \\
\hline \multicolumn{5}{|l|}{$\%$ FtF Courses... } \\
\hline$\ldots 50-75 \%$ & $\begin{array}{c}0.045^{* * *} \\
(0.009)\end{array}$ & $\begin{array}{c}0.003 \\
(0.014)\end{array}$ & $\begin{array}{c}-0.118 * * \\
(0.052)\end{array}$ & $\begin{array}{c}-0.002 \\
(0.017)\end{array}$ \\
\hline$\ldots 75-90 \%$ & $\begin{array}{c}0.040 * * * \\
(0.010)\end{array}$ & $\begin{array}{c}0.053 * * * \\
(0.016)\end{array}$ & $\begin{array}{c}-0.382 * * * \\
(0.058)\end{array}$ & $\begin{array}{c}0.076 * * * \\
(0.019)\end{array}$ \\
\hline$\ldots 90-100 \%$ & $\begin{array}{c}0.053 * * * \\
(0.010)\end{array}$ & $\begin{array}{c}0.198 * * * \\
(0.018)\end{array}$ & $\begin{array}{c}-1.000 * * * \\
(0.065)\end{array}$ & $\begin{array}{c}0.169 * * * \\
(0.022)\end{array}$ \\
\hline Age & $\begin{array}{c}-0.005 * * * \\
(0.000)\end{array}$ & $\begin{array}{c}-0.009 * * * \\
(0.001)\end{array}$ & $\begin{array}{c}0.047 * * * \\
(0.003)\end{array}$ & $\begin{array}{c}0.004 * * * \\
(0.001)\end{array}$ \\
\hline Female & $\begin{array}{c}0.045 * * * \\
(0.006)\end{array}$ & $\begin{array}{c}0.043 * * * \\
(0.009)\end{array}$ & $\begin{array}{c}-0.157 * * * \\
(0.032)\end{array}$ & $\begin{array}{c}0.130 * * * \\
(0.011)\end{array}$ \\
\hline Black & $\begin{array}{c}-0.096 * * * \\
(0.006)\end{array}$ & $\begin{array}{c}-0.096 * * * \\
(0.010)\end{array}$ & $\begin{array}{c}0.281 * * * \\
(0.034)\end{array}$ & $\begin{array}{c}-0.324 * * * \\
(0.011)\end{array}$ \\
\hline Other race & $\begin{array}{c}-0.051 * * * \\
(0.010)\end{array}$ & $\begin{array}{c}-0.049 * * * \\
(0.014)\end{array}$ & $\begin{array}{l}0.085 * \\
(0.047)\end{array}$ & $\begin{array}{c}-0.037 * * \\
(0.016)\end{array}$ \\
\hline International & $\begin{array}{c}0.073 * * * \\
(0.026)\end{array}$ & $\begin{array}{c}0.144 * * * \\
(0.031)\end{array}$ & $\begin{array}{c}-0.375 * * * \\
(0.097)\end{array}$ & $\begin{array}{c}0.269 * * * \\
(0.036)\end{array}$ \\
\hline Lives in dorm & $\begin{array}{c}-0.057 * * * \\
(0.009)\end{array}$ & $\begin{array}{c}0.106 * * * \\
(0.013)\end{array}$ & $\begin{array}{c}-0.199 * * * \\
(0.038)\end{array}$ & $\begin{array}{c}0.184 * * * \\
(0.015)\end{array}$ \\
\hline Honors Student & $\begin{array}{c}0.283 * * * \\
(0.019)\end{array}$ & $\begin{array}{c}0.023 \\
(0.017)\end{array}$ & $\begin{array}{c}0.237 * * * \\
(0.042)\end{array}$ & $\begin{array}{c}0.381 * * * \\
(0.018)\end{array}$ \\
\hline $\mathrm{N}$ & 26006 & 13962 & 13962 & 13962 \\
\hline
\end{tabular}

Note: See notes in Table 7. 


\section{APPENDIX \\ Heterogeneity by Student and Instructor Characteristics}

We examine whether the impact of instruction modality on student learning outcomes differs by student and instructor characteristics. To do, we estimate our most comprehensive specification separately across a range of dimensions for each group. Appendix Tables 6A-6D present results for each of the four academic performance measures broken down by age, gender, race (White, non-White), age (Age $\leq 25$ versus Age $>25$ ), living in a dormitory, international student status (international versus domestic). To keep it concise, we only present the estimates corresponding to semester-by-semester differences between FtF instruction and online instruction, which is obtained by a sum of the FtF coefficient and the interaction between FtF and semester dummies in equation (1). ${ }^{20}$ The results indicate that, prior to the pandemic, students in FtF instruction are consistently less likely to withdraw from their classes than their online counterparts across all categories. The only exception is international students, for whom the advantage of FtF students seems to have disappeared after Fall 2017. While the differences in the likelihood of withdrawing between the two types of students go away in the initial post-pandemic semesters, they reappear in Spring 2022 for all groups, except for white students and international students.

As for receiving a passing grade, the results in Appendix Table 6B indicate a robust advantage for FtF students in the pre-pandemic period. The difference between the two modalities appears to have been erased early on in the post-pandemic period, only to re-emerge again in Fall 2021 and Spring 2022 for most student groups.

Concerning the outcome of receiving an $\mathrm{A}$, the results in Appendix Table $6 \mathrm{C}$ presents a more nuanced picture. In general, students in $\mathrm{FtF}$ instruction perform better than their online peers

\footnotetext{
${ }^{20}$ The full results are available from the authors upon request.
} 
in the pre-pandemic period for most student groups, except for students living in a dormitory and international students. There are no discernable patterns for students living in a dormitory, while there are no differences between the two modalities for international students. The overall pattern is somewhat unclear in the post-pandemic period. For instance, the differences become smaller and less precise for female and male students. With regard to race, white students in FtF classes continue to outperform their online peers, while the opposite seems to be the case for students of other races. Concerning student age, younger students perform similarly in online and FtF classes, while the FtF advantage continues for older students.

Finally, in terms of the outcome of the Final Grade, the results in Appendix Table 6D are largely consistent with the other outcomes. In the pre-pandemic era, FtF students have an advantage for most student types, except for students living in a dormitory and international students, where the advantage is less robust and mostly insignificant. In the post-pandemic semesters, there appears to be a temporary reversal to the FtF advantage initially, which seems to have disappeared or reversed back to the pre-pandemic pattern in the last two semesters.

We next turn our attention to differences in student performance in $\mathrm{FtF}$ and online classes broken down by instructor characteristics, as presented in Appendix Table 7A-7D. We consider differences by instructor gender, race, and age (Age $\leq 45$ and Age $>45)$. In general, the impact of FtF instruction by instructor characteristics follows a pattern similar to those observed for student characteristics. Across all four performance outcomes, students in FtF classes generally outperform those in online classes prior to the pandemic, regardless of instructor characteristics. In the post-pandemic period, the performance differences between the students in the two types of modalities becomes smaller and less precise, with some initial reversal of the relationship followed by a reversal back to the pre-pandemic pattern. 


\section{Majors}

Next, we explore another aspect of heterogeneity in student performance, specifically the types of majors pursued by students at the University. This analysis aims to reveal any differences in academic outcomes between $\mathrm{FtF}$ and online instruction across students with varying academic interests and specializations. There are several reasons why such differences may occur. On the one hand, certain majors require a lot of hands-on or in-person instruction and might be more difficult to teach online, which could result in lower academic performance outcomes for online students in these majors. On the other hand, more theoretical majors and those that require a lot of reading and writing might be better suited for online instruction, which could result in higher performance outcomes for online students in these majors. Additionally, different majors might attract students with different learning styles or academic strengths, which could also affect how well they perform in different instructional environments. Finally, the quality and delivery of

online instruction may vary by major, as different departments or faculty members may have varying levels of experience or training in delivering online courses.

To provide insights into these considerations, we examine our models separately by six types of majors, including (i) Business, (ii) Social Sciences, (iii) Engineering, Technology, and Hard Sciences, (iv) Health Sciences, and (v) Arts and Humanities. The results from this analysis presented in Appendix Figures 7A-7E suggest that the pattern observed for the full sample is largely consistent across fields of study. Students in FtF instruction appear to possess better learning outcomes than their online counterparts prior to the pandemic, with a less discernable relationship in the post-pandemic period. One possible exception to this pattern is Health Sciences, where the differences are smaller in magnitude and less precisely estimated. While we do not have 
a definitive reason for why this may be expected, one possible explanation is that Health Sciences may attract students who are more likely to be self-motivated and disciplined, and this could possibly result in more consistent performance outcomes between $\mathrm{FtF}$ and online instruction.

\section{Internet Speed}

We augmented our data with a measure of access to high-speed internet in the zip code of the student's home. We constructed this measure based on the Fixed Broadband Deployment Data from the Federal Communications Commission's (FCC) Form 477, which includes information about the internet service providers (ISPs) and the quality of the internet service they offer at the Census block level. ${ }^{21}$ We identified Census blocks as having access to high-speed internet if at least one ISP offers internet through one of the following technologies: "Cable Modem-DOCSIS 3.0," "Cable Modem-DOCSIS 3.1," or "Optical Carrier / Fiber to the end-user."22 The majority of the students live in areas where fast internet access is widespread. We group students as having access to High-speed Internet if at least $90 \%$ of the population in their zip codes have fast internet.

As shown in Table 1, the proportion of the population living in neighborhoods with access to highspeed internet is slightly higher among students in online courses than those in $\mathrm{FtF}$ courses.

We perform a sub-group analysis directed towards exploring the role of access to technology in explaining the disparity in learning outcomes between online and FtF instruction. We do this by producing our estimates broken down by a measure of access to high-speed internet. Note that the students living in a dormitory are excluded from this analysis. The top

\footnotetext{
${ }^{21}$ These data and their more detailed description are in the following link: https://www.fcc.gov/general/broadbanddeployment-data-fcc-form- 477.

${ }^{22}$ Using the population counts in each Census block and the crosswalk between the Census tracts and the zip codes provided by the Department of and Urban Development's (HUD) Office of Policy Development and Research, we computed the share of each zip code's population that has access to fast internet. It is important to underline that having access to fast internet technology in a neighborhood does not necessarily mean that a household's actual internet download/upload speed is fast. For example, a household does not have a fast internet connection if the household does not purchase that service, even though their ISP supplies it. Put differently, we do not have data about the actual internet service, but only about the services offered.
} 
panel of Appendix Figure 8A presents estimates for the students living in zip codes with widespread access to high-speed internet, and Appendix Figure 8B shows those living in other zip codes. As illustrated in the figures, there are no discernable differences in student performance between the two categories. For both groups, students in FtF instruction outperform their online counterparts in almost all semesters leading up to the pandemic. Then there seems to be a reversal in the relationship at the onset of the pandemic, which then disappears and begins to converge back to its pre-pandemic trend. However, the post-pandemic differences are much smaller in magnitude and also less precisely estimated. 


\section{Appendix Figure 1 \\ The Difference in Student Learning Outcomes Between FtF vs. Online Classes Over Time (No Instructor or Course Fixed Effects)}

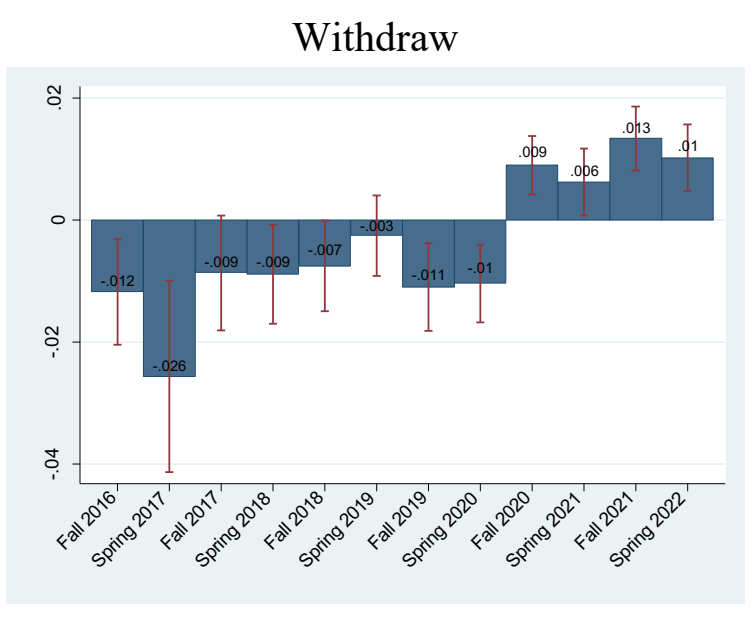

Pass

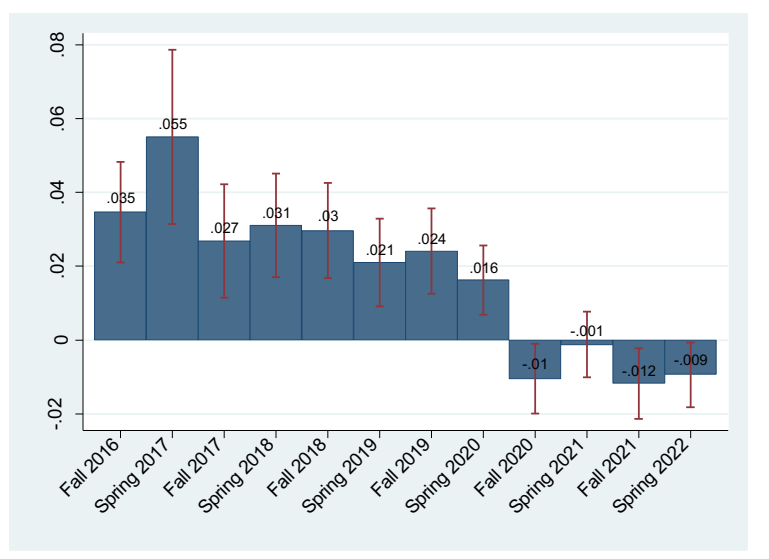

Obtained Grade A

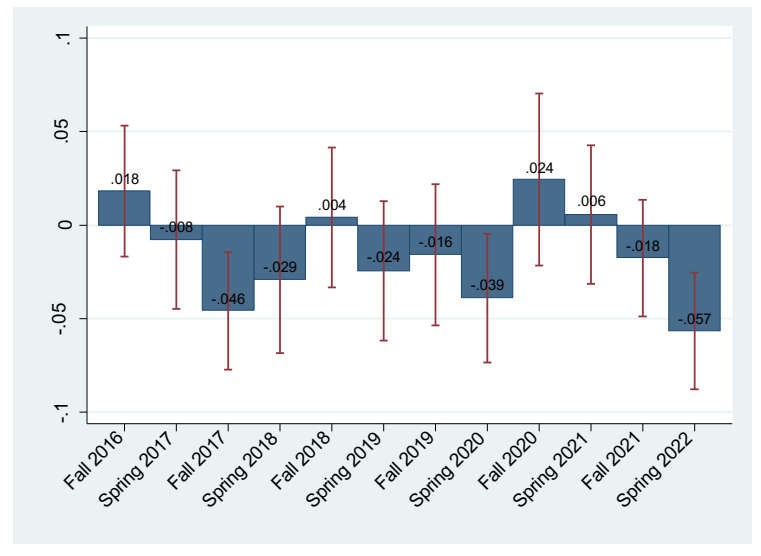

Final Grade

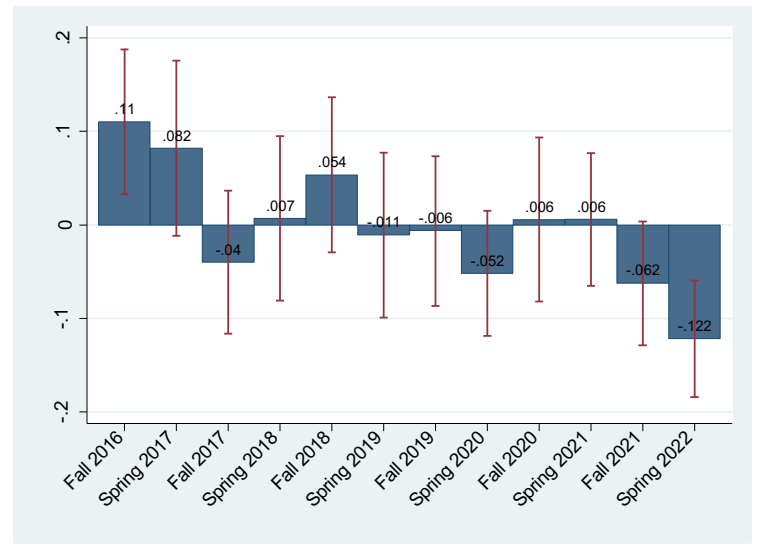

Notes: The figure shows estimates obtained from regressions identical to equation (1), except that instructor and course fixed effects are not controlled for. See notes in Figure 3. 


\section{Appendix Figure 2 \\ The Difference in Student Learning Outcomes Between FtF vs. Online Classes Over Time (No Instructor Fixed Effects)}

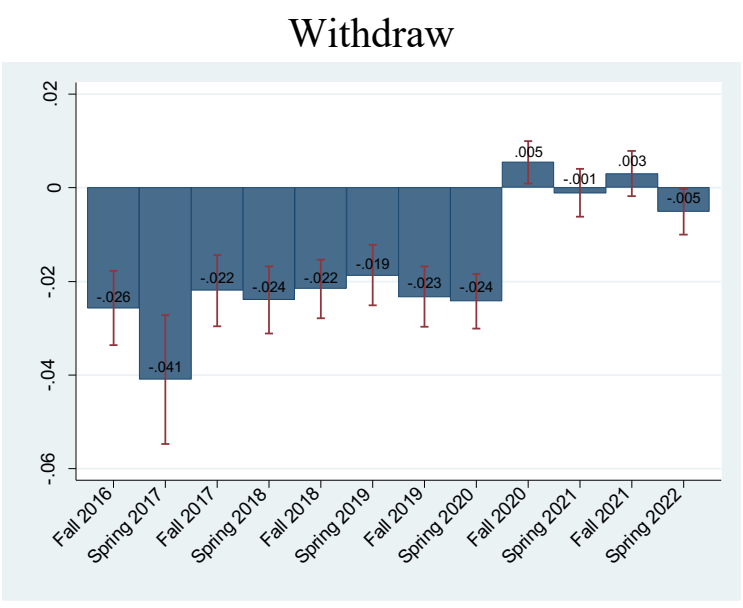

Pass

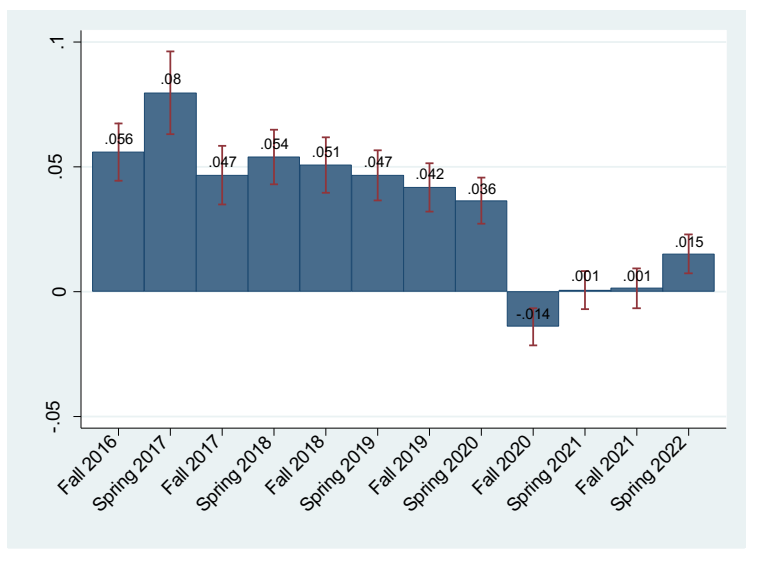

Obtained Grade A

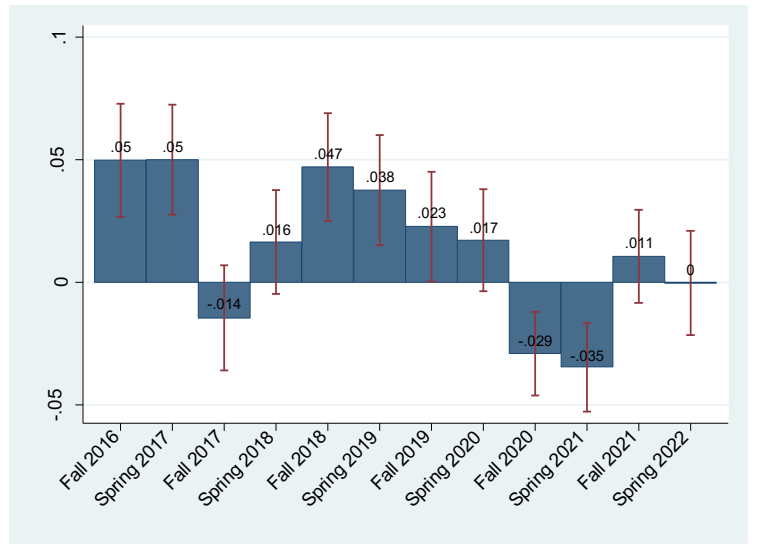

Final Grade

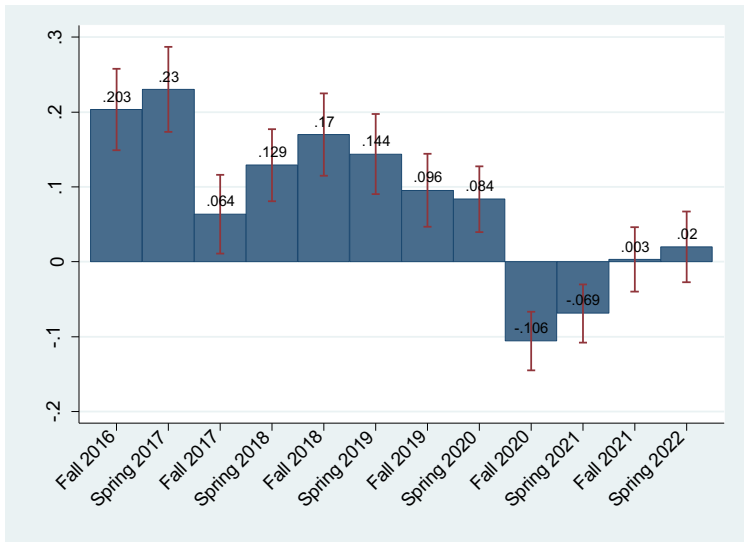

Notes: The figure shows estimates obtained from regressions identical to equation (1), except that instructor fixed effects are not controlled for. See notes in Figure 3. 


\section{Appendix Figure 3 \\ The Difference in Student Learning Outcomes Between FtF vs. Online Classes Over Time (No Course Fixed Effects)}
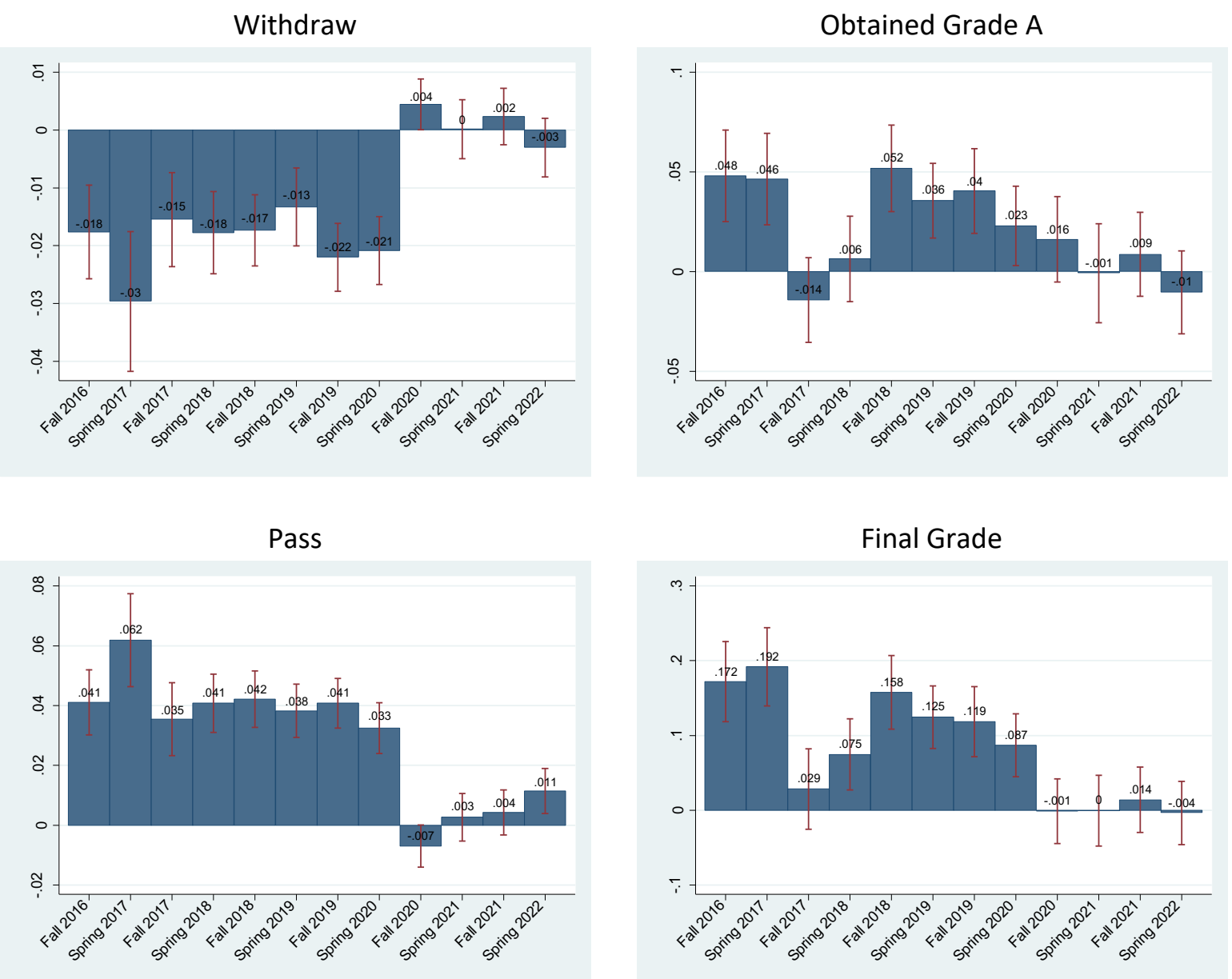

Notes: The figure shows estimates obtained from regressions identical to equation (1), except that course fixed effects are not controlled for. See notes in Figure 3. 
Appendix Figure 4

The Difference in Student Characteristics in FtF vs. Online Classes Over Time

Student Age

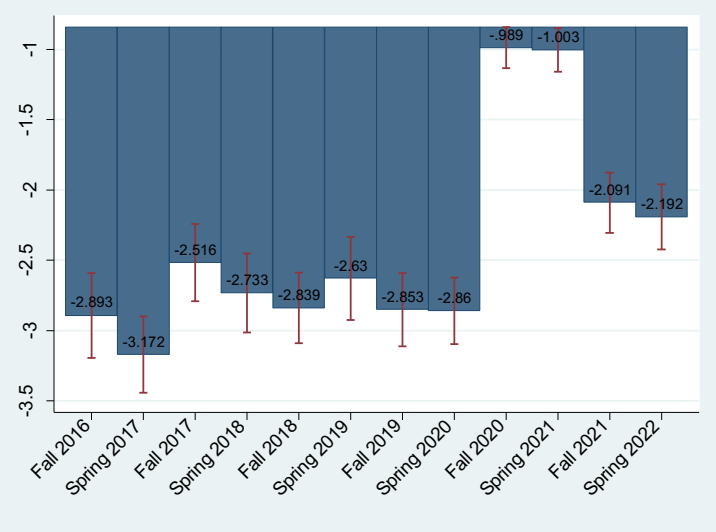

Female Student

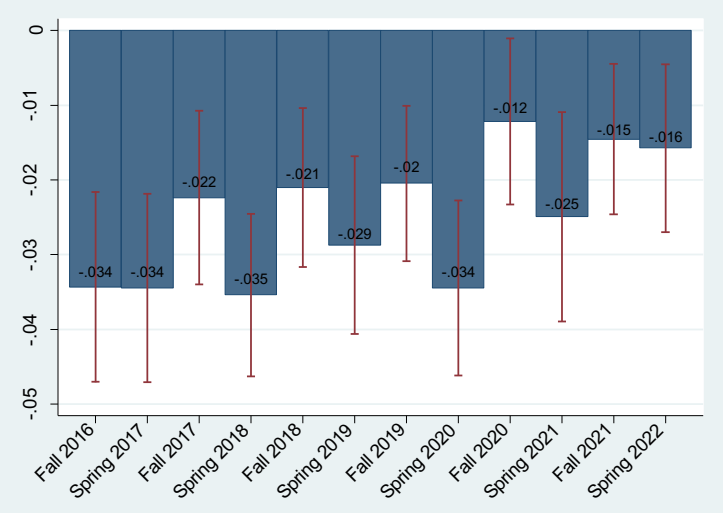

White Student

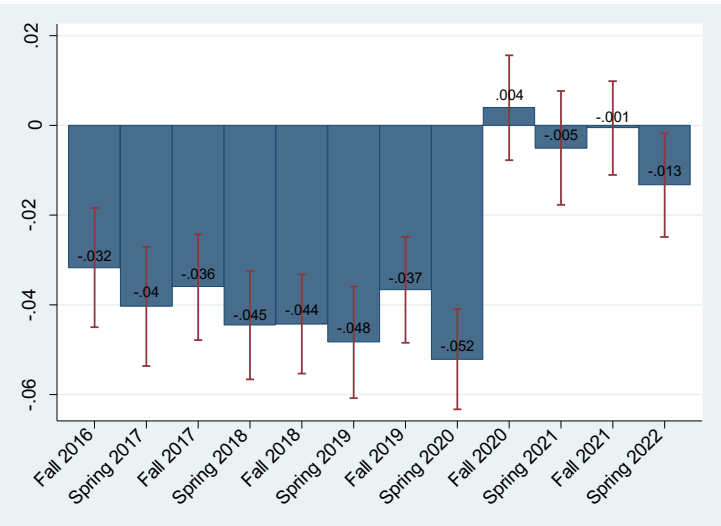

Black Student

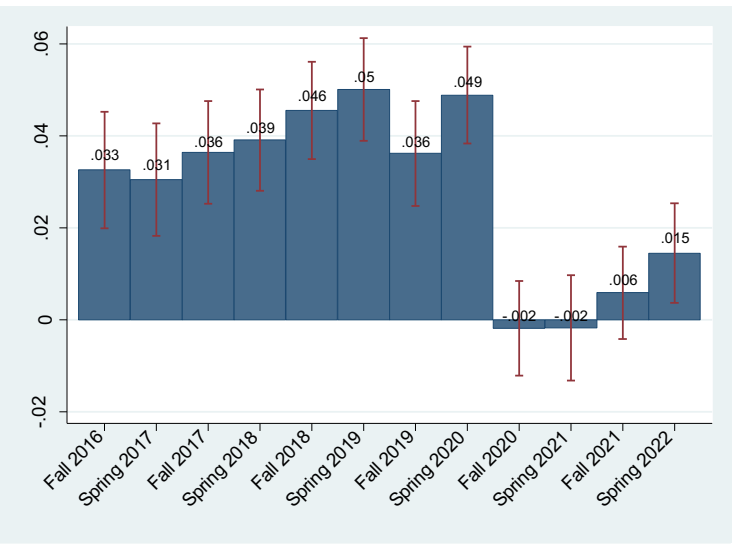

International Student

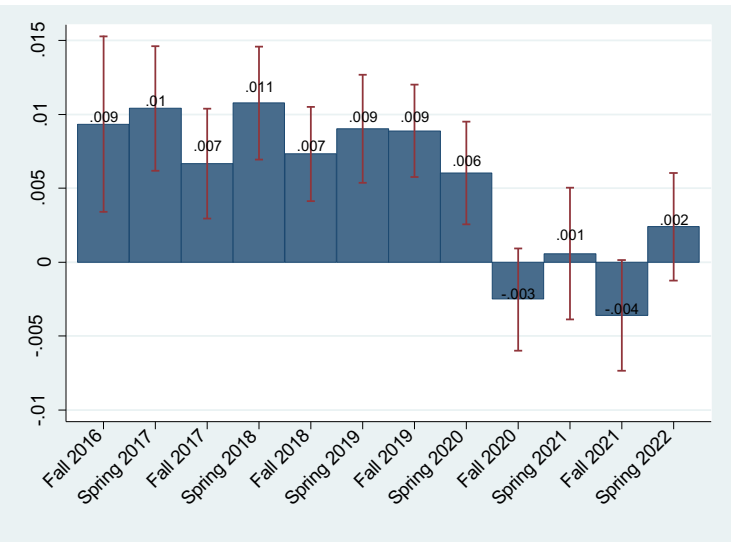

Lives in Dorm

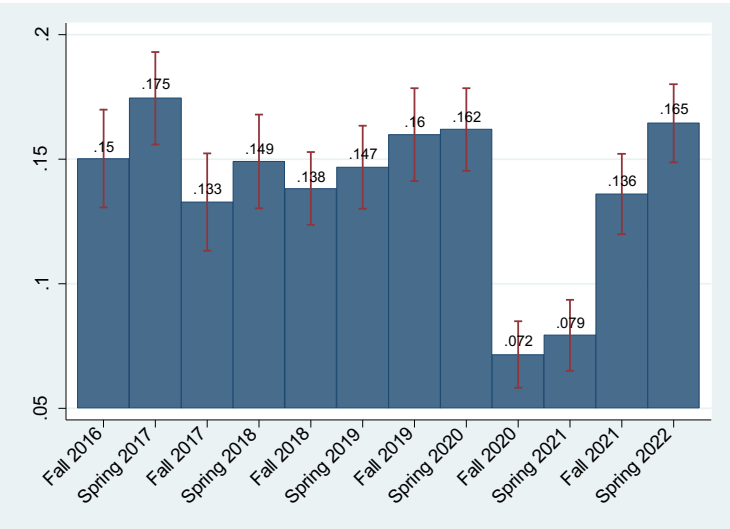




\section{Honors Student}

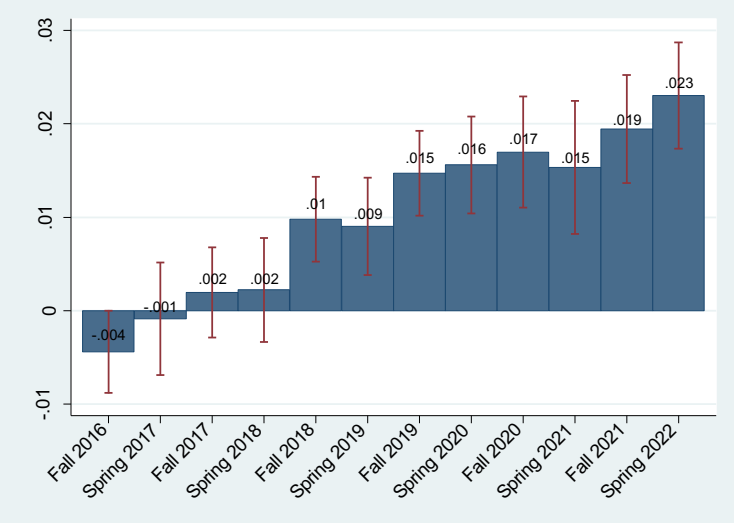

Notes: Bars represent the sum of the coefficients of the FtF dummy and the corresponding semester dummy obtained from estimating regressions identical to equation (1), except that student fixed effects and characteristics are not controlled for. Capped lines are two standard deviation confidence intervals. Numbers over the bars are the values of the point estimates. 
Appendix Figure 5

The Difference in Instructor Characteristics in FtF vs. Online Classes Over Time
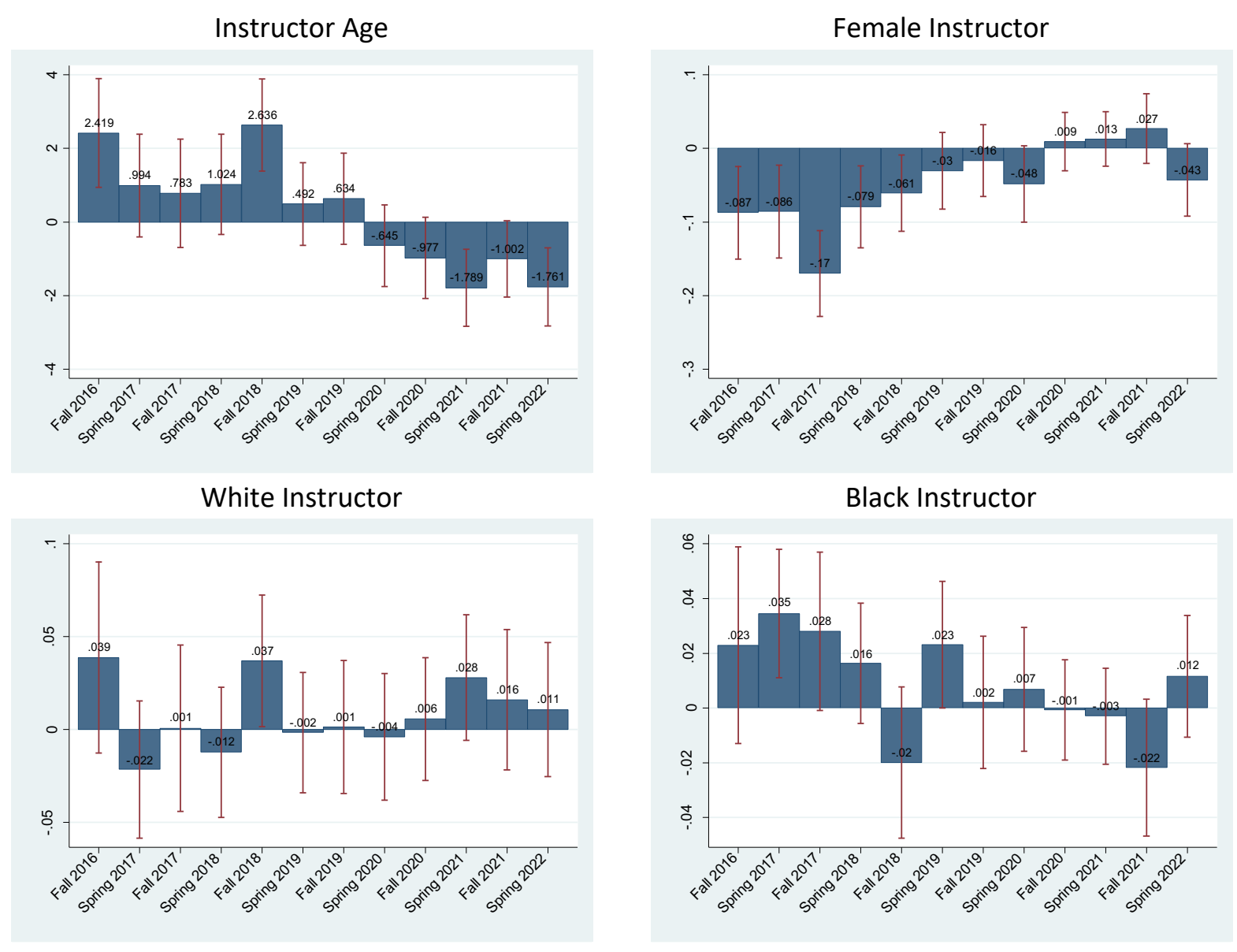

Notes: Bars represent the sum of the coefficients of the FtF dummy and the corresponding semester dummy obtained from estimating regressions identical to equation (1), except that instructor fixed effects and characteristics are not controlled for. Capped lines are two standard deviation confidence intervals. Numbers over the bars are the values of the point estimates. 
The Difference in Course Characteristics in FtF vs. Online Classes Over Time

Capstone/Writing Intensive Course

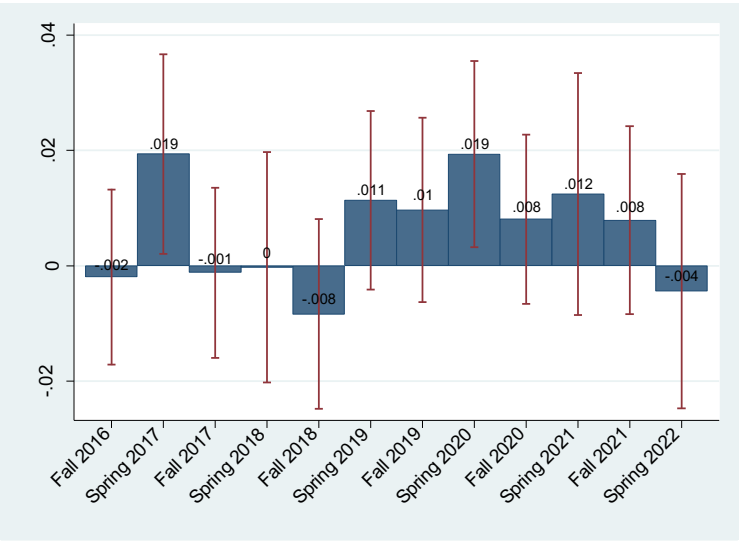

100-Level Course

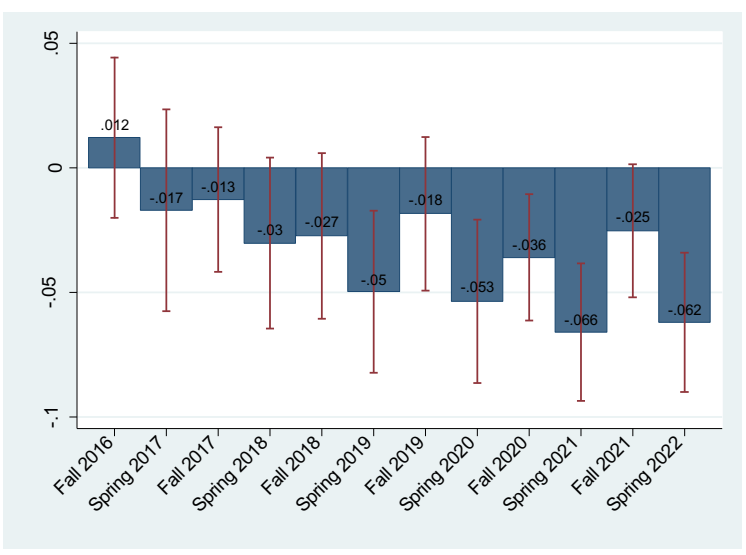

200-Level Course

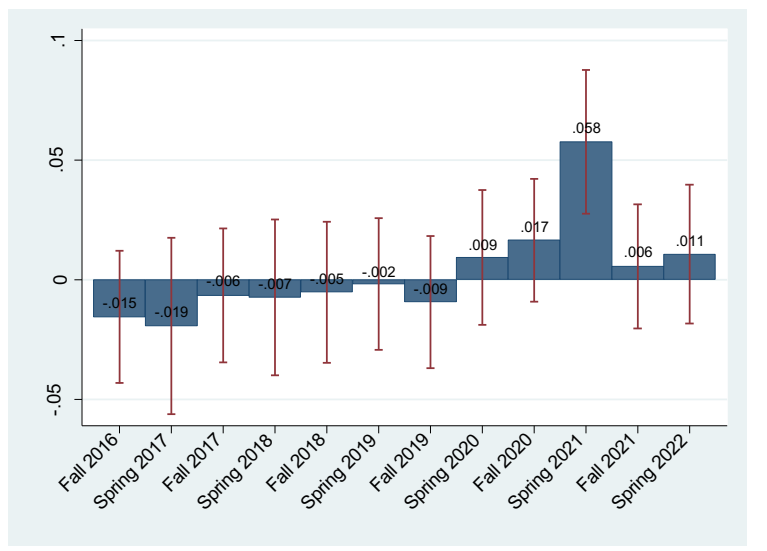

300-Level Course

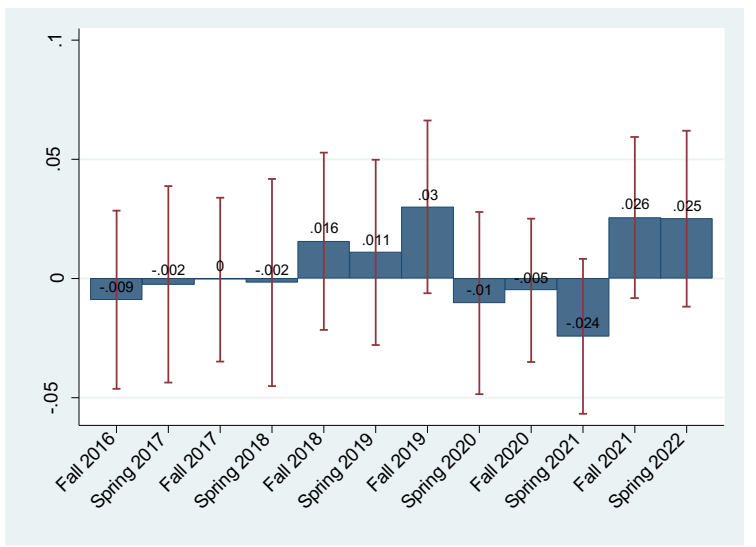

400- or Higher Level Course

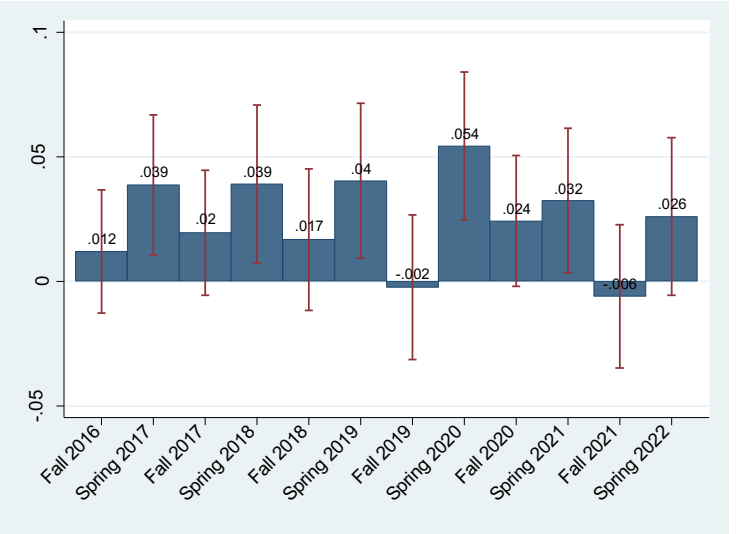

Notes: Bars represent the sum of the coefficients of the FtF dummy and the corresponding semester dummy obtained from estimating regressions identical to equation (1), except that course fixed effects and characteristics are not controlled for. Capped lines are two standard deviation confidence intervals. Numbers over the bars are the values of the point estimates. 


\section{Appendix Figure 7A}

\section{The Difference in Student Learning Outcomes Between FtF vs. Online Classes Over Time}

For Students in Business Majors

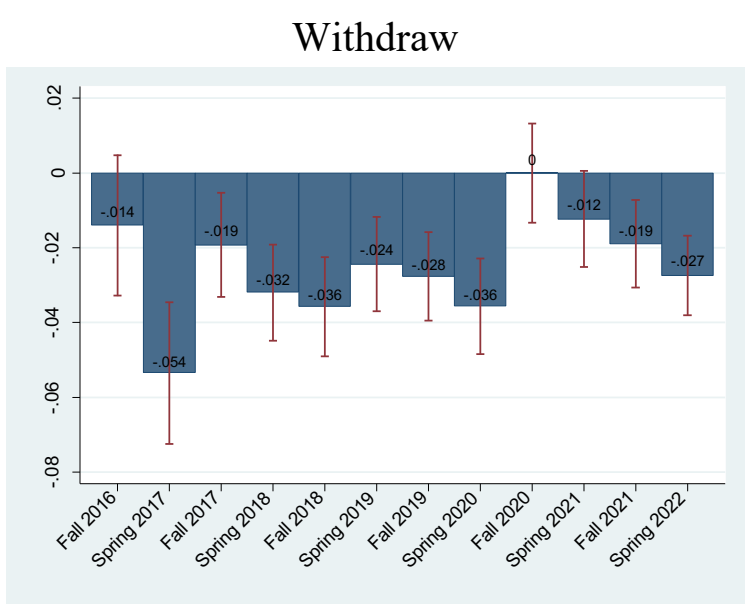

Pass

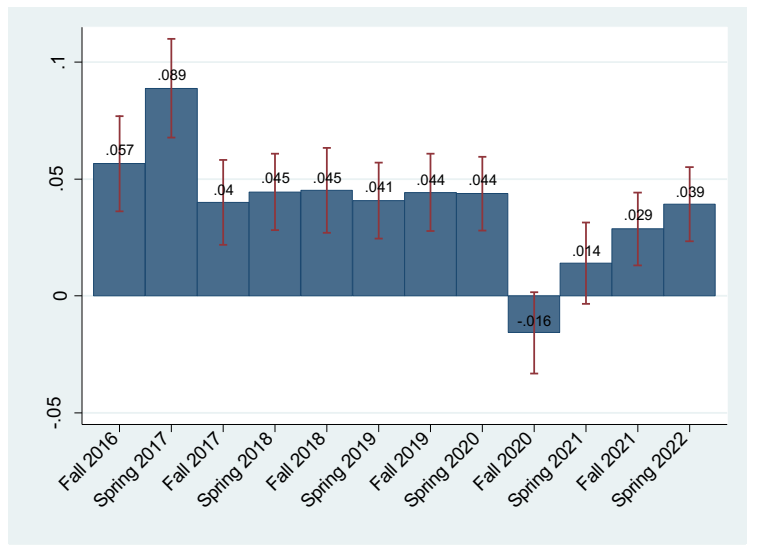

Obtained Grade A

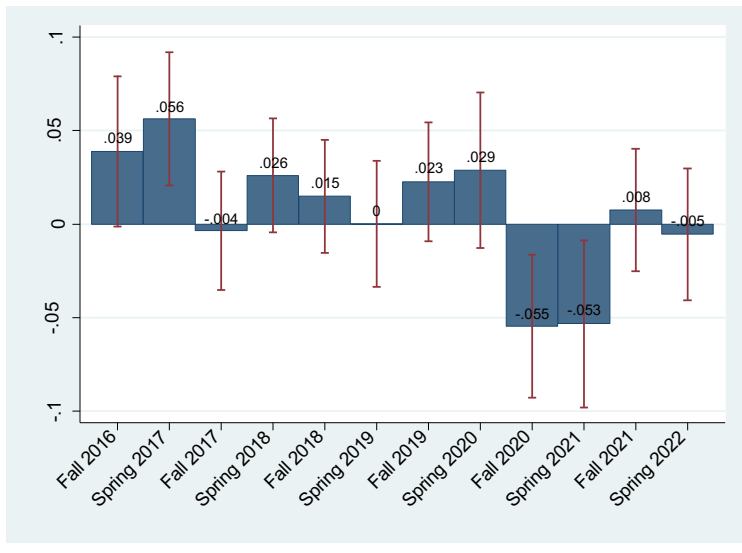

Final Grade

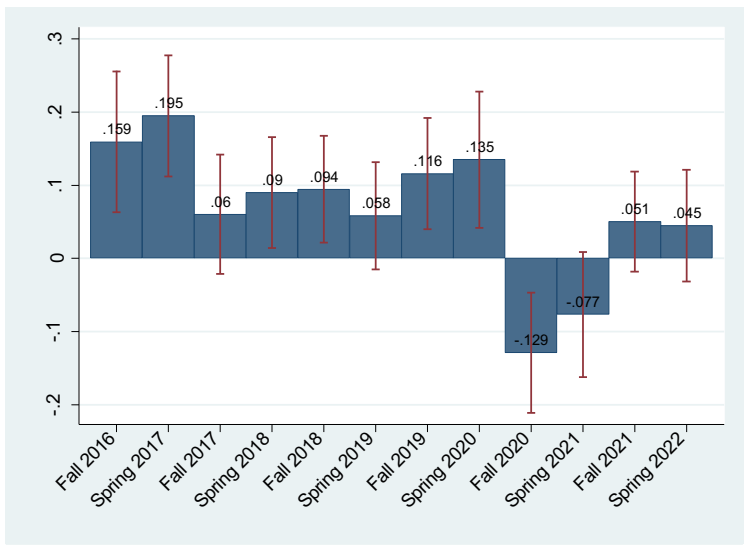

Notes: See notes in Figure 3. Only students in business majors enter into the regressions. The number of observations is 114,898. Example majors: Accounting, Business administration, Finance, Management, Tourism. 


\section{Appendix Figure 7B}

\section{The Difference in Student Learning Outcomes Between FtF vs. Online Classes Over Time}

For Students in Social Science Majors

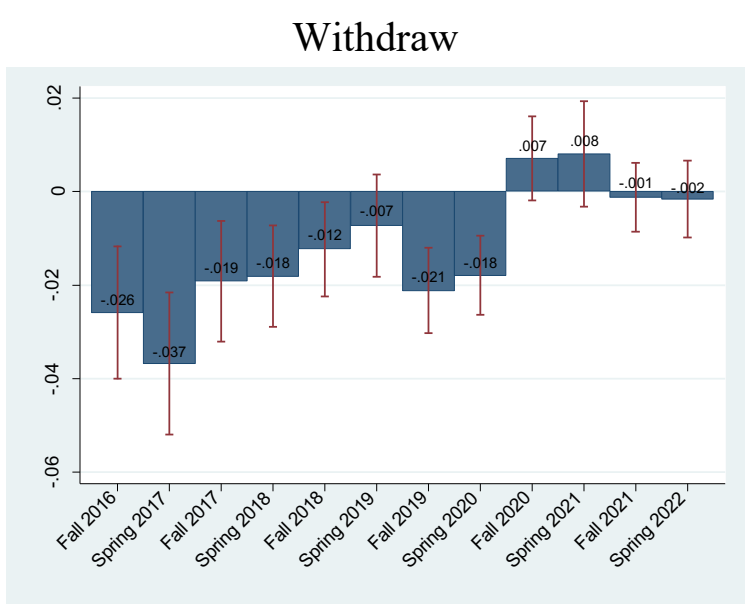

Pass

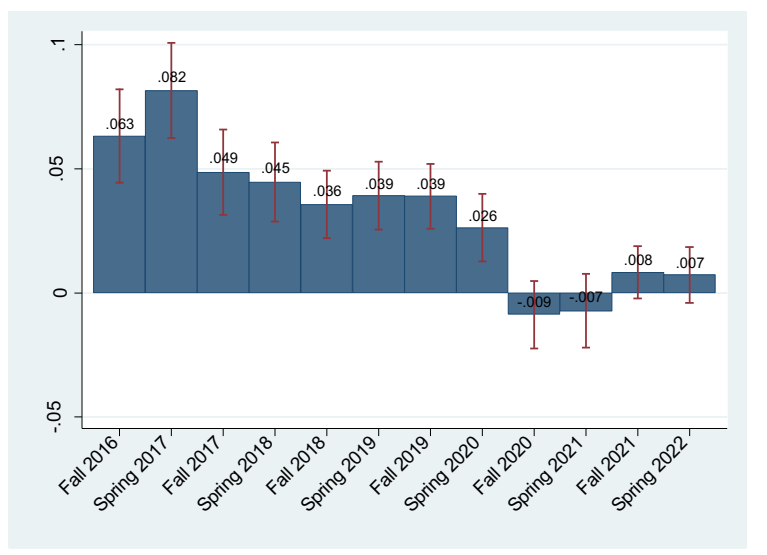

Obtained Grade A

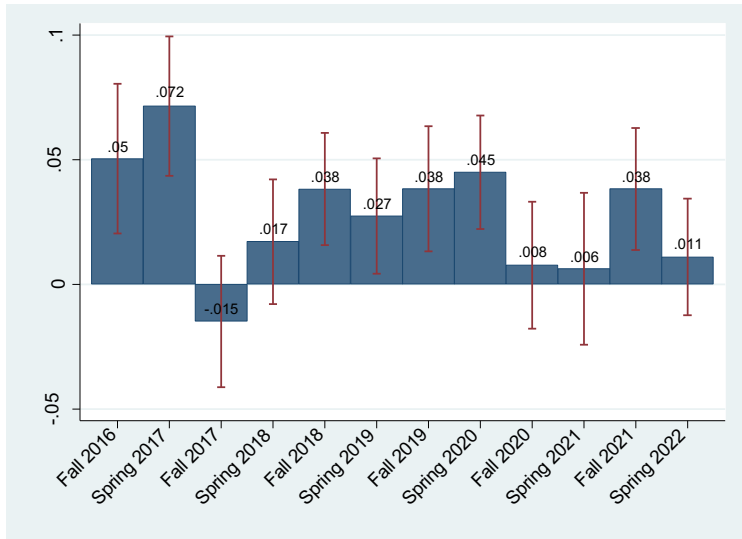

Final Grade

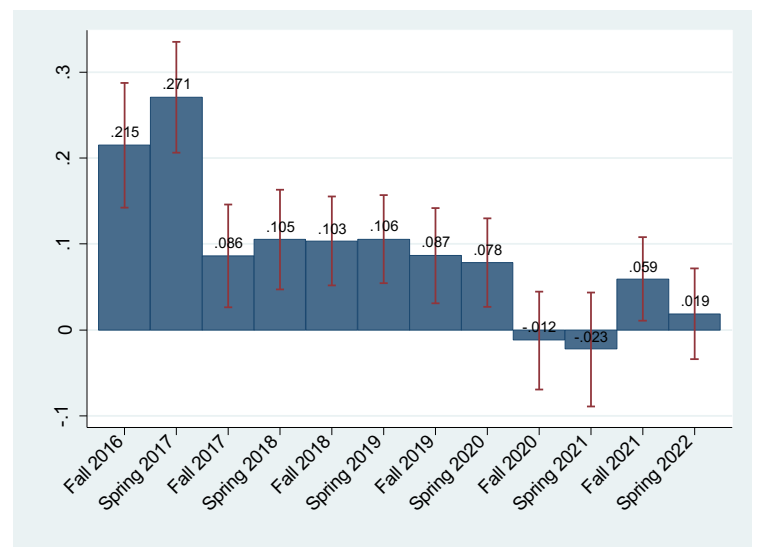

Notes: See notes in Figure 3. Only students in social science majors enter into the regressions. The number of observations is 181,557. Example majors: Anthropology, Communication studies, Economics, Journalism, Political Science. 


\section{Appendix Figure 7C}

\section{The Difference in Student Learning Outcomes Between FtF vs. Online Classes Over Time}

For Students in Engineering/Technology/Hard Sciences Majors

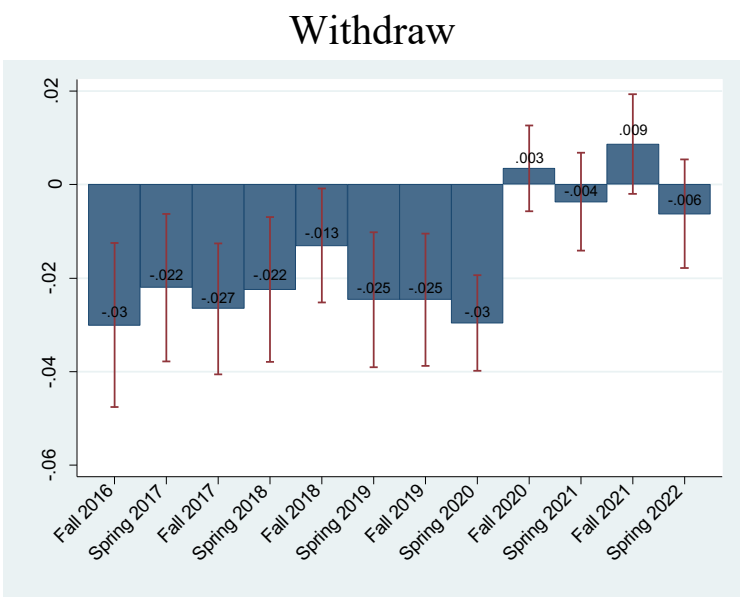

Pass

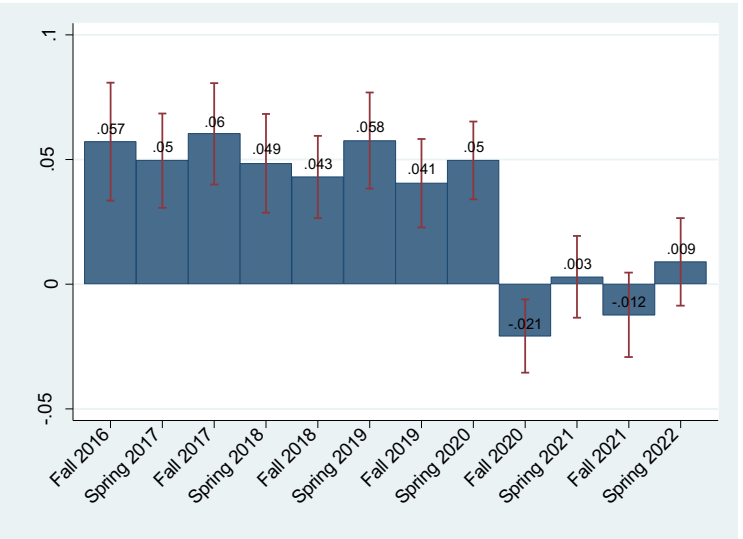

Obtained Grade A

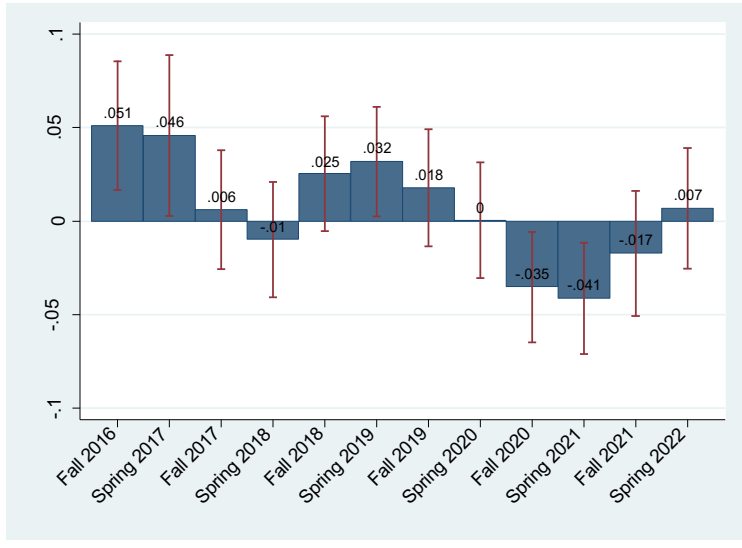

Final Grade

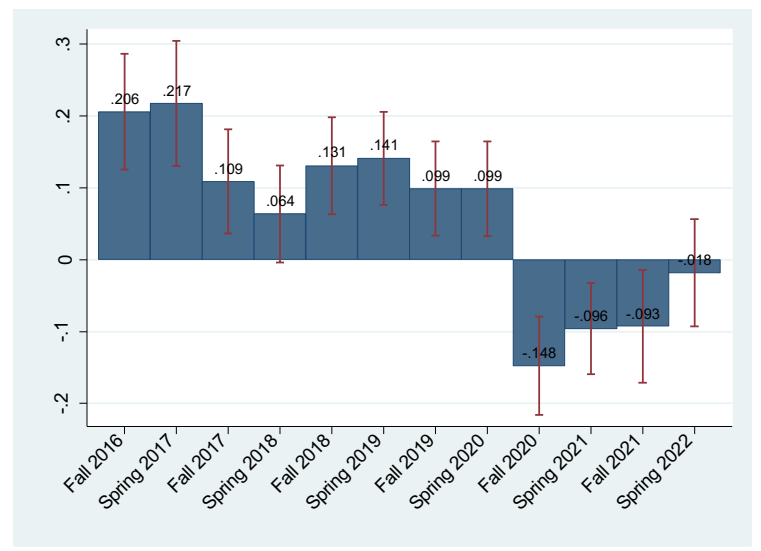

Notes: See notes to Figure 3. Only students in Engineering/Technology/Hard Sciences majors enter into the regressions. The number of observations is 144,137. Example majors: Computer Science, Industrial Engineering Technology, Polymer Science, Biological sciences, Mathematics, Physics. 


\section{Appendix Figure 7D}

\section{The Difference in Student Learning Outcomes Between FtF vs. Online Classes Over Time For Students in Health-Related Majors}

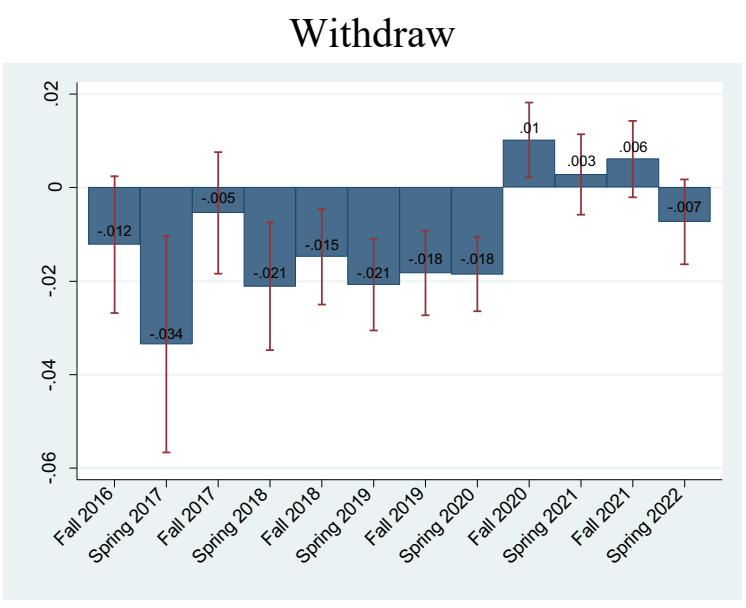

Pass

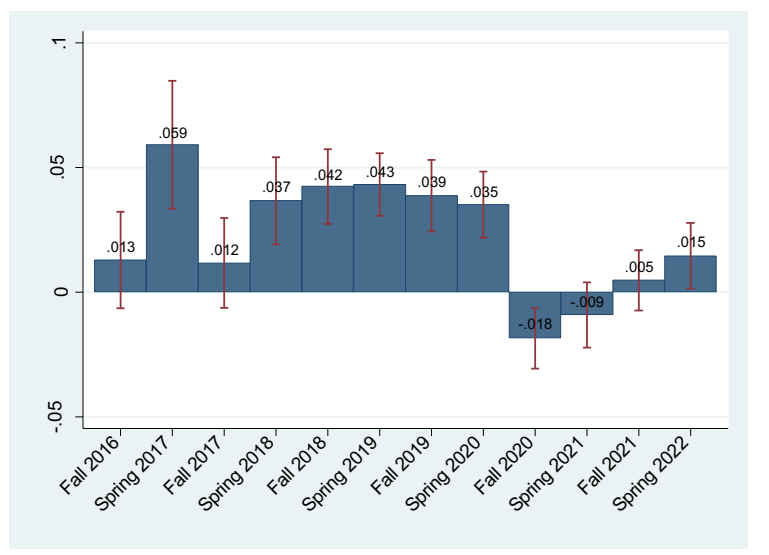

Obtained Grade A

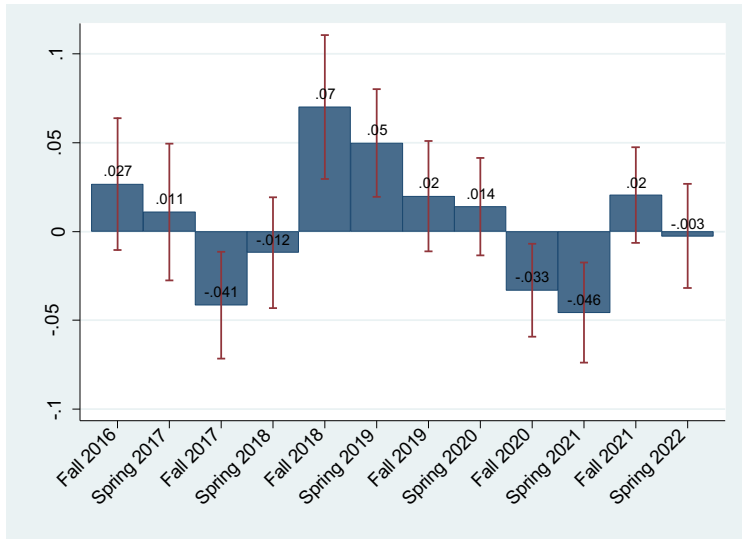

Final Grade

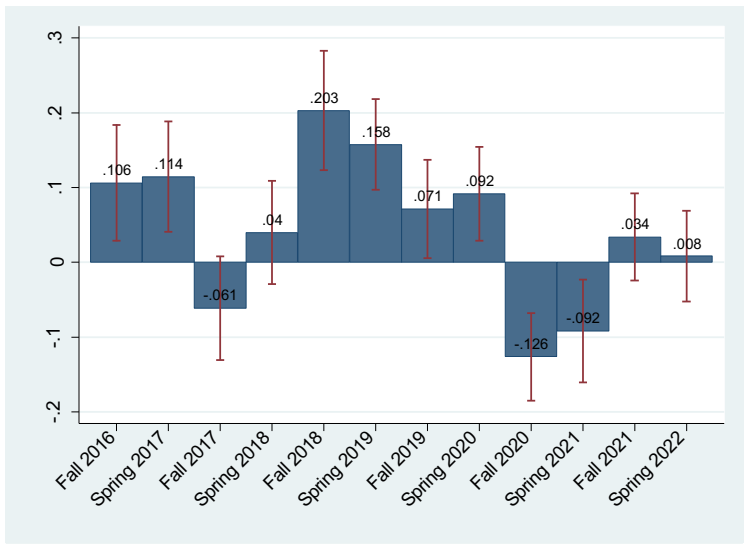

Notes: See notes in Figure 3. Only students in health-related majors enter into the regressions. The number of observations is 172,906. Example majors: Athletic training, Child and family sciences, Kinesiology, Nursing, Nutrition and dietetics. 
The Difference in Student Learning Outcomes Between FtF vs. Online Classes Over Time For Students in Arts/Humanities/Other Majors

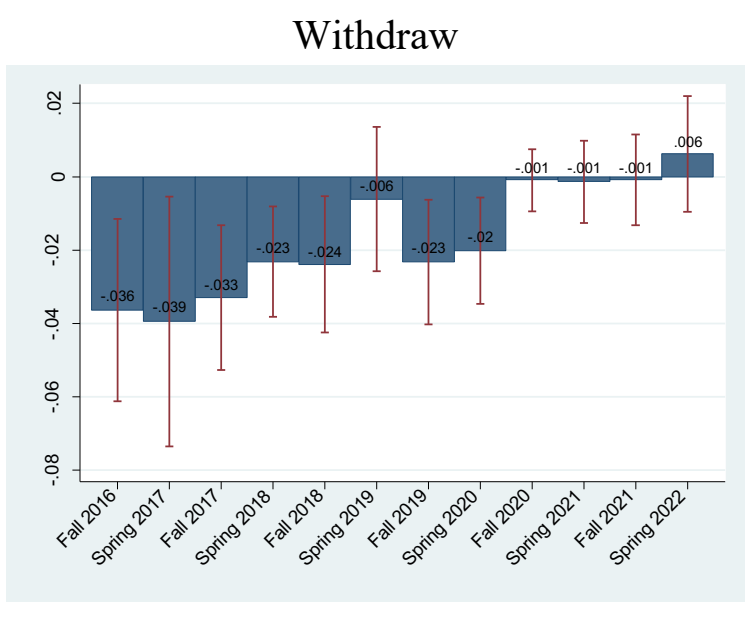

Pass

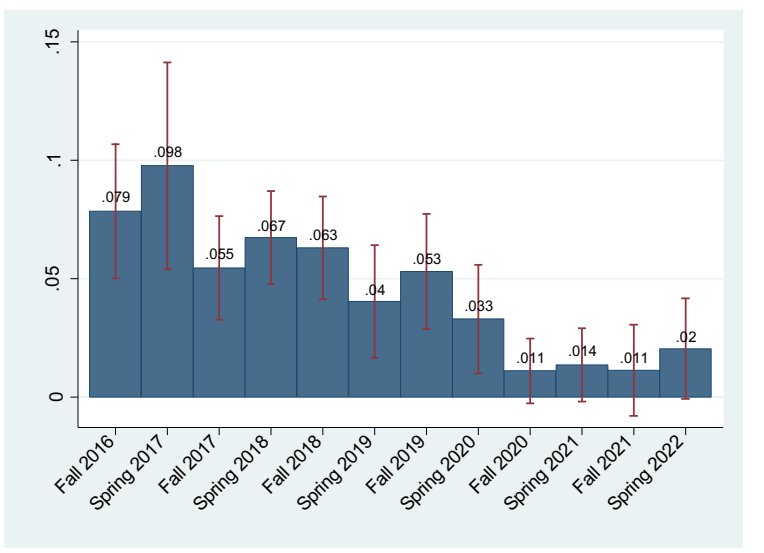

Obtained Grade A

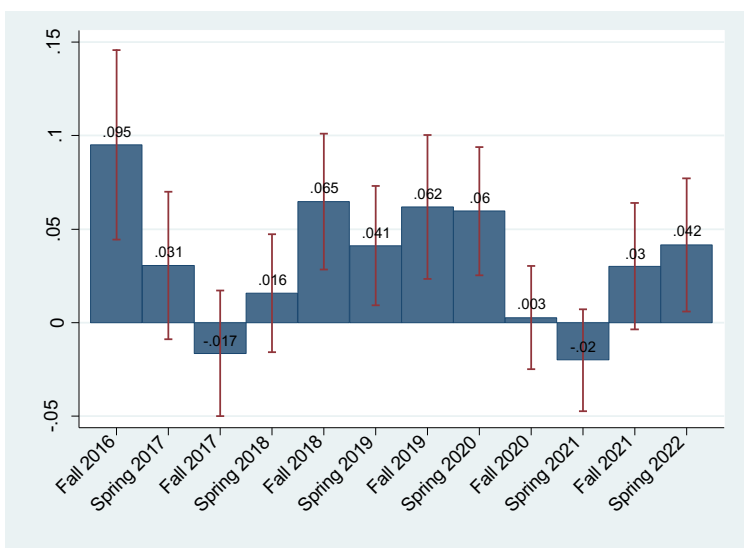

Final Grade

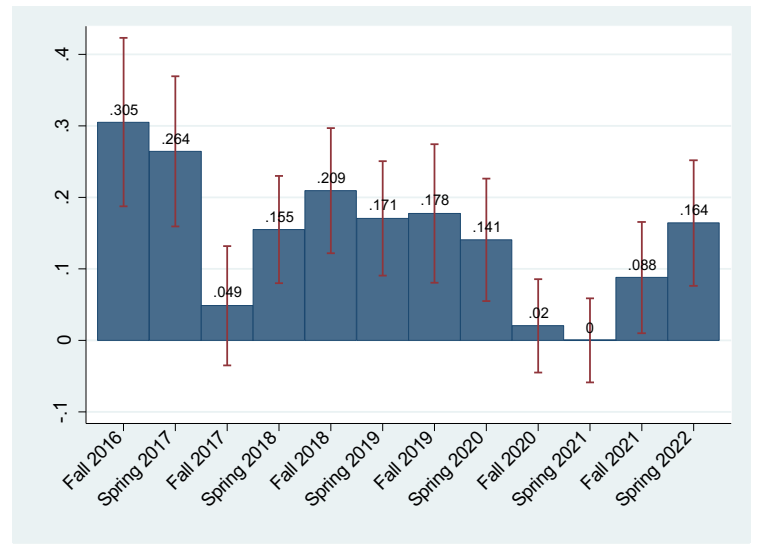

Notes: See notes in Figure 3. Only students in Art/Humanities/Other majors enter into the regressions. The number of observations is 119,841. Example majors: Dance, Music, Theater, English, History, Religion, Interdisciplinary studies. 


\section{Figure 8A}

The Difference in Student Learning Outcomes Between FtF vs. Online Classes Over Time For Students Who Live in Areas with Widespread Access to Fast Internet

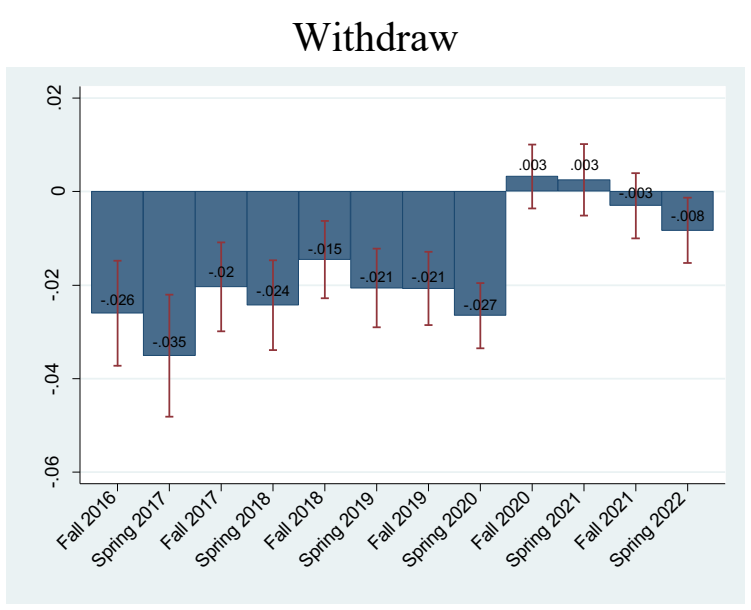

Pass

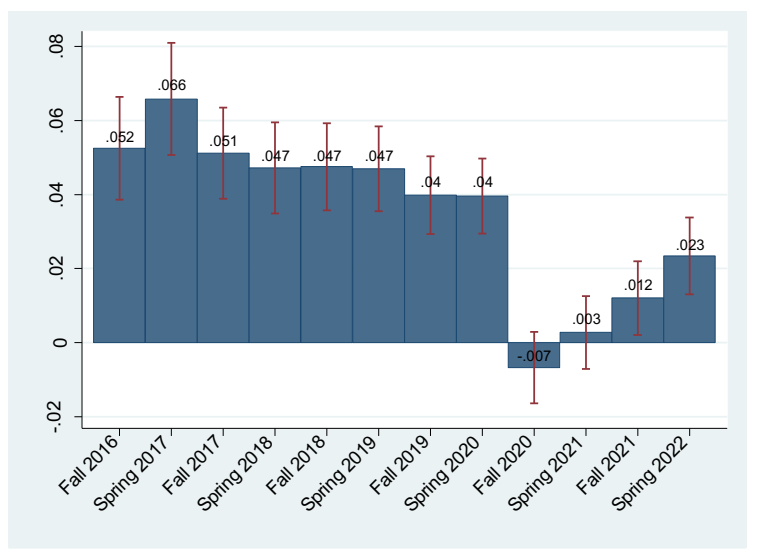

Obtained Grade A

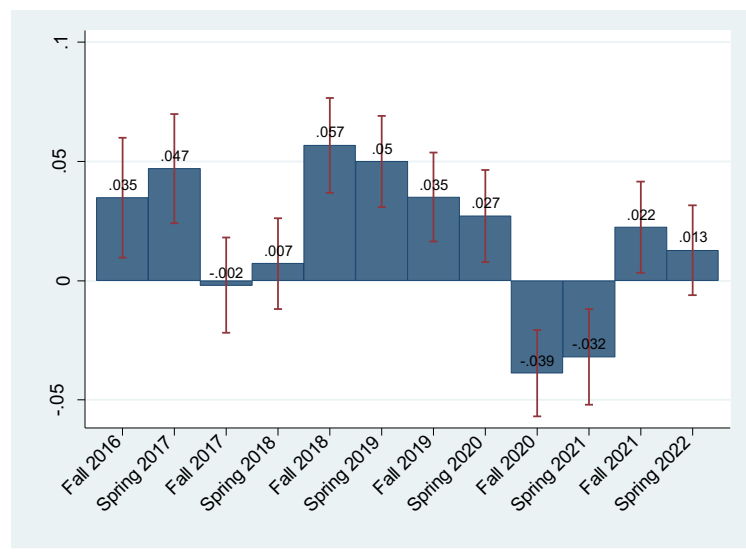

Final Grade

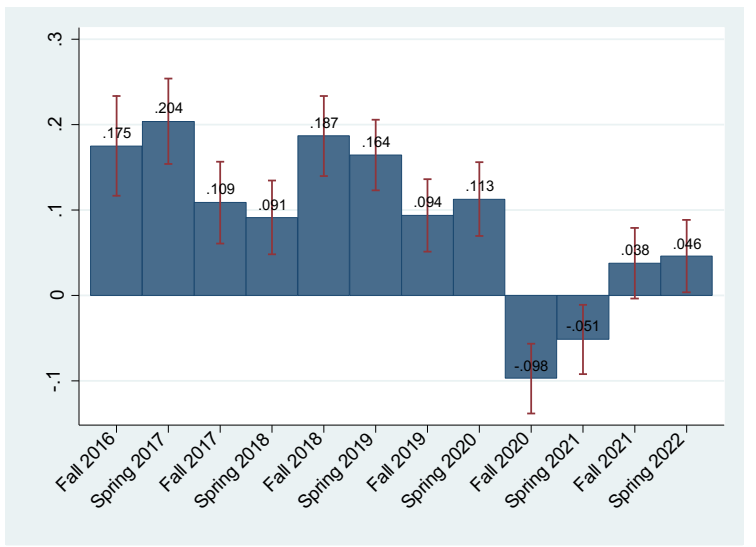

Notes: See notes in Figure 3. Only students in whose home address zip code at least $90 \%$ of the population has access to fast internet technologies enter into the regressions. The number of observations is 261,979 . 


\section{Figure 8B}

\section{The Difference in Student Learning Outcomes Between FtF vs. Online Classes Over Time}

For Students Who Live in Areas without Widespread Access to Fast Internet

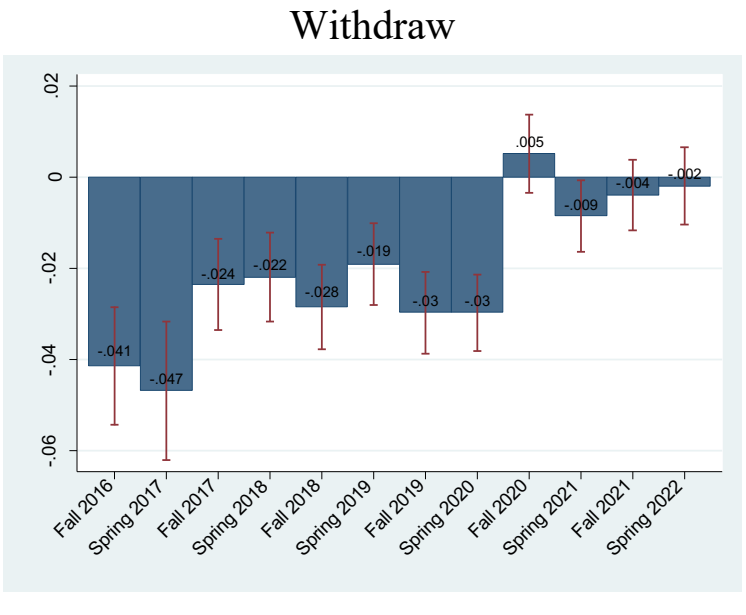

Pass

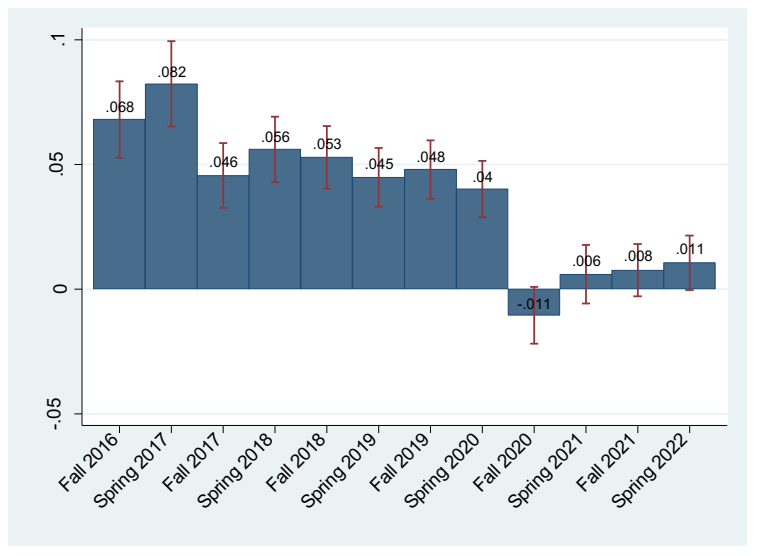

Obtained Grade A

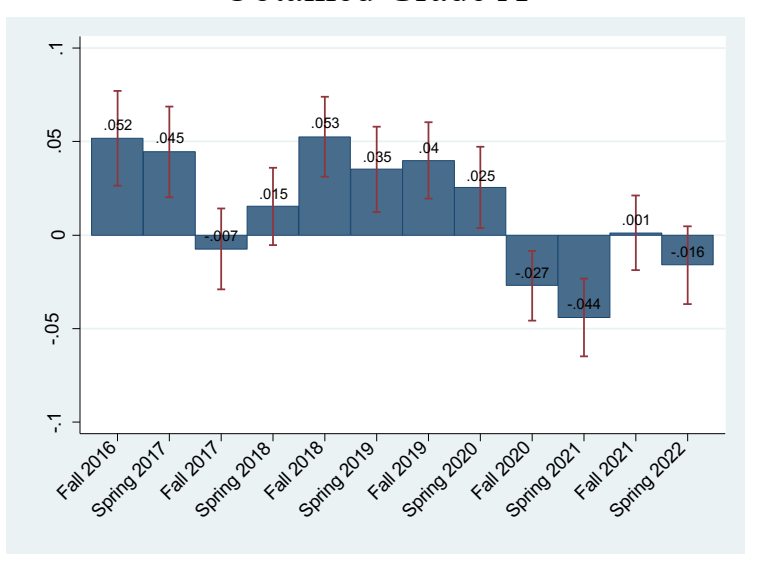

Final Grade

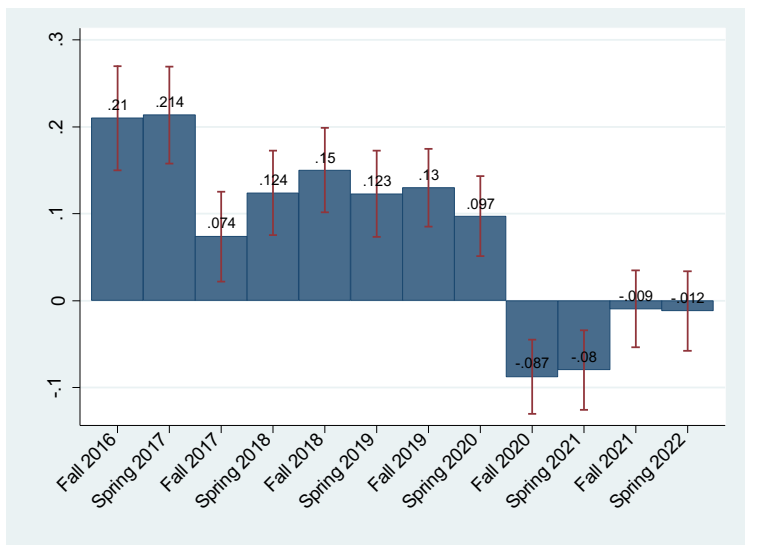

Notes: See notes in Figure 3. Only students in whose home address zip code less than $90 \%$ of the population has access to fast internet technologies enter into the regressions. The number of observations is 210,062 . 


\section{Appendix Table 1 \\ Student and Instructor Characteristics by Semester}

Panel A: Students

\begin{tabular}{lcccc}
\hline Semester & $\begin{array}{c}\text { Number of } \\
\text { Students }\end{array}$ & $\begin{array}{c}\text { Students Who Take } \\
\text { a Mix of FtF and } \\
\text { Online Courses }\end{array}$ & $\begin{array}{c}\text { Students Who Take } \\
\text { Classes From } \\
\text { Multiple Departments }\end{array}$ & $\begin{array}{c}\text { Average } \\
\text { Number of } \\
\text { Classes Taken }\end{array}$ \\
\hline Fall 2016 & 11,435 & $5,249(45.9 \%)$ & $9,882(86.4 \%)$ & 5.80 \\
Spring 2017 & 10,155 & $4,494(44.3 \%)$ & $8,755(86.2 \%)$ & 5.74 \\
Fall 2017 & 11,491 & $5,878(51.2 \%)$ & $10,051(87.5 \%)$ & 5.92 \\
Spring 2018 & 10,335 & $4,801(46.5 \%)$ & $8,931(86.4 \%)$ & 5.71 \\
Fall 2018 & 11,630 & $5,339(45.9 \%)$ & $10,238(88.2 \%)$ & 5.88 \\
Spring 2019 & 10,470 & $5,415(51.7 \%)$ & $9,102(86.9 \%)$ & 5.61 \\
Fall 2019 & 11,310 & $5,263(46.5 \%)$ & $9,975(88.2 \%)$ & 5.83 \\
Spring 2020 & 10,245 & $5,056(49.4 \%)$ & $8,871(86.6 \%)$ & 5.55 \\
Fall 2020 & 11,216 & $6,519(58.1 \%)$ & $9,791(87.3 \%)$ & 5.77 \\
Spring 2021 & 9,993 & $4,964(49.7 \%)$ & $8,658(86.6 \%)$ & 5.53 \\
Fall 2021 & 10,464 & $6,070(58.0 \%)$ & $9,120(87.2 \%)$ & 5.71 \\
Spring 2022 & 9,486 & $5,244(55.3 \%)$ & $8,090(85.3 \%)$ & 5.51 \\
\hline Total & 128,213 & $64,292(50.1 \%)$ & $111,464(86.9 \%)$ & 5.71 \\
\hline
\end{tabular}

Panel B: Instructors

\begin{tabular}{lcccc}
\hline Semester & $\begin{array}{c}\text { Number of } \\
\text { Instructors }\end{array}$ & $\begin{array}{c}\text { Instructors Who } \\
\text { Teach a Mix of FtF } \\
\text { and Online Courses }\end{array}$ & $\begin{array}{c}\text { Instructors Who } \\
\text { Teach Courses in } \\
\text { Multiple Departments }\end{array}$ & $\begin{array}{c}\text { Average Number } \\
\text { of Unique } \\
\text { Courses Taught }\end{array}$ \\
\hline Fall 2016 & 982 & $133(13.5 \%)$ & $85(8.7 \%)$ & 2.28 \\
Spring 2017 & 975 & $138(14.2 \%)$ & $105(10.8 \%)$ & 2.29 \\
Fall 2017 & 937 & $149(15.9 \%)$ & $103(11.0 \%)$ & 2.34 \\
Spring 2018 & 911 & $150(16.5 \%)$ & $103(11.3 \%)$ & 2.41 \\
Fall 2018 & 893 & $164(18.4 \%)$ & $102(11.4 \%)$ & 2.39 \\
Spring 2019 & 866 & $160(18.5 \%)$ & $104(12.0 \%)$ & 2.37 \\
Fall 2019 & 887 & $170(19.2 \%)$ & $94(10.6 \%)$ & 2.29 \\
Spring 2020 & 836 & $181(21.7 \%)$ & $101(12.1 \%)$ & 2.37 \\
Fall 2020 & 838 & $202(24.1 \%)$ & $95(11.3 \%)$ & 2.21 \\
Spring 2021 & 819 & $196(23.9 \%)$ & $96(11.7 \%)$ & 2.25 \\
Fall 2021 & 887 & $182(20.5 \%)$ & $95(10.7 \%)$ & 2.18 \\
Spring 2022 & 851 & $183(21.5 \%)$ & $106(12.5 \%)$ & 2.27 \\
\hline Total & 10,682 & $2,008(18.8 \%)$ & $1,189(11.1 \%)$ & 2.30 \\
\hline
\end{tabular}


Appendix Table 2

Average Student Characteristics by Modality Over Time

\begin{tabular}{lcccccccc}
\hline & \multicolumn{2}{c}{ Age } & \multicolumn{2}{c}{ Female } & \multicolumn{2}{c}{ White } & \multicolumn{2}{c}{ Black } \\
\hline & $(1)$ & $(2)$ & $(3)$ & $(4)$ & $(5)$ & $(6)$ & $(7)$ & $(8)$ \\
\hline & Online & FtF & Online & FtF & Online & FtF & Online & FtF \\
\hline Fall 2016 & 24.21 & 21.53 & 0.64 & 0.63 & 0.58 & 0.61 & 0.32 & 0.28 \\
Spring 2017 & 25.17 & 21.67 & 0.65 & 0.63 & 0.61 & 0.61 & 0.31 & 0.28 \\
Fall 2017 & 23.80 & 21.08 & 0.64 & 0.62 & 0.59 & 0.61 & 0.31 & 0.28 \\
Spring 2018 & 25.01 & 21.32 & 0.65 & 0.63 & 0.62 & 0.60 & 0.28 & 0.28 \\
Fall 2018 & 24.87 & 20.70 & 0.66 & 0.63 & 0.62 & 0.60 & 0.28 & 0.30 \\
Spring 2019 & 24.59 & 21.11 & 0.66 & 0.63 & 0.62 & 0.61 & 0.28 & 0.29 \\
Fall 2019 & 24.81 & 20.63 & 0.67 & 0.63 & 0.62 & 0.60 & 0.29 & 0.29 \\
Spring 2020 & 24.77 & 21.00 & 0.66 & 0.63 & 0.62 & 0.60 & 0.28 & 0.28 \\
Fall 2020 & 21.98 & 20.63 & 0.65 & 0.62 & 0.59 & 0.64 & 0.31 & 0.25 \\
Spring 2021 & 22.31 & 21.09 & 0.65 & 0.61 & 0.60 & 0.64 & 0.30 & 0.23 \\
Fall 2021 & 23.73 & 20.51 & 0.66 & 0.65 & 0.60 & 0.61 & 0.30 & 0.28 \\
Spring 2022 & 24.16 & 20.82 & 0.65 & 0.64 & 0.60 & 0.60 & 0.29 & 0.28 \\
\hline
\end{tabular}

\begin{tabular}{lcccccc}
\hline & \multicolumn{2}{c}{ International } & \multicolumn{2}{c}{ Lives in Dorm } & \multicolumn{2}{c}{ Honors Student } \\
\hline & $(9)$ & $(10)$ & $(11)$ & $(12)$ & $(13)$ & $(14)$ \\
\hline & Online & FtF & Online & FtF & Online & FtF \\
\hline Fall 2016 & 0.02 & 0.03 & 0.23 & 0.31 & 0.01 & 0.03 \\
Spring 2017 & 0.01 & 0.03 & 0.16 & 0.32 & 0.01 & 0.04 \\
Fall 2017 & 0.01 & 0.02 & 0.26 & 0.36 & 0.02 & 0.05 \\
Spring 2018 & 0.01 & 0.03 & 0.18 & 0.37 & 0.03 & 0.06 \\
Fall 2018 & 0.01 & 0.03 & 0.16 & 0.38 & 0.03 & 0.07 \\
Spring 2019 & 0.01 & 0.03 & 0.19 & 0.37 & 0.03 & 0.07 \\
Fall 2019 & 0.01 & 0.03 & 0.13 & 0.38 & 0.03 & 0.08 \\
Spring 2020 & 0.01 & 0.03 & 0.18 & 0.36 & 0.04 & 0.08 \\
Fall 2020 & 0.02 & 0.02 & 0.27 & 0.34 & 0.06 & 0.09 \\
Spring 2021 & 0.01 & 0.03 & 0.25 & 0.29 & 0.07 & 0.09 \\
Fall 2021 & 0.01 & 0.02 & 0.20 & 0.39 & 0.04 & 0.09 \\
Spring 2022 & 0.01 & 0.02 & 0.19 & 0.40 & 0.04 & 0.09 \\
\hline
\end{tabular}

Note: The table presents the averages of the student attributes for online (odd-numbered columns) and FtF (evennumbered) classes in each semester. 
Appendix Table 3

Average Instructor Characteristics by Modality Over Time

\begin{tabular}{lcccccccc}
\hline & \multicolumn{2}{c}{ Age } & \multicolumn{2}{c}{ Female } & \multicolumn{2}{c}{ White } & \multicolumn{2}{c}{ Black } \\
\hline & $(1)$ & $(2)$ & $(3)$ & $(4)$ & $(5)$ & $(6)$ & $(7)$ & $(8)$ \\
\hline & Online & FtF & Online & FtF & Online & FtF & Online & FtF \\
\hline Fall 2016 & 41.57 & 44.66 & 0.63 & 0.48 & 0.81 & 0.84 & 0.05 & 0.04 \\
Spring 2017 & 43.66 & 44.74 & 0.64 & 0.51 & 0.86 & 0.83 & 0.02 & 0.05 \\
Fall 2017 & 43.73 & 45.02 & 0.72 & 0.47 & 0.86 & 0.87 & 0.04 & 0.04 \\
Spring 2018 & 44.85 & 45.66 & 0.62 & 0.50 & 0.88 & 0.86 & 0.04 & 0.04 \\
Fall 2018 & 44.03 & 45.38 & 0.62 & 0.49 & 0.85 & 0.88 & 0.07 & 0.03 \\
Spring 2019 & 45.54 & 45.57 & 0.56 & 0.50 & 0.86 & 0.85 & 0.06 & 0.05 \\
Fall 2019 & 44.28 & 43.71 & 0.60 & 0.51 & 0.87 & 0.84 & 0.07 & 0.04 \\
Spring 2020 & 45.30 & 45.12 & 0.62 & 0.51 & 0.85 & 0.85 & 0.07 & 0.04 \\
Fall 2020 & 44.94 & 43.95 & 0.52 & 0.52 & 0.84 & 0.84 & 0.06 & 0.03 \\
Spring 2021 & 46.01 & 45.28 & 0.52 & 0.57 & 0.82 & 0.84 & 0.05 & 0.04 \\
Fall 2021 & 45.26 & 43.72 & 0.54 & 0.51 & 0.80 & 0.84 & 0.09 & 0.03 \\
Spring 2022 & 46.51 & 44.15 & 0.58 & 0.49 & 0.81 & 0.82 & 0.06 & 0.05 \\
\hline
\end{tabular}

Note: The table presents the averages of the instructor attributes for online (odd-numbered columns) and FtF (evennumbered) classes in each semester. 


\section{Appendix Table 4 \\ Falsification Test \\ The Relationship Between Future Online Course Taking and Current Class Performance}

\begin{tabular}{lcccc}
\hline & $(1)$ & $(2)$ & $(3)$ & $(4)$ \\
\hline Future Online & & & Earned & Final \\
& Withdraw & Passed & Grade A & $\begin{array}{c}\text { Grade } \\
\end{array}$ \\
\hline Time-Varying Controls & 0.000 & 0.003 & -0.007 & -0.011 \\
\hline Student+Instructor+Term+Course FEs & $(0.002)$ & $(0.003)$ & $(0.004)$ & $(0.010)$ \\
\hline $\mathrm{N}$ & 192265 & 192265 & 185362 & 185276 \\
\hline
\end{tabular}

Notes: The unit of observation is a student $\times$ class. Only FtF classes in the Fall semesters (except Fall 2021) enter into the regressions. Future Online $=1$ if the student will take at least one online class in the subsequent two semesters.

Appendix Table 5

Falsification Test

The Relationship Between Current Class Modality and The Performance of Past Students

\begin{tabular}{lcccc}
\hline & $(1)$ & $(2)$ & $(3)$ & $(4)$ \\
& $\begin{array}{c}\text { Withdraw } \\
\text { average in } \\
\text { the last four } \\
\text { semesters }\end{array}$ & $\begin{array}{c}\text { Pass } \\
\text { average in } \\
\text { the last four } \\
\text { semesters }\end{array}$ & $\begin{array}{c}\text { Grade A } \\
\text { average in the } \\
\text { last four } \\
\text { semesters }\end{array}$ & $\begin{array}{c}\text { Average Final } \\
\text { Grade in the } \\
\text { last four } \\
\text { semesters }\end{array}$ \\
\hline $\mathrm{FtF}$ & 0.000 & 0.000 & 0.003 & 0.004 \\
& $(0.000)$ & $(0.001)$ & $(0.002)$ & $(0.005)$ \\
\hline Time-Varying Controls & Yes & Yes & Yes & Yes \\
\hline Student+Instructor+Term+Course FEs & Yes & Yes & Yes & Yes \\
\hline $\mathrm{N}$ & 434597 & 434597 & 434480 & 434432 \\
\hline \multicolumn{2}{l}{ Notes: The unit of observation is a student $\times$ class. Outcomes are the means in the past four semesters in FtF classes. }
\end{tabular}


Appendix Table 6A

Heterogeneity by Student Attributes

The Difference in Propensity to Withdraw Between FtF and Online Classes by Semester

\begin{tabular}{|c|c|c|c|c|c|c|}
\hline & (1) & (2) & (3) & (4) & $(5)$ & $(6)$ \\
\hline & Female & Male & White & Non-White & Age $<=25$ & Age $>25$ \\
\hline Fall 2016 & $-0.025 * * *$ & $-0.031 * * *$ & $-0.022 * * *$ & $-0.035 * * *$ & $-0.030 * * *$ & $-0.016^{*}$ \\
\hline Spring 2017 & $-0.040 * * *$ & $-0.036 * * *$ & $-0.032 * * *$ & $-0.049 * * *$ & $-0.041 * * *$ & $-0.031 * * *$ \\
\hline Fall 2017 & $-0.022 * * *$ & $-0.025 * * *$ & $-0.021 * * *$ & $-0.025 * * *$ & $-0.020 * * *$ & $-0.024 * * *$ \\
\hline Spring 2018 & $-0.022 * * *$ & $-0.022 * * *$ & $-0.018 * * *$ & $-0.029 * * *$ & $-0.021 * * *$ & $-0.020 * * *$ \\
\hline Fall 2018 & $-0.016 * * *$ & $-0.028 * * *$ & $-0.021 * * *$ & $-0.017 * * *$ & $-0.021 * * *$ & $-0.020 * * *$ \\
\hline Spring 2019 & $-0.010 * * *$ & $-0.031 * * *$ & $-0.014 * * *$ & $-0.022 * * *$ & $-0.018 * * *$ & $-0.024 * * *$ \\
\hline Fall 2019 & $-0.018 * * *$ & $-0.033 * * *$ & $-0.021 * * *$ & $-0.026 * * *$ & $-0.025 * * *$ & $-0.013 * *$ \\
\hline Spring 2020 & $-0.017 * * *$ & $-0.035 * * *$ & $-0.023 * * *$ & $-0.023 * * *$ & $-0.022 * * *$ & $-0.037 * * *$ \\
\hline Fall 2020 & $0.005 * *$ & 0.002 & 0.002 & $0.006^{*}$ & 0.003 & 0.005 \\
\hline Spring 2021 & -0.000 & -0.004 & -0.001 & -0.001 & -0.000 & $-0.020 * *$ \\
\hline Fall 2021 & 0.003 & $-0.008 * *$ & -0.002 & 0.002 & -0.001 & -0.004 \\
\hline Spring 2022 & $-0.006 * *$ & $-0.009 * *$ & -0.002 & $-0.014 * * *$ & $-0.005^{*}$ & -0.005 \\
\hline $\mathrm{N}$ & 467421 & 264467 & 443750 & 288150 & 646946 & 84587 \\
\hline
\end{tabular}

\begin{tabular}{lcccc}
\hline & $(7)$ & $(8)$ & $(9)$ & $(10)$ \\
\hline & Lives in & Not in & & \\
& Dorm & Dorm & International & Domestic \\
\hline Fall 2016 & -0.008 & $-0.030^{* * *}$ & $-0.036^{* *}$ & $-0.027 * * *$ \\
Spring 2017 & $-0.033^{* * *}$ & $-0.038^{* * *}$ & $-0.069^{* *}$ & $-0.038^{* * *}$ \\
Fall 2017 & $-0.014^{* *}$ & $-0.024 * * *$ & $-0.058^{* * *}$ & $-0.022^{* * *}$ \\
Spring 2018 & $-0.021^{* * *}$ & $-0.022^{* * *}$ & 0.011 & $-0.023^{* * *}$ \\
Fall 2018 & $-0.026^{* * *}$ & $-0.020^{* * *}$ & 0.001 & $-0.020^{* * *}$ \\
Spring 2019 & $-0.020^{* * *}$ & $-0.019^{* * *}$ & 0.019 & $-0.018^{* * *}$ \\
Fall 2019 & $-0.024^{* * *}$ & $-0.024^{* * *}$ & -0.003 & $-0.023 * * *$ \\
Spring 2020 & $-0.016^{* * *}$ & $-0.026^{* * *}$ & 0.003 & $-0.024 * * *$ \\
Fall 2020 & -0.001 & $0.006^{* *}$ & $0.023 *$ & 0.003 \\
Spring 2021 & 0.001 & -0.002 & -0.012 & -0.001 \\
Fall 2021 & 0.004 & -0.002 & -0.023 & -0.000 \\
Spring 2022 & -0.006 & $-0.005^{*}$ & -0.019 & $-0.007 * * *$ \\
\hline $\mathrm{N}$ & 225477 & 506293 & 15010 & 716331 \\
\hline
\end{tabular}

Notes: Estimates are obtained from running equation (1) over the subsamples, and they show the difference between FtF and online classes. See notes in Table 3. 
Appendix Table 6B

Heterogeneity by Student Attributes

The Difference in Propensity to Pass Between FtF and Online Classes by Semester

\begin{tabular}{|c|c|c|c|c|c|c|}
\hline & (1) & (2) & (3) & (4) & $(5)$ & $(6)$ \\
\hline & Female & Male & White & Non-White & Age $<=25$ & Age $>25$ \\
\hline Fall 2016 & $0.050 * * *$ & $0.074 * * *$ & $0.048 * * *$ & $0.076 * * *$ & $0.063 * * *$ & $0.047 * * *$ \\
\hline Spring 2017 & $0.073 * * *$ & $0.080 * * *$ & $0.066 * * *$ & $0.089 * * *$ & $0.079 * * *$ & $0.062 * * *$ \\
\hline Fall 2017 & $0.043 * * *$ & $0.055 * * *$ & $0.045 * * *$ & $0.050 * * *$ & $0.046 * * *$ & $0.043 * * *$ \\
\hline Spring 2018 & $0.051 * * *$ & $0.046 * * *$ & $0.041 * * *$ & $0.061 * * *$ & $0.046 * * *$ & $0.042 * * *$ \\
\hline Fall 2018 & $0.043 * * *$ & $0.052 * * *$ & $0.043 * * *$ & $0.050 * * *$ & $0.048 * * *$ & $0.042 * * *$ \\
\hline Spring 2019 & $0.037 * * *$ & $0.060 * * *$ & $0.039 * * *$ & $0.052 * * *$ & $0.044 * * *$ & $0.056 * * *$ \\
\hline Fall 2019 & $0.042 * * *$ & $0.043 * * *$ & $0.034 * * *$ & $0.054 * * *$ & $0.042 * * *$ & $0.034 * * *$ \\
\hline Spring 2020 & $0.033 * * *$ & $0.044 * * *$ & $0.031 * * *$ & $0.044 * * *$ & $0.036 * * *$ & $0.036 * * *$ \\
\hline Fall 2020 & $-0.012 * * *$ & -0.002 & -0.003 & $-0.020 * * *$ & $-0.009 * *$ & 0.001 \\
\hline Spring 2021 & 0.000 & 0.006 & $0.010 * *$ & -0.009 & 0.002 & 0.016 \\
\hline Fall 2021 & $0.007 *$ & 0.009 & $0.013 * * *$ & -0.000 & $0.007 *$ & $0.022 * *$ \\
\hline Spring 2022 & $0.018 * * *$ & $0.016^{* * *}$ & $0.015 * * *$ & $0.019 * * *$ & $0.014 * * *$ & $0.020 * *$ \\
\hline $\mathrm{N}$ & 467421 & 264467 & 443750 & 288150 & 646946 & 84587 \\
\hline
\end{tabular}

\begin{tabular}{lcccc}
\hline & $(7)$ & $(8)$ & $(9)$ & $(10)$ \\
\hline & $\begin{array}{c}\text { Lives in } \\
\text { Dorm }\end{array}$ & $\begin{array}{c}\text { Not in } \\
\text { Dorm }\end{array}$ & International & Domestic \\
\hline Fall 2016 & $0.050^{* * *}$ & $0.057^{* * *}$ & 0.015 & $0.059^{* * *}$ \\
Spring 2017 & $0.079 * * *$ & $0.071^{* * *}$ & $0.069^{*}$ & $0.076^{* * *}$ \\
Fall 2017 & $0.029 * * *$ & $0.052^{* * *}$ & $0.048^{*}$ & $0.047 * *$ \\
Spring 2018 & $0.039 * * *$ & $0.050^{* * *}$ & 0.021 & $0.049 * * *$ \\
Fall 2018 & $0.043^{* * *}$ & $0.049^{* * *}$ & 0.005 & $0.046^{* * *}$ \\
Spring 2019 & $0.038^{* * *}$ & $0.046^{* * *}$ & 0.025 & $0.045^{* * *}$ \\
Fall 2019 & $0.024 * *$ & $0.043^{* * *}$ & 0.016 & $0.042^{* * *}$ \\
Spring 2020 & $0.026^{* * *}$ & $0.040^{* * *}$ & -0.020 & $0.038^{* * *}$ \\
Fall 2020 & -0.009 & $-0.008^{* *}$ & -0.011 & $-0.009 * *$ \\
Spring 2021 & -0.005 & 0.004 & $0.038 * *$ & 0.002 \\
Fall 2021 & 0.009 & $0.009^{* *}$ & 0.018 & $0.008^{* *}$ \\
Spring 2022 & 0.009 & $0.017 * * *$ & 0.016 & $0.017 * * *$ \\
\hline $\mathrm{N}$ & 225477 & 506293 & 15010 & 716331 \\
\hline
\end{tabular}

Note: See notes in Appendix Table 6A. 
Appendix Table 6C

Heterogeneity by Student Attributes

The Difference in Propensity to Earn an A Between FtF and Online Classes by Semester

\begin{tabular}{lcccccc}
\hline & $(1)$ & $(2)$ & $(3)$ & $(4)$ & $(5)$ & $(6)$ \\
\hline Fall 2016 & Female & Male & White & Non-White & Age $<=25$ & Age $>25$ \\
Spring 2017 & $0.054^{* * *}$ & $0.047^{* * *}$ & $0.064^{* * *}$ & $0.038^{* * *}$ & $0.057^{* * *}$ & $0.064^{* * *}$ \\
Fall 2017 & $0.055^{* * *}$ & $0.033^{* *}$ & $0.066^{* * *}$ & $0.024 *$ & $0.050^{* * *}$ & $0.056^{* * *}$ \\
Spring 2018 & -0.012 & -0.019 & 0.001 & $-0.033^{* * *}$ & $-0.018^{* *}$ & $0.025^{*}$ \\
Fall 2018 & $0.017^{*}$ & 0.002 & $0.020^{* *}$ & 0.001 & 0.009 & $0.036^{* *}$ \\
Spring 2019 & $0.055^{* * *}$ & $0.033^{* * *}$ & $0.051^{* * *}$ & $0.045^{* * *}$ & $0.051^{* * *}$ & $0.062^{* * *}$ \\
Fall 2019 & $0.036^{* * *}$ & $0.022^{* *}$ & $0.038^{* * *}$ & $0.024 * *$ & $0.030^{* * *}$ & $0.048^{* * *}$ \\
Spring 2020 & $0.040^{* * *}$ & $0.022^{*}$ & $0.036^{* * *}$ & $0.032^{* *}$ & $0.030^{* * *}$ & $0.038^{* * *}$ \\
Fall 2020 & $0.031^{* * *}$ & 0.013 & $0.020^{* *}$ & $0.032^{* * *}$ & $0.029 * * *$ & 0.007 \\
Spring 2021 & $-0.021^{* *}$ & $-0.022^{* *}$ & $-0.023^{* * *}$ & $-0.016^{*}$ & $-0.021 * * *$ & -0.017 \\
Fall 2021 & $-0.028^{* * *}$ & $-0.044^{* * *}$ & $-0.035^{* * *}$ & $-0.030^{* * *}$ & $-0.035^{* * *}$ & -0.025 \\
Spring 2022 & $0.020^{* *}$ & 0.008 & $0.031^{* * *}$ & -0.006 & 0.013 & $0.029 *$ \\
\hline $\mathrm{N}$ & 0.002 & 0.009 & $0.020^{* *}$ & $-0.020^{* *}$ & -0.002 & $0.033^{*}$ \\
\hline
\end{tabular}

\begin{tabular}{|c|c|c|c|c|}
\hline & (7) & $(8)$ & (9) & $(10)$ \\
\hline & $\begin{array}{l}\text { Lives in } \\
\text { Dorm }\end{array}$ & $\begin{array}{l}\text { Not in } \\
\text { Dorm }\end{array}$ & International & Domestic \\
\hline Fall 2016 & $0.088 * * *$ & $0.041 * * *$ & -0.074 & $0.057 * * *$ \\
\hline Spring 2017 & 0.027 & $0.048 * * *$ & -0.030 & $0.050 * * *$ \\
\hline Fall 2017 & $-0.042 * * *$ & -0.002 & -0.023 & -0.012 \\
\hline Spring 2018 & -0.008 & $0.015^{*}$ & -0.053 & $0.014^{*}$ \\
\hline Fall 2018 & $0.036 * *$ & $0.053 * * *$ & 0.003 & $0.049 * * *$ \\
\hline Spring 2019 & -0.004 & $0.041 * * *$ & 0.030 & $0.034 * * *$ \\
\hline Fall 2019 & -0.004 & $0.034 * * *$ & -0.059 & $0.035 * * *$ \\
\hline Spring 2020 & 0.017 & $0.026^{* * *}$ & $0.082 *$ & $0.024 * * *$ \\
\hline Fall 2020 & -0.003 & $-0.031 * * *$ & $-0.053 *$ & $-0.021 * * *$ \\
\hline Spring 2021 & $-0.034 * * *$ & $-0.035 * * *$ & -0.004 & $-0.034 * * *$ \\
\hline Fall 2021 & $0.034 * * *$ & 0.011 & -0.021 & $0.017 * *$ \\
\hline Spring 2022 & 0.007 & 0.001 & -0.062 & 0.006 \\
\hline $\mathrm{N}$ & 216688 & 480471 & 14641 & 682091 \\
\hline
\end{tabular}

Note: See notes in Appendix Table 6A. 
Appendix Table 6D

Heterogeneity by Student Attributes

The Difference in Final Grades Between FtF and Online Classes by Semester

\begin{tabular}{|c|c|c|c|c|c|c|}
\hline & (1) & (2) & (3) & (4) & (5) & (6) \\
\hline & Female & Male & White & Non-White & Age $<=25$ & Age $>25$ \\
\hline Fall 2016 & $0.190 * * *$ & $0.231 * * *$ & $0.208 * * *$ & $0.210 * * *$ & $0.221 * * *$ & $0.234 * * *$ \\
\hline Spring 2017 & $0.221 * * *$ & $0.205 * * *$ & $0.216 * * *$ & $0.217 * * *$ & $0.225 * * *$ & $0.222 * * *$ \\
\hline Fall 2017 & $0.062 * * *$ & 0.048 & $0.083 * * *$ & 0.029 & $0.054 * *$ & $0.114 * * *$ \\
\hline Spring 2018 & $0.116 * * *$ & $0.068 * * *$ & $0.102 * * *$ & $0.098 * * *$ & $0.088 * * *$ & $0.159 * * *$ \\
\hline Fall 2018 & $0.174 * * *$ & $0.121 * * *$ & $0.152 * * *$ & $0.162 * * *$ & $0.168 * * *$ & $0.174 * * *$ \\
\hline Spring 2019 & $0.141 * * *$ & $0.108 * * *$ & $0.125 * * *$ & $0.134 * * *$ & $0.127 * * *$ & $0.166 * * *$ \\
\hline Fall 2019 & $0.130 * * *$ & $0.072 * * *$ & $0.099 * * *$ & $0.127 * * *$ & $0.099 * * *$ & $0.139 * * *$ \\
\hline Spring 2020 & $0.105 * * *$ & $0.080 * * *$ & $0.079 * * *$ & $0.115 * * *$ & $0.100 * * *$ & $0.072 * *$ \\
\hline Fall 2020 & $-0.088^{* * *}$ & $-0.056 * *$ & $-0.061 * * *$ & $-0.108 * * *$ & $-0.081 * * *$ & -0.006 \\
\hline Spring 2021 & $-0.048 * *$ & $-0.082 * * *$ & -0.028 & $-0.114 * * *$ & $-0.063 * * *$ & -0.040 \\
\hline Fall 2021 & $0.041 * *$ & -0.007 & $0.066 * * *$ & -0.034 & 0.017 & $0.074 * *$ \\
\hline Spring 2022 & 0.028 & 0.030 & $0.060 * * *$ & -0.026 & 0.021 & 0.054 \\
\hline $\mathrm{N}$ & 448307 & 248545 & 424303 & 272566 & 617073 & 79395 \\
\hline
\end{tabular}

\begin{tabular}{|c|c|c|c|c|}
\hline & (7) & (8) & (9) & $(10)$ \\
\hline & $\begin{array}{c}\text { Lives in } \\
\text { Dorm }\end{array}$ & $\begin{array}{l}\text { Not in } \\
\text { Dorm }\end{array}$ & International & Domestic \\
\hline Fall 2016 & $0.270 * * *$ & $0.181 * * *$ & -0.131 & $0.215 * * *$ \\
\hline Spring 2017 & $0.197 * * *$ & $0.204 * * *$ & 0.056 & $0.218 * * *$ \\
\hline Fall 2017 & -0.035 & $0.095 * * *$ & -0.074 & $0.060 * * *$ \\
\hline Spring 2018 & $0.057 *$ & $0.107 * * *$ & -0.018 & $0.102 * * *$ \\
\hline Fall 2018 & $0.132 * * *$ & $0.166^{* * *}$ & 0.106 & $0.157 * * *$ \\
\hline Spring 2019 & 0.042 & $0.144 * * *$ & $0.190 * *$ & $0.130 * * *$ \\
\hline Fall 2019 & 0.020 & $0.107 * * *$ & -0.067 & $0.112 * * *$ \\
\hline Spring 2020 & $0.064 *$ & $0.104 * * *$ & 0.098 & $0.096 * * *$ \\
\hline Fall 2020 & $-0.053 * *$ & $-0.090 * * *$ & -0.102 & $-0.078 * * *$ \\
\hline Spring 2021 & $-0.075 * * *$ & $-0.062 * * *$ & 0.071 & $-0.061 * * *$ \\
\hline Fall 2021 & $0.082 * * *$ & 0.009 & -0.051 & 0.027 \\
\hline Spring 2022 & 0.009 & 0.023 & $-0.122 *$ & $0.031 *$ \\
\hline $\mathrm{N}$ & 216567 & 480158 & 14638 & 681660 \\
\hline
\end{tabular}

Note: See notes in Appendix Table 6A. 
Appendix Table 7A

Heterogeneity by Teacher Attributes

The Difference in Propensity to Withdraw Between FtF and Online Classes by Semester

\begin{tabular}{|c|c|c|c|c|c|c|}
\hline & (1) & (2) & (3) & (4) & $(5)$ & (6) \\
\hline & Female & Male & White & Non-White & Age $<=45$ & Age $>45$ \\
\hline Fall 2016 & $-0.038 * * *$ & $-0.015^{* *}$ & $-0.033 * * *$ & -0.004 & $-0.033 * * *$ & $-0.024 * * *$ \\
\hline Spring 2017 & $-0.053 * * *$ & -0.011 & $-0.039 * * *$ & -0.022 & $-0.045 * * *$ & $-0.034 * * *$ \\
\hline Fall 2017 & $-0.032 * * *$ & -0.009 & $-0.025 * * *$ & -0.002 & $-0.024 * * *$ & $-0.020 * * *$ \\
\hline Spring 2018 & $-0.030 * * *$ & $-0.013 * * *$ & $-0.022 * * *$ & $-0.025 * *$ & $-0.023 * * *$ & $-0.024 * * *$ \\
\hline Fall 2018 & $-0.027 * * *$ & $-0.015 * * *$ & $-0.024 * * *$ & 0.009 & $-0.025 * * *$ & $-0.014 * * *$ \\
\hline Spring 2019 & $-0.027 * * *$ & -0.005 & $-0.019 * * *$ & -0.005 & $-0.022 * * *$ & $-0.014 * * *$ \\
\hline Fall 2019 & $-0.026 * * *$ & $-0.017 * * *$ & $-0.023 * * *$ & $-0.012 *$ & $-0.023 * * *$ & $-0.022 * * *$ \\
\hline Spring 2020 & $-0.031 * * *$ & $-0.010 * *$ & $-0.023 * * *$ & $-0.029 * * *$ & $-0.019 * * *$ & $-0.028 * * *$ \\
\hline Fall 2020 & 0.001 & $0.007 * *$ & 0.003 & 0.007 & -0.003 & $0.007 * *$ \\
\hline Spring 2021 & -0.005 & 0.002 & -0.001 & -0.007 & -0.006 & -0.001 \\
\hline Fall 2021 & $-0.007 * *$ & $0.007 * *$ & -0.001 & 0.001 & -0.002 & -0.000 \\
\hline Spring 2022 & $-0.015 * * *$ & 0.006 & $-0.009 * * *$ & 0.004 & $-0.009 * * *$ & $-0.009 * *$ \\
\hline $\mathrm{N}$ & 384199 & 344547 & 619307 & 106471 & 399965 & 328923 \\
\hline
\end{tabular}

Notes: Estimates are obtained from running equation (1) over the subsamples, and they show the difference between $\mathrm{FtF}$ and online classes. See notes in Table 3.

Appendix Table 7B

Heterogeneity by Teacher Attributes

The Difference in Propensity to Pass Between FtF and Online Classes by Semester

\begin{tabular}{|c|c|c|c|c|c|c|}
\hline & (1) & (2) & (3) & (4) & $(5)$ & (6) \\
\hline & Female & Male & White & Non-White & Age $<=45$ & Age $>45$ \\
\hline Fall 2016 & $0.077 * * *$ & $0.033 * * *$ & $0.064 * * *$ & $0.033 * *$ & $0.062 * * *$ & $0.051 * * *$ \\
\hline Spring 2017 & $0.090 * * *$ & $0.047 * * *$ & $0.077 * * *$ & $0.050 * * *$ & $0.086^{* * *}$ & $0.067 * * *$ \\
\hline Fall 2017 & $0.059 * * *$ & $0.029 * * *$ & $0.050 * * *$ & 0.016 & $0.048 * * *$ & $0.041 * * *$ \\
\hline Spring 2018 & $0.058 * * *$ & $0.036 * * *$ & $0.050 * * *$ & $0.040 * * *$ & $0.058 * * *$ & $0.040 * * *$ \\
\hline Fall 2018 & $0.054 * * *$ & $0.039 * * *$ & $0.051 * * *$ & 0.014 & $0.052 * * *$ & $0.038 * * *$ \\
\hline Spring 2019 & $0.059 * * *$ & $0.023 * * *$ & $0.045 * * *$ & $0.046 * * *$ & $0.052 * * *$ & $0.038 * * *$ \\
\hline Fall 2019 & $0.053 * * *$ & $0.024 * * *$ & $0.043 * * *$ & $0.032 * *$ & $0.044 * * *$ & $0.041 * * *$ \\
\hline Spring 2020 & $0.048 * * *$ & $0.017 * * *$ & $0.037 * * *$ & $0.043 * * *$ & $0.029 * * *$ & $0.050 * * *$ \\
\hline Fall 2020 & -0.002 & $-0.015 * * *$ & $-0.008^{* *}$ & -0.008 & 0.004 & $-0.017 * * *$ \\
\hline Spring 2021 & $0.011 * *$ & $-0.011 * *$ & 0.002 & 0.003 & 0.008 & 0.001 \\
\hline Fall 2021 & $0.017 * * *$ & -0.007 & $0.009 * *$ & 0.000 & $0.018 * * *$ & -0.001 \\
\hline Spring 2022 & $0.023 * * *$ & 0.002 & $0.019 * * *$ & 0.002 & $0.024 * * *$ & $0.012 * *$ \\
\hline $\mathrm{N}$ & 384199 & 344547 & 619307 & 106471 & 399965 & 328923 \\
\hline
\end{tabular}

Note: See notes in Appendix Table 7A. 
Appendix Table 7C

Heterogeneity by Teacher Attributes

The Difference in Propensity to Earn an A Between FtF and Online Classes by Semester

\begin{tabular}{|c|c|c|c|c|c|c|}
\hline & (1) & $(2)$ & (3) & (4) & $(5)$ & (6) \\
\hline & Female & Male & White & Non-White & Age $<=45$ & Age $>45$ \\
\hline Fall 2016 & $0.079 * * *$ & 0.019 & $0.044 * * *$ & $0.115 * * *$ & $0.063 * * *$ & $0.030 *$ \\
\hline Spring 2017 & $0.050 * * *$ & $0.047 * * *$ & $0.047 * * *$ & 0.037 & $0.057 * * *$ & $0.036^{* *}$ \\
\hline Fall 2017 & -0.011 & -0.010 & $-0.018^{*}$ & 0.018 & 0.001 & $-0.035 * * *$ \\
\hline Spring 2018 & $0.020 * *$ & -0.003 & $0.014 *$ & 0.005 & $0.041 * * *$ & $-0.023 *$ \\
\hline Fall 2018 & $0.056 * * *$ & $0.033 * *$ & $0.044 * * *$ & $0.035 * *$ & $0.053 * * *$ & $0.042 * * *$ \\
\hline Spring 2019 & $0.054 * * *$ & 0.005 & $0.029 * * *$ & $0.039 * *$ & $0.054 * * *$ & 0.005 \\
\hline Fall 2019 & $0.063 * * *$ & -0.003 & $0.037 * * *$ & -0.007 & $0.062 * * *$ & 0.002 \\
\hline Spring 2020 & $0.023 * *$ & 0.018 & $0.035 * * *$ & $-0.040 * *$ & $0.032 * * *$ & $0.023^{*}$ \\
\hline Fall 2020 & -0.002 & $-0.039 * * *$ & $-0.020 * *$ & -0.024 & 0.011 & $-0.046 * * *$ \\
\hline Spring 2021 & -0.016 & $-0.057 * * *$ & $-0.034 * * *$ & $-0.039 * *$ & $-0.020 * *$ & $-0.047 * * *$ \\
\hline Fall 2021 & $0.029 * * *$ & 0.008 & $0.018 * *$ & -0.002 & $0.049 * * *$ & -0.013 \\
\hline Spring 2022 & 0.009 & 0.000 & 0.004 & -0.009 & $0.040 * * *$ & $-0.024 * *$ \\
\hline $\mathrm{N}$ & 365629 & 328147 & 590348 & 100744 & 381103 & 312821 \\
\hline
\end{tabular}

Note: See notes in Appendix Table 7A.

Appendix Table 7D

Heterogeneity by Teacher Attributes

The Difference in Final Grade Between FtF and Online Classes by Semester

\begin{tabular}{|c|c|c|c|c|c|c|}
\hline & $(1)$ & $(2)$ & (3) & $(4)$ & $(5)$ & $(6)$ \\
\hline & Female & Male & White & Non-White & Age $<=45$ & Age $>45$ \\
\hline \multicolumn{7}{|c|}{ Difference between FtF and Online in } \\
\hline Fall 2016 & $0.300 * * *$ & 0.072 & $0.192 * * *$ & $0.316^{* * *}$ & $0.223 * * *$ & $0.150 * * *$ \\
\hline Spring 2017 & $0.239 * * *$ & $0.172 * * *$ & $0.224 * * *$ & $0.132 * * *$ & $0.260 * * *$ & $0.168 * * *$ \\
\hline Fall 2017 & $0.097 * * *$ & 0.002 & $0.058 * *$ & 0.060 & $0.099 * * *$ & -0.005 \\
\hline Spring 2018 & $0.144 * * *$ & 0.040 & $0.101 * * *$ & $0.082 *$ & $0.177 * * *$ & 0.014 \\
\hline Fall 2018 & $0.185^{* * *}$ & $0.125 * * *$ & $0.157 * * *$ & $0.103 * *$ & $0.178 * * *$ & $0.130 * * *$ \\
\hline Spring 2019 & $0.204 * * *$ & 0.033 & $0.121 * * *$ & $0.151 * * *$ & $0.178 * * *$ & $0.068 * * *$ \\
\hline Fall 2019 & $0.195 * * *$ & 0.004 & $0.118 * * *$ & 0.035 & $0.171 * * *$ & 0.039 \\
\hline Spring 2020 & $0.115 * * *$ & 0.054 & $0.111 * * *$ & 0.015 & $0.088 * * *$ & $0.130 * * *$ \\
\hline Fall 2020 & -0.027 & $-0.126 * * *$ & $-0.077 * * *$ & $-0.074 *$ & 0.012 & $-0.147 * * *$ \\
\hline Spring 2021 & 0.003 & $-0.151 * * *$ & $-0.062 * * *$ & $-0.091 * *$ & -0.029 & $-0.094 * * *$ \\
\hline Fall 2021 & $0.071 * * *$ & -0.032 & 0.026 & 0.003 & $0.111 * * *$ & $-0.052 * *$ \\
\hline Spring 2022 & 0.046 & -0.005 & 0.023 & 0.010 & $0.113 * * *$ & $-0.056 * *$ \\
\hline $\mathrm{N}$ & 365362 & 327974 & 589936 & 100717 & 380837 & 312637 \\
\hline
\end{tabular}

Note: See notes in Appendix Table 7A. 